Natiorıal Library

of Canada

Acquisitions and

Bibliographic Services Branch

395 Wellington Street

Ottawa. Ontaro

KIA ON4
Bibliotheque nationale

du Canada

Direction des acquisitions ef

des services bibliographiques

395, ne Wellington

Ottawa (Onlario)

KIAONA
NOTICE
Qu his Note ieterence

AVIS
The quality of this microform is heavily dependent upon the quality of the original thesis submitted for microfilming. Every effort has been made to ensure the highest quality of reproduction possible.

If pages are missing, contact the university which granted the degree.

Some pages may have indistinct print especially if the original pages were typed with a poor typewriter ribson or if the university sent us an inferior photocopy.

Reproduction in full or in part of this microform is governed by the Canadian Copyright Act, R.S.C. 1970, c. C-30, and subsequent amendments.
La qualité de cette microforme dépend grandement de la qualité de la thèse soumise au microfilmage. Nous avons tout fait pour assurer une qualité supérieure de reproduction.

S'il manque des pages, veuillez communiquer avec l'université qui a conféré le grade.

La qualité d'impression de certaines pages peut laisser à désirer, surtout si les pages originales ont été dactylographiées à l'aide d'un ruban usé ou si l'université nous a fait parvenir une photocopie de qualité inférieure.

La reproduction, même partielle, de cette microforme est soumise à la Loi canadienne sur le droit d'auteur, SRC 1970, c. C-30, et ses amendements subséquents. 


\title{
THE OCCURRENCE OF FLOW MARKS DURING IN.JECTION MOLDING OF LINEAR POLYETHYLENE
}

\author{
By \\ Marie-Claude Heuzey \\ Department of Chemical Engineering \\ McGill University, Montreal
}

March 1996

A Thesis submitted to the faculty of Graduate Studies and Research in partial fulfillment of the requirements of the degree of Master of Engineering

() Marie-Claude Heuzcy 1996 
National Libran'

of Canada

Acquisitions and

Bibliographic Services Branch

395 Wellinglon Street

Otlawa. Onlario

KIAONA
Bibliotheque nationale

du Canada

Direction des acquisitions et des services bibliographiques

395, rue Wellington

Oltawa (Ontario)

K1A ON4
The author has granted an irrevocable non-exclusive licence allowing the National Library of Canada to reproduce, loan, distribute or sell copies of his/her thesis by any means and in any form or format, making this thesis available to interested persons.
L'auteur a accordé une licience irrévocable et non exclusive permettant à la Bibliotrièque nationale du Canada de reproduire, prêter, distribuer ou vendre des copies de sa thèse de quelque manière et sous quelque forme que ce soil pour mettre des exemplaires de cette thèse à la disposition des personnes intéressées.

L'auteur conserve la propriété du drcit d'auteur qui prolège sa thèse. Ni la thèse ni des extraits substantiels de celle-ci ne doivent être imprimés ou autrement reproduits sans son autorisation. 


\begin{abstract}
Injection molding is a high rate production process for manufacturing plastic parts. There is often a conflict between good appearance and short cycle time. Injection molded parts can show several types of surface defect. It is believed that wall slip may be associated with some types of defect, because wall slip can modify the distributions of velocity, wall shear stress, pressure and heat flux. The work described here involves an experimental study of the occurrence of flow marks during injection molding of linear polyethylene, and the possible relationship between these defects and wall slip. It also involves the investigation of the feasibility of incorporating wall slip models in the $2.5 \mathrm{D}$ computer simulation of the injection molding process.
\end{abstract}




\section{Résumé}

Le moulage par injection est un procédé de mise en forme des matières plastiques a hatut rendement de production. Toutefois, les temps de cycle courts se font souvent iu détriment de l'apparence extéricure. Les pièces moukées par injection peuvent présenter plusieurs types de défaut de surface. Il est suggéré que le glissement a la paroi soit associé à certain de ces défauts, puisque le glissement à la paroi peut modifier les distributions de vitesse, de contrainte de cisaillement, de pression ainsi que te transfert de chaleur. Le présent travail décrit une étude expérimentale de la génération des lignes d'écoulement lors du moulage par injection du polyéthylène linéaire, ainsi que la relation entre ces défauts et le glissement à la paroi. Il comprend aussi une étude de faisabilité de l'incorporation des modeles de glissement dans la simulation 2.5D par ordinatcur du procédé de moulage par injection. 


\section{Remerciements}

J'aimerais d'abord remercier le directeur de mes travaux, Dr Dealy, pour son excellente supervision, sa patience et ses nombreux encouragements lors de cette étape de ma vie. Je tiens aussi à souligner l'aide précicuse des chercheurs et techniciens de l'Institut des Materiaux Industricls: Dong Ming Gao, Andres Garcia Rejon, Yves Simard, sans qui l'achèvement de ce projet n'eut êté possible. J'ai beaucoup apprécié lors de mes recherches préliminaires l'assistance de Michel Lanoue de la compagnie IPL et celle du Dr Ornar Khennache de Camoplast. Je suis également fort reconnaissante envers mes confrères et consocurs de l'Université McGill, Paula Wood-Adams, Martin Sentmanat, François Koran, pour leur franche camaraderic et l'esprit d'entraide qui règne au cinquième ćtage.

Je ne peux remercier assez ma famille et mes amis pour leur soutien constant et leur présence réconfortante: Christiane, Denis, Andrée, Jearı-Pierre, Louise, Annick, Chantal, Michel, et ccux que j'oublie de nommer mais qui sont tous fort chers a mes yeux.

Irinalement, merci à Luc et Add̀le, dont les visites presque quotidiennes ont contribué à l'avancement de la science dans la douceur et l'harmonie. 


\section{Acknowledgements}

I am very grateful to the people of GI: Corporate Rescarch \& Development in Schenectady, NY, for the enlightening discussions: Dr. William Richards, Dr. Therese Jordan, Dr. Noberto Silvi and Dr. Andrew Poslinski. I would also like to thank Dr. Charlie Stewart of the Dupont Company for his advice and for supplying the Teflon ${ }^{\mathrm{m}}$ solutions. 


\section{Table of Contents}

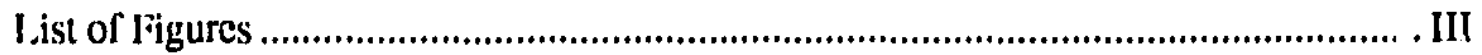

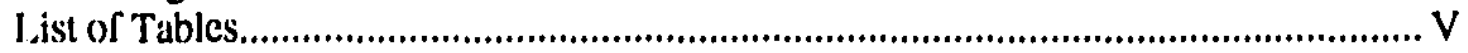

1. Introduction..................................................................................................... 1

2. Injection Molding of Thermoplastics.................................................................... 1

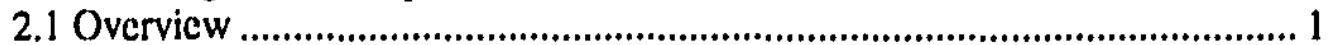

2.2 Possible Role of Slip in Polymer Processing.................................................... 3

2.3 Occurrence of Flow Marks in Injection Molding .......................................... 5

2.4 Simulation of Injection Molding ............................................................ 11

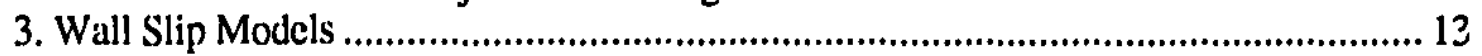

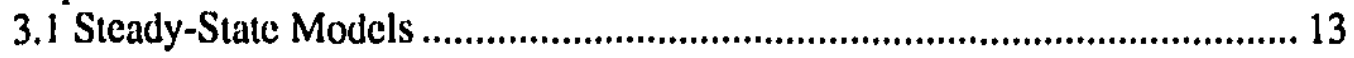

3.2 Transient Models ....................................................................................... 18

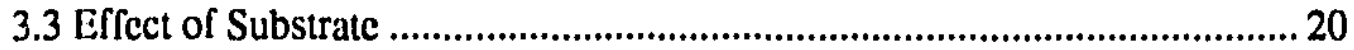

4. Scope and Objectives of this Work ...................................................................... 22

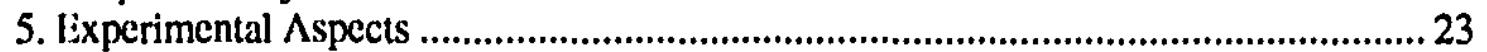

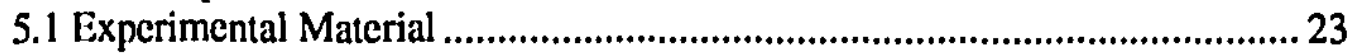

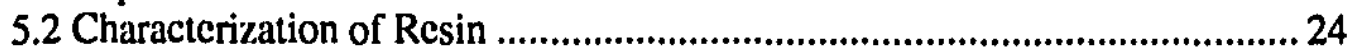

5.2.1 Rheological Properties and Slip Behavior...................................... 24

5.2.2 Thermal Properties ........................................................................... 25

5.2.2.1 Heat Capacity Measurements ........................................ 25

5.2.2.2 Thermal Conductivity Measurements.............................. 26

5.2.3 PVT Measurements ................................................................. 26

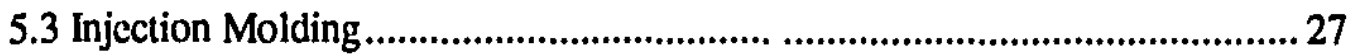

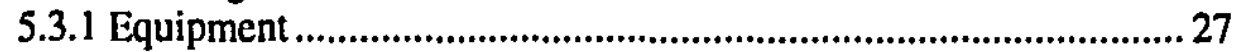

5.3.2 Molding Conditions .......................................................................... 28

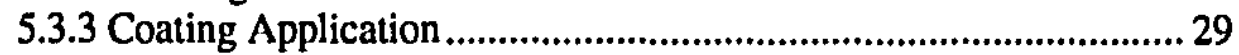

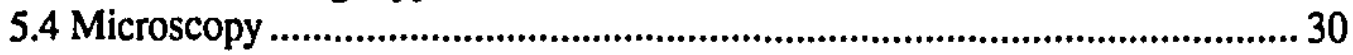

6. Theoretical and Numerical Aspects ............................................................................... 31

6.1 Description of Plasfill ................................................................................... 31

6.1.1 General Assumptions for Simulation of Mold Filling Stage............ 32

6.1.2 Numerical Procedure ...................................................................... 36

6.2 Incorporation of Slip Models....................................................................... 38

6.2.1 General Equations for Simulation of Mold Filling with Wall

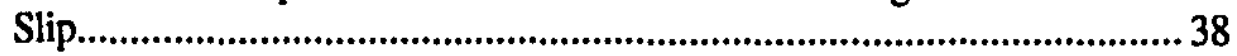

6.2.2 General Model for the Slip Velocity............................................. 40

6.2.2.1 Steady-State Slip Model.................................................. 40

6.2.2.2 Dynamic Slip Model .......................................................4 41

6.2.3 Numerical Implementation ............................................................. 44

6.3 Validation of Computer Model Predictions...................................................... 47 


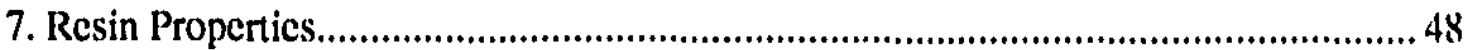

7.1 Viscosity and Slip Behavior.................................................................. 48

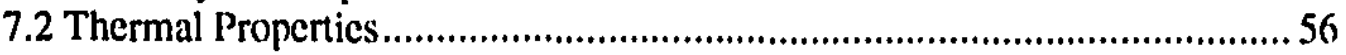

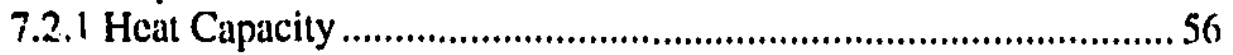

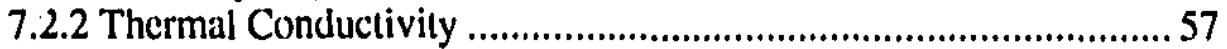

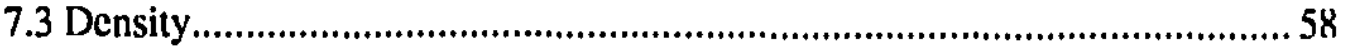

8. Experimental Results of Injection Molding...........................................................60

8.1 Effect of Mold Thickness ....................................................................61

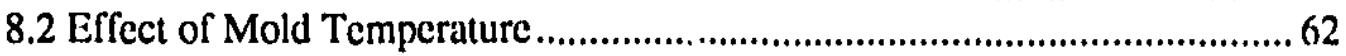

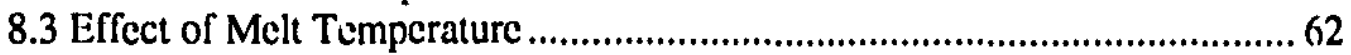

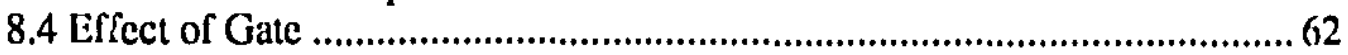

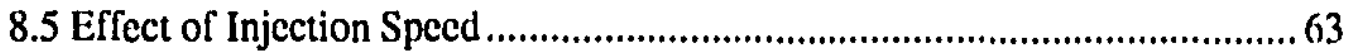

8.6 Effect of Coating............................................................................................63

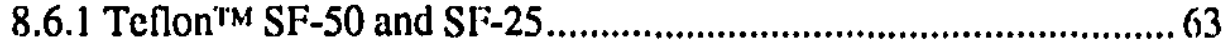

8.6.2 Silicone Oil .............................................................................63

8.7 Microscopic Observations of Molded Surfaces and Filled-I.IPPI: sample..... 64

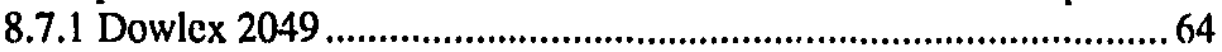

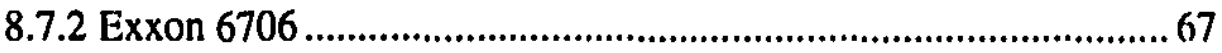

8.7.3 Filled-LDPE Sample .................................................................. 70

9. Additional Experiments on the Effect of Injection Speed.............................................72

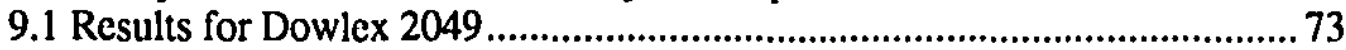

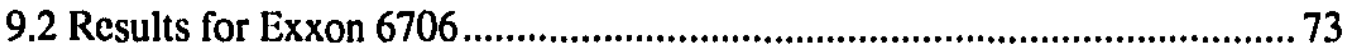

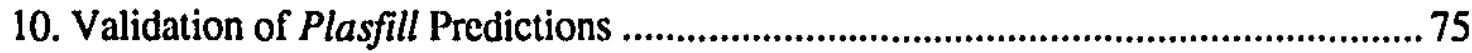

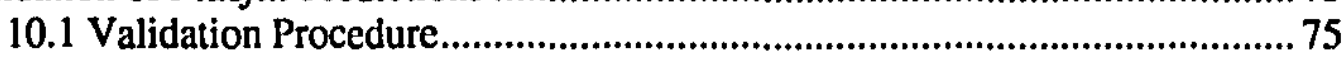

10.2 Effect of Injection Speed ......................................................................... 78

10.2.1 Simulations for Dowlex 2049 .....................................................78

10.2.1.1 10\% of Maximum Injection Spect................................. 78

10.2.1.2 20\% of Maximum Injection Speed................................. 80

10.2.2 Simulations for Exxon 6706 ..................................................... 81

10.2.2.1 20\% of Maximum Injection Speed................................. 81

10.2.2.2 30\% of Maximum Injection Speed................................ 83

10.3 Critical Conditions for the Occurrence of Flow Marks ................................86

11. Proposed Mechanism for Alternate Flow Mark Formation ........................................ 90

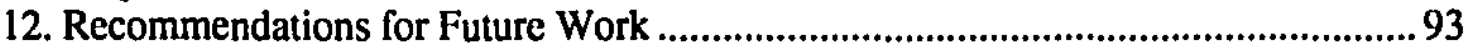

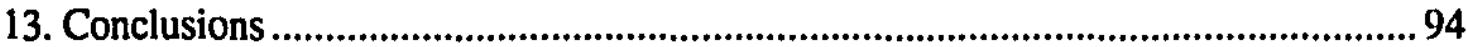

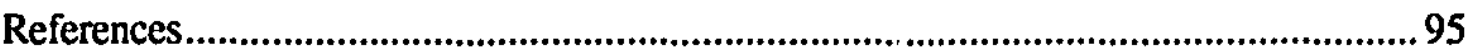

Appendix A: Geometry and Meshing of the Plate Mold..............................................99

Appendix B: Results from Plasfill Simulations............................................................. 100 
I Figure 2.1 Injection Molding Machine .................................................................. 2

Figure 2.2 Elongational effect on a fluid element at the die exit .................................. 4

Irigure 2.3 Ilow marks resulting from injection molding .............................................. 6

Figurc 2.4 Typical flow mark classification ............................................................... 8

Figure 2.5 Unsymmetrical fountain flow leading to flow marks formation ................... 9

Figure 3.1 Geometry of the sliding plate rheometer ................................................ 13

Figure 3.2 Geometry of a slit for rheometer experiments............................................. 16

Figure 3.3 Slip velocity predicted by equation 3.9 ..................................................... 17

Figurc 6.1 Coordinate axis for mold filling in Plasfill ..................................................... 33

Figure 7.1 Flow curves of Dowlex 2049 at three temperatures......................................5 50

Figure 7.2 1/b vs. Wall Shear Stress for Dowlex 2049..............................................52

Figure 7.3 Principle of time-superposition applied to Dowlex 2049 ..............................53

Figure 7.4 Viscosity curves of Dowlex 2049 for three temperatures............................54

Figure 7.5 Heat Capacity as a function of temperature for Dowlex 2049 .....................56

Figure 7.6 Thermal Conductivity as a function of temperature for Dowlex 2049 ........ 57

Figure 7.7 Specific volume as a function of temperature and pressure .......................... 59

Figurc 8.1 Defects found on Dowlex 2049 molded plates..........................................61

Figure 8.2 Flow marks section on Dowlex 2049 sample (10X)................................... 64

Figure 8.3 Transition zone between smooth and dull surfaces (LLDPE,80X) ............. 65

Figure 8.4 Transition zone between smooth and dull surfaces (LLDPE, 350X) ..........6 65

Figure 8.5 End (or tail) of the dull region of a flow line (LLDPE, 80X)........................ 66

Figure 8.6 End (or tail) of the dull region of a flow line (LLDPE, 350X) ....................66

Figure 8.7 Flow marks section on Exxon 6706 sample .................................................. 67

Figure 8.8 Transition zone between smooth and dull surfaces (HDPE, 35X) .............. 68

Figure 8.9 Transition zone between smooth and dull surfaces (HDPE, 300X) ............ 68

Figure 8.10 Transition zone between smooth and dull surfaces (HDPE, 1500X) .......... 69 
Figure 8.11 Detail of a small thorn area (HDPl: 500X) 69)

Figure 8.12 Transition zone between smooth and dull siitlaces (filled-I,DPI:, 50X) .... 7i)

Figure 8.13 Transition zone between smooth and dull surfaces (fillod-I.DI):

350X) 71

Figure 9.1 Viscosity curves of Exxon 6706 for four temperatures ........................... 74

Figure 10.1 Actual screw position and second-order polynomial ............................. 76

Figure 10.2 Lincar and step flow rates calculated from screw pesition........................ 77

Figure 10.3 Experimental and calculated pressures for $10 \%$ of maximum injection

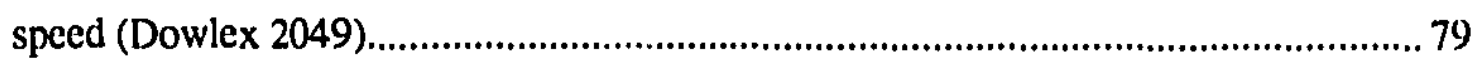

Figure 10.4 Experimental and calculated pressures for $20 \%$ of maximum injection speed (Dowlex 2049).

Figure 10.5 Experimental and calculated pressures for $20 \%$ of maximum injection speed (Exxon 6706)

Figure 10.6 Experimental and calculated pressures for $30 \%$ of maximum injection speed (Exxon 6706) 85

Figure 10.7 Wall shear struss at the flow front for Dowlex 2049 88

Figure 10.8 Wall shear rate at the flow front for Dowlex 2049. 88

Figure 10.9 Wall shear stress at the flow front for Exxon 6706 89

Figure 10.10 Wall shear rate at the flow front for Exxon 6706 89

Figure 11.1 Waves created on a partially molten HDPE plate (50X)........................91

Figure 11.2 Waves created on a partially molten HDPE plate (150X) 92 
Table 5.1 Polyethylene resins used in exploratory studies .............................................. 23

Table 5.2 Molecular weight information for resin used in experimental studies ............ 23

Table 5.3 Capillary dies used in this work ................................................................. 25

Tuble 5.4 Injection molding conditions for Dowlex 2049 .............................................. 29

Table 7.1 lïtted Carreau-WLF parameters for Dowlex 2049 ......................................... 55

Table 7.2 Shift factors calculated for Dowlex 2049 .....................................................55

Table 9.1 Physical propertics of Exxon 6706 and Dowlex 2049 .................................. 72

Table 9.2 Fitted Carreau-WLF parameters for Exxon 6706 and Dowlex 2049............ 73

Table 10.1 Imposed variable flow rate for $10 \%$ of maximum injection speed

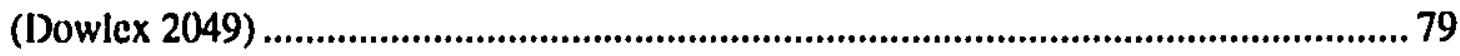

Table 10.2 Imposed variable flow rate for $20 \%$ of maximum injection speed

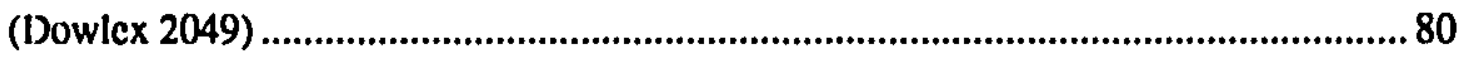

Table 10.3 Imposed variable flow rate for $20 \%$ of maximum injection speed

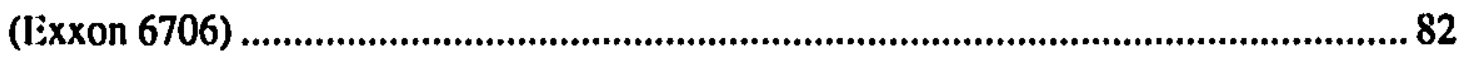

Table 10.4 Imposed variable flow rate for $30 \%$ of maximum injection speed

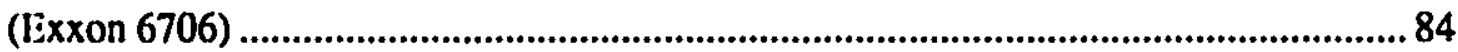




\section{Introduction}

Injection molding is a commonly used and versatile manufacturing process for use with thermoplastics and thermosets. It is a high rate production process with good dimensional control. Injection molding is a cyclic, non-stcady state process, in contrast with extrusion which is continuous and operates at a steady state, which involves the filling of a mold with molten polymer under high pressure.

Injection molded parts often show several types of surface defect. It has been hypothesized that wall slip may be associated with some of these defects. Wall slip is a violation of the usual "no-slip" assumption that states that a fluid adheres to any wall it is in contact with. Wall slip of molten plastics has been obscrved above a certain critical shear stress in rheological measurements. Wall slip is also believed to be related to certain types of extrudate distortion.

The objectives of the proposed research are to analyze the occurrence of flow marks during the injection molding of linear polycthylene and evaluate its possible relation to wall slip. The work includes an experimental study and a simulation of the process.

\section{Injection Molding of Thermoplastics}

\subsection{Overview}

In injection molding, pellets or granules are melted and sheared (plasticated) in a cylinder, and the melt is then forced into a mold either by a hydraulic plunger or by reciprocal motion of the screw. The pressure may exceed 20,000 psi (140 MPa), and the size of injection molding machines is specified by the clamping force on the mold. 
Most modern recent equipment for injection molding is of the reciprocating screw type. lijgure 2.1 shows a typical injection molding machine [1]. As the pressure builds up at the entrance of the dic, due to the accumulation of material, the rotating screw moves backward under this pressure to a predetermined distance (or volume of material). The screw then stops rotating and is pushed forward hydraulically, forcing the molten plastic into the die cavity. When the part is solidified, the mold is opened to release it and the whole cycle starts again.

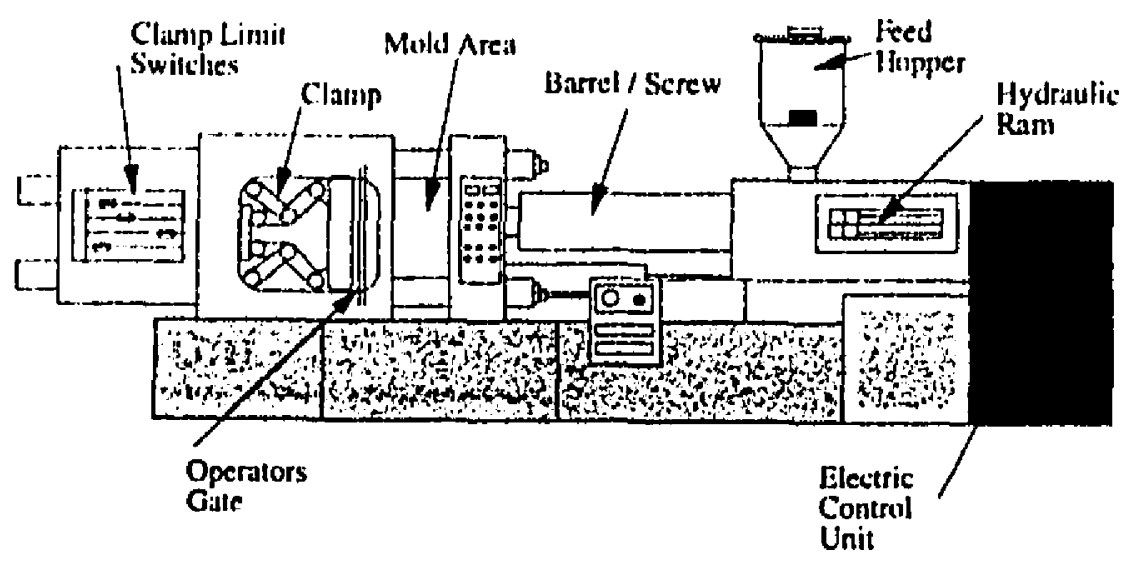

Fig. 2.1 Injection Molding Machine [1].

The plastics conversion industry makes growing use of injection molding, because of the high production rate that results from short cycles and automated control. Considering the high cost of molds, the production volume must be high for this process to be economical. One also wants the shortest possible cycle, but at the same time, a product having good appeararce and mechanical properties is desired.

The injection conditions result in a complex polymer flow pattern and in complex temperature and pressure distributions. Several manufacturers are still optimizing control parameters by trial-and-error, optimizing mold design and molding conditions by means of 
experiments. The present trend, however, is towards modeling and process simulation. This subject is covered in more detail in section 2.4.

\subsection{Possible Role of Slip in Polymer Processing}

The stick-slip phenomenon has previously been associated with the occurrence of extrudate distortion in capillary flow and extrusion [2]. Benbow ct al. [3] have postulated that the polymer melt looses adhesion at the metallic wall and slips when the wall sheur stress exceeds a critical value. The wall shear stress then decreases to a value lower than the critical one and adhesion is promoted, whereupon the shear stress increases again.

Hatzikiriakos and Dealy [4] studied the role of slip and fracture in the cyclic flow of HDPE in a capillary. Linear polymers often exhibit two distinct branches in their capillary flow curves (wall shear stress vs. wall shear rate). This behavior gives rise to oscillatory flow in a constant piston-speed rheometer. Based on earlier work [5, 6], they established a model that predicts correctly the essential features of the curves of pressure and flow rate vs. time. Their model includes wall slip, and their results led them to believe that the jump from the low flow branch to the high flow branch is due to slip. The jump back to the low flow branch occurs when adhesion is reestablished, as suggested by Benbow et al. [3].

In later work, Hatzikiriakos and Dealy [7] studied the effect of surface coatings on wall slip of LLDPE in a sliding plate rheometer. The results suggest that slip is a consequence of adhesive failuee at the polymer/plate interface. This conclusion is supported by the observation that the critical shear stress for the onset of slip scales well with the work of adhesion of the interface. Hatzikiriakos [8] investigated numerically the origin of the sharkskin phenomenon for HDPE and LLDPE in capillary flow. He concluded that wall slip is not a necessary condition for the occurrence of sharkskin, although it may affect it. He also suggested that the occurrence of slip is not inevitably accompanied by the appearance of surface defects. According to his numerical study, the latter occur at a critical shear stress higher than the one at which slip occurs. 
1:arlier work by Piau et al. [9], through visualization of upstream flow during the extrusion of silicones, showed that the sharkskin defect is an exit phenomenon related to the relaxation of strains at the orifice outlet (figure 2.2). Their assumption was supported by the fact that experiments performed with various wall materials had shown that wall slip was unlikely or minor, and could not be responsible for the observed phenomenon. Later studics confirmed this hypothesis $[10,11]$.

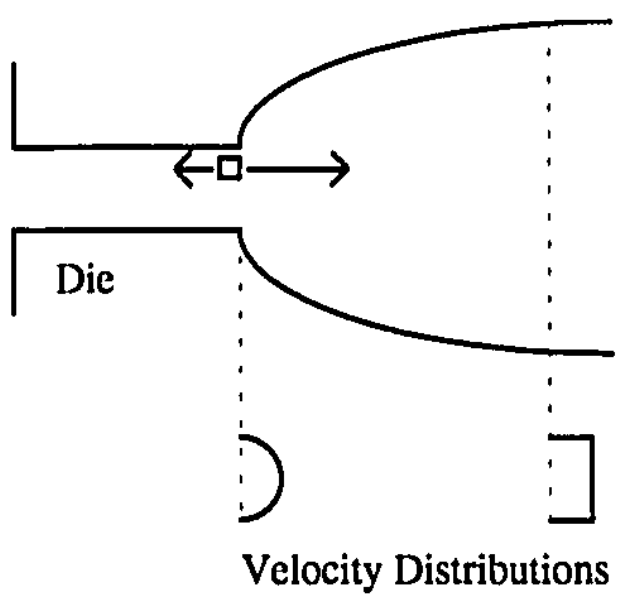

Fig. 2.2 Elongational effect on a fluid element at the die exit.

Injection molding involves high wall shear stresses, and there is a possibility that wall slip occurs during filling. For instance, in a visualization experiment by Yokoi $[12,13]$ of alternate flow marks during injection molding, wall slip may play an important role even if it is not explicitly stated. In a study of surface defects during injection molding of rubbermodified thermoplastics, Chang [14] used a slip mechanism at a step increase in cavity thickness, between the gate and the cavity, to explain the first flow instability during filling.

The occurrence of wall slip can modify the flow front velocity, wail shear stress, pressure distribution and heat transfer $[4,6]$. It is reasonable to assume that it may be associated with flow mark generation in injection molding. One manifestation of slip in injection molding is the dynamic three-phase boundary condition where the interface between the 
polymer melt and a second immiscible fluid (in this case, air) intersects the solid surface of the mold. The movement of this contact line violates the adherence or usual no-slip boundary condition $[15,16]$. In section 2.4 , we show how slip has been used in calculations as a numerical convenience, but the problem itself may be a physical and a mathematical issue at the same time. Schowalter [17] has raised the question as to what extent the problem of numerical simulation is a mathematical problem rather than inappropriate boundary conditions.

\subsection{Occurrence of Flow Marks in Injection Molding}

The broadening of the range of application of injection molding requires improved product quality. However, there is an obvious conflict between high quality exterior appearance and short cycle time, especially for general purpose resins. Undesirable exterior appearances are often thought to result from flow in the mold and are thus called flow marks.

A. Poslinski of General Electric [18] has enumerated six types of flow mark (fig. 2.3):

1. STREAKING: visible surface lines oriented in the direction of flow that usually appear near the gate, part corners, and changes in flow direction

2. GHOSTING: shadowing effect downstream of surface imprints like lettering, outlines of an insert, transducer locations

3. DEGRADATION: V-shaped regions typically of brown color and rough texture that most frequently appear near the end of the flow

4. READTHROUGH: glossy bands near lifter pins/lines where the flow-through area changes slightly

5. KNIT LINES: lines where two split melt fronts have merged together during the filling of the mold, usually disappearing further in the flow direction

6. PATCHES: large patches of grainy white texture spread randomly on both sides of the part, where one side is a negative imprint of the other (reverse image). 


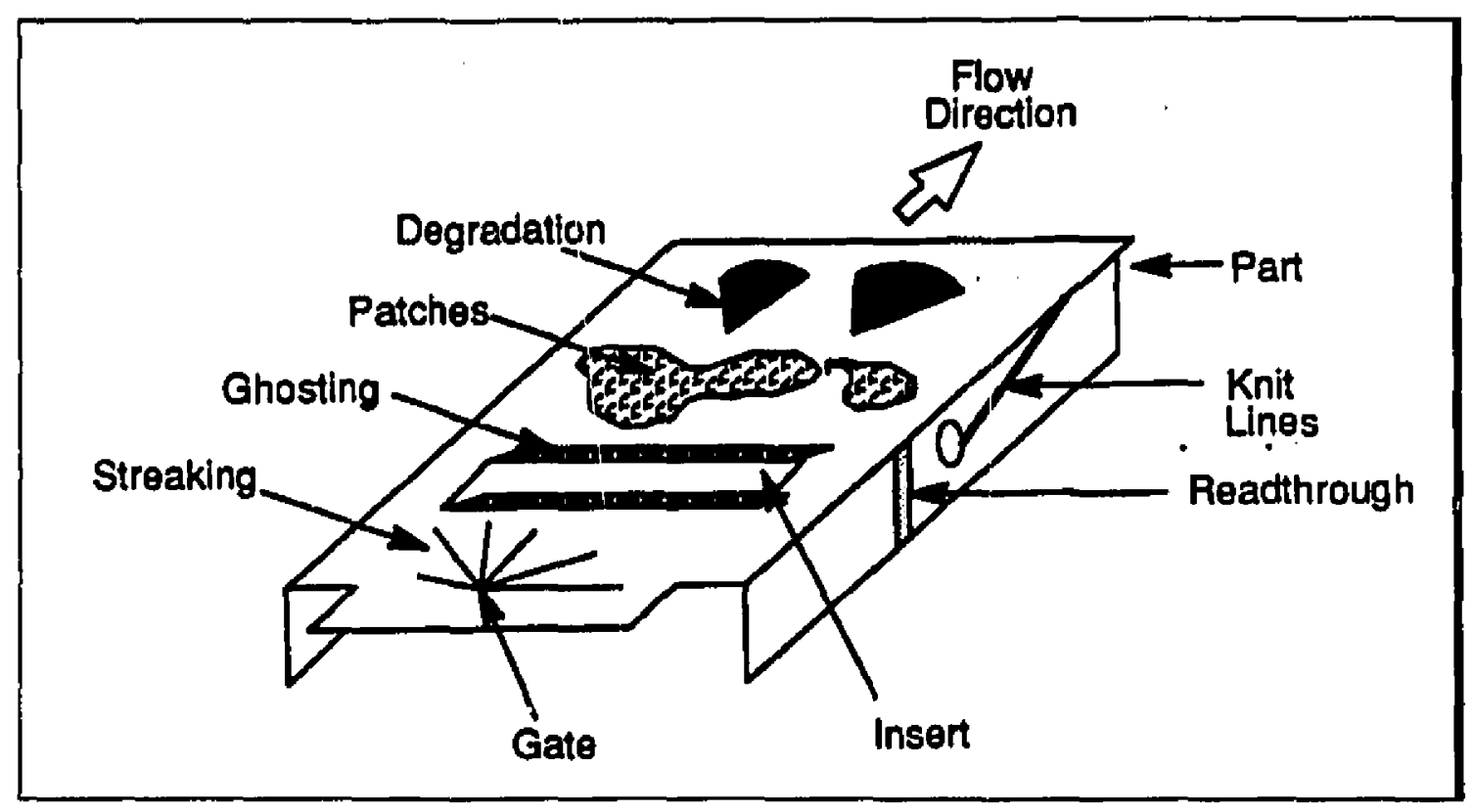

Fig. 2.3 Flow marks resulting from injection molding [18].

Three possible mechanisms have been proposed to explain the generation of the last type of defect during mold filling:

1. melt flow instabilities through gate contraction. (If this is correct, patches should appear near the gate and fade with increasing flow length, which is not observed.)

2. adhesion loss between solid skin and mold surface. (However, random slip of solid skin would not explain reverse images of patches.)

3. periodic stick-slip of advancing melt front. (Slightly different temperatures of mold halves may induce slip on one side.)

It seems that periodic stick-slip of the advancing melt front is the most likely candidate to explain patch formation.

Patches are, to some extent, similar to the alternate flow marks observed by Yokoi et al. $[12,13]$. Since conventional measuring methods cannot reveal the actual cause of flow marks, this group of researchers have carried out flow visualization experiments, using techniques such as a glass-inserted mold $[12,13,19,20]$, a laser-light-sheet mold $[21]$ and 
a gate-magnetization mold [22] to look at the flow inside a cavity. They classified flow marks in threc groups in terms of surface conditions (fig. 2.4):

(1) Micro-grooves like those in LP records

(2) Synchronous dull and gloss surface segments

(3) Alternate dull and gloss surface segmentis.

Yokoi et al. visualized and analyzed the generation process of the above three groups using the glass-inserted mold. Based on their visualization experiments, they proposed a mechanism for the generation of each type of flow mark. The following are the authors' hypothesis on why each type of flow marks occurs [13]:

(1) The generation of micro-grooved flow marks starts with the cooling of a portion of the melt at a cavity wall and the growth of a solid layer. The repeated phenomena of getting over these solid layers and cooling on the cavity wall results in a grooved surface. These flow marks are thus associated with cooling during slow flows (low injection speeds).

(2) Synchronous phase flow marks are generated especially in the case of high!y viscous material in a narrow gate: high flowing resistance and pressure build-up results in a "spurting" effect. These flow marks are generally associated with poor gate design and are characterized as "pulsating gate flows".

(3) Alternate flow marks are associated with rapid flows. They are typically observed in high molecular weight or filled systems and are generated through a repeated unsymmetrical fountain flow process (figure 2.5). According to the author, there is a clear correlation between the shear stress level on a cavity wall and the flow mark region. Consequently, this unsymmetrical flow is thought to occur duc to melt fracture on the cavity surface. 


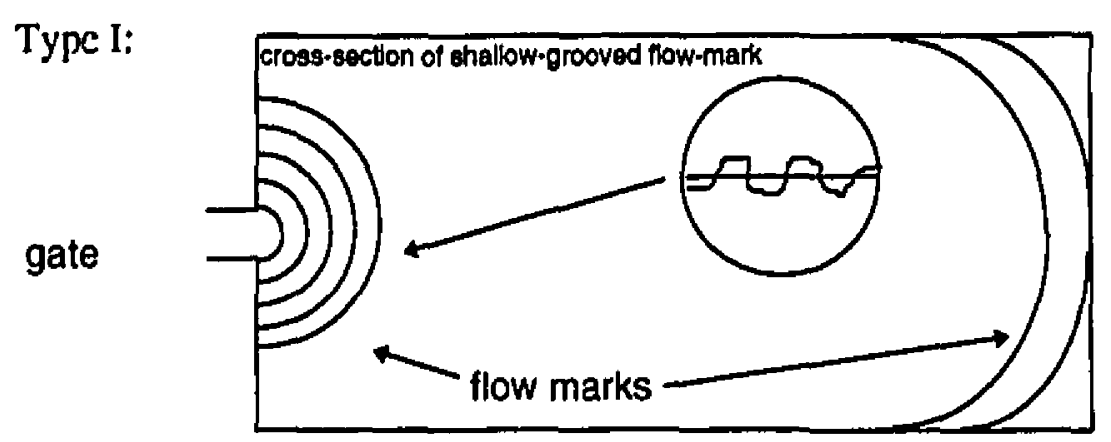

Type II:

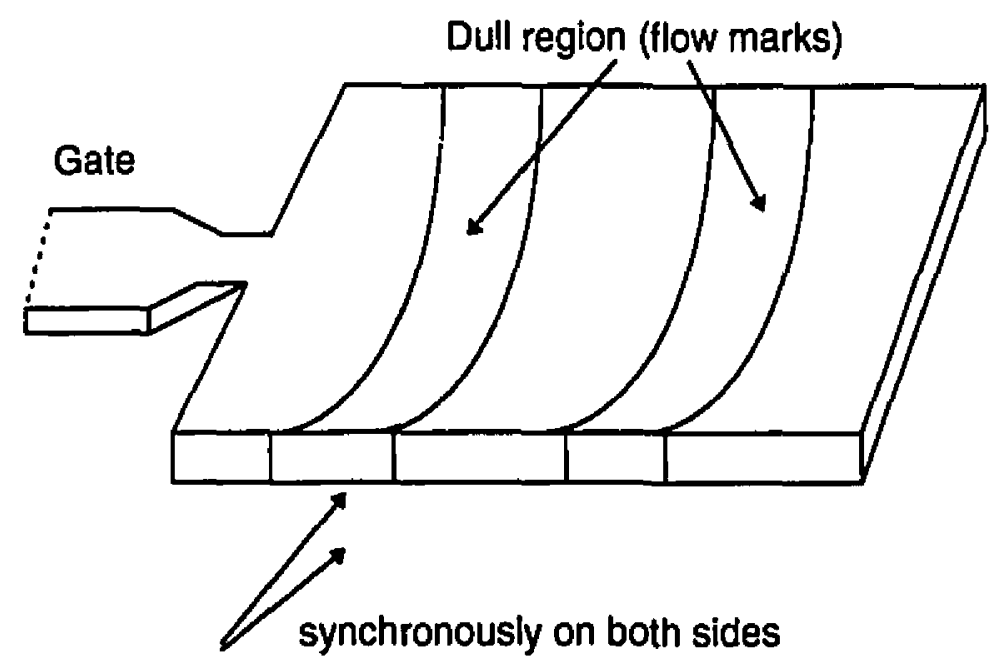

Type III:

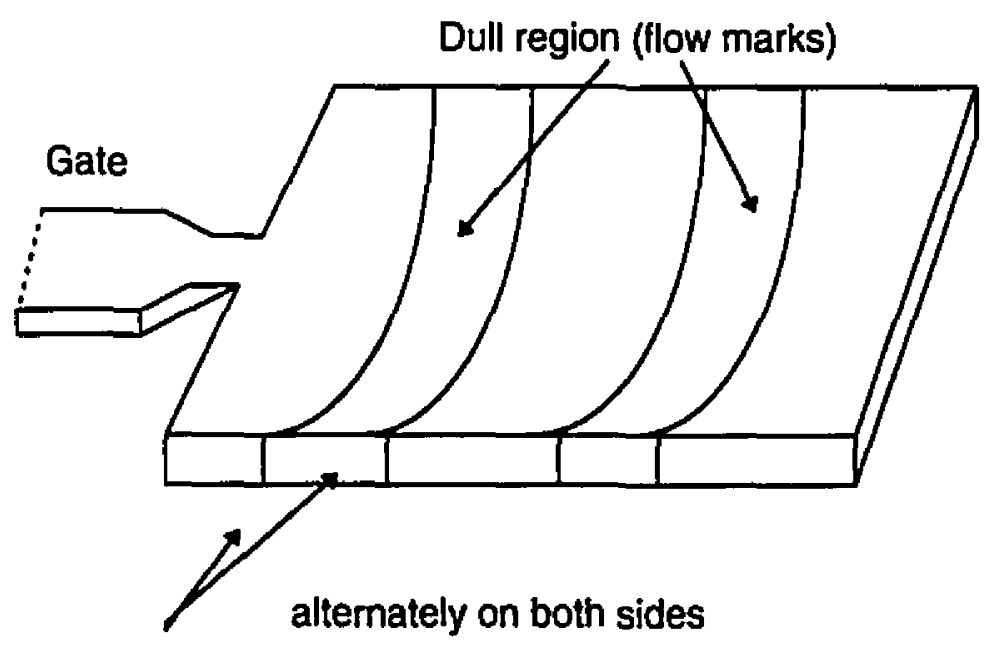

Fig. 2.4 Typical flow mark classification (adapted from [12]). 

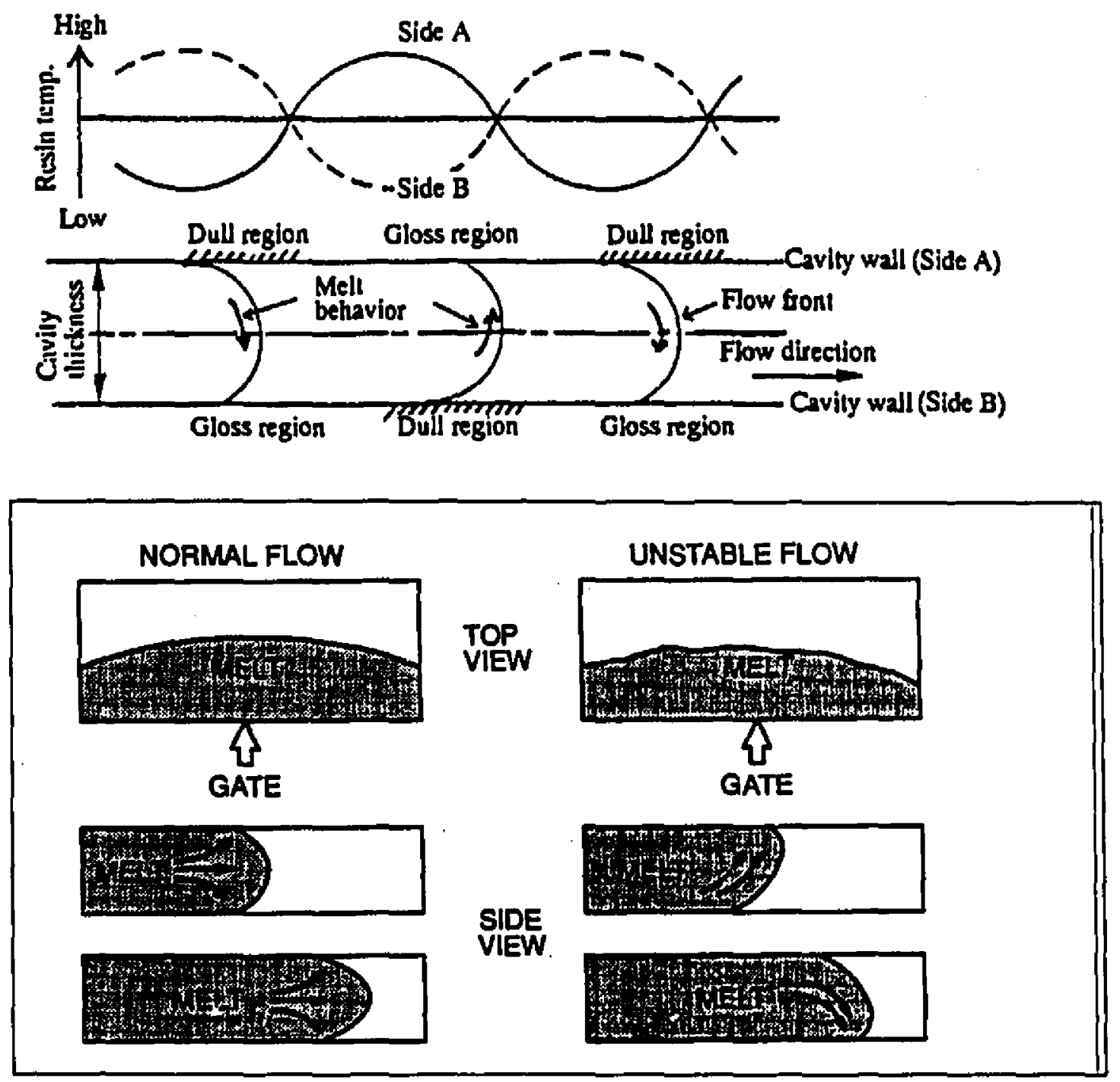

Fig. 2.5 Unsymmetrical fountain flow leading to flow marks formation [13].

The mechanism of patch formation proposed carlier [18] is supported by the experimental observations of Yokoi [13]. The unstable fountain flow was detected by two methods (glass-insert and gate-magnetization). Temperature measurements showed a temperature gradient between the gloss (hotter) and dull (colder) regions (fig. 2.5). The schematic 
model suggested by Yokoi for the generation of alternate flow marks is as follows (for PP/talc):

1- melt fractures/separates on one wall

2- occurrence of unsymmetrical fountain flow.

The fractured/separated side of the part has a dull surface. This surface goes through the following cycle:
a) flowing out of hotter melt
b) temperature rise
c) restraint of fracturing/separating
d) becomes progressively a gloss surface.

The other side, not fractured and not separated, goes simultaneously through this cycle:
a) flowing into of colder melt
b) temperature drop
c) acceleration of fracturing/separating
d) becomes progressively a dull surface.

It is possible that slip plays a role in the fracturing/separating mechanism. Yokoi also made SEM examinations of LDPE samples, which revealed melt fracture in the dull regions.

Flow marks (or patches) have been observed for a variety of resins: polycarbonateacrylonitrile/butadiene/styrene (PC/ABS) alloys (Hamada and Tsunasawa, [23]), rubber modified acrylonitrile/styrene/acrylate (ASA) polymers (Chang, [14]), low density polyethylene (LDPE) and polypropylene (PP)/talc (Yokoi, [13]), blends of BPA polycarbonate (BPAPC) and acrylonitrile/butadiene/styrene (ABS) (Cycolac®) (Hobbs, [24]). In this last paper, Hobbs concludes that evidence gathered in his investigation indicates that periodically alternating roughened bands, which develop at high injection rates, arise exclusively from stick/slip flow at high wall shear stresses. Wall slip is accentuated by lower friction coefficients associated with increased melt surface roughness. 
Injection molders like IPL (St-Damien, Québec) and Camoplast (Richmond, Québec) also confirmed the frequent occurrence of these surface defects on common resins: high and low density polyethylene (HDPE, LDPE) and polypropylene (PP). A sample of filledLDPE was provided by IPL for Scanning Electron Microscopy (SEM) analysis. However, it seems that this phenomenon is not restricted to filled systems or heterogeneous polymers, and can also occur in the molding of homogeneous polymers. We chose to study the occurrence of slip and flow marks during the injection molding of lincar PE. Further justification for this choice of material is given in section 5.1.

\subsection{Simulation of Injection Molding}

In addition to its use in equipment design, flow simulation has other uscful applications. Extrapolation or scale-up problems can be analyzed, the effect of individual variables isolated and sensitivity and stability problems explored [25]. All this can be achicved at a lower cost than if carried out experimentally.

The injection molding process consists of four stages:
1) plasticating screw extrusion
2) mold filling
3) packing
4) cooling and solidification of molded part.

The mold filling process is the most thoroughly treated aspect of the process in simulation software packages. This is a complex process, and flow visualization studics have been useful both for mold design and the mathematical simulation of the process. "The mold filling process reflects all the interesting and complicating facets of polymer processing: non-isothermal, transient flow of non-Newtonian fluids in a complex geometry with simultaneous structuring and solidification" [25]. 
Mold filling simulation requires the calculation of pressure, velocity and temperature distributions throughout the mold flow region. The calculation must also account for the position and shape of the advancing front. Several software packages have been developed in order to simulate certain aspects of polymer processing. These include: Polyflow (Bclgium), Moldflow (Australia), Plasfill (Canada, National Research Council), FIDAP (Illinois, USA), McKam-3 (Canada, McGill University), C-Flow (NY, UnitedStates), Adina (Mass., USA ).

As of today, no commercial injection molding software includes wall slip models, although the slip phenomena and the evolution of free surface shape appear to be crucial in any realistic flow simulation. FIDAP does offer the possibility of using a slip condition at the wall, but no degree of freedom is allowed for the advancement of the contact line. Kamal, Goyal [15] and Chu [15, 16] included in McKam-2 a slip boundary condition to alleviate the singularities in the calculated flow structure. They divided the boundary at the top of the mold into two regions, a no-slip region, where both the normal and tangential components of velocity vanish, and a slip region where only the normal component of velocity vanishes (no flow through the top boundary). For the tangential component of velocity, a dynamic condition that allows slip at the wall was used. Their results indicated that in the fountain flow region, the slip boundary condition was essential to maintain the shape of the flow front.

A finite element analysis of powder injection molding (PIM) including a slip model has been published by Kwon and Park [26]. Many experimental studies report the apparent slip of powder/binder mixtures as a peculiar aspect of the behavior of filled materials. Slip was modeled in two different ways: a slip layer model and a slip velocity model. The authors concluded that the slip layer model represents better the real thermomechanical PIM filling process with respect to both momentum and thermal transport, while the slip velocity model can account only for momentum transport. 


\section{Wall Slip Models}

For Newtonian fluids, the assumption of "no-slip" at the fluid/wall interface reproduces well experimental observations. However, for non-Newtonian polymers, the no-slip assumption often does not reproduce experimental results [27|. This leads to the hypothesis that the melt velocity at the wall is not zero as normally assumed. In this section, we describe several static and dynamic wall slip models and examine the elfect of the substrate on wall slip.

\subsection{Steady-State Models}

The earliest wall slip models established were of the power-law type (Kalika and Denn [28]). Hatzikiriakos and Dealy [5] performed experiments in a sliding plate rheometer developed at McGill University, with HDPE at ambient pressure. If we assume that the slip velocity is the same on both plates, for the sliding plate geometry shown in figure 3.1, the nominal shear strain is given by:

no slip condition

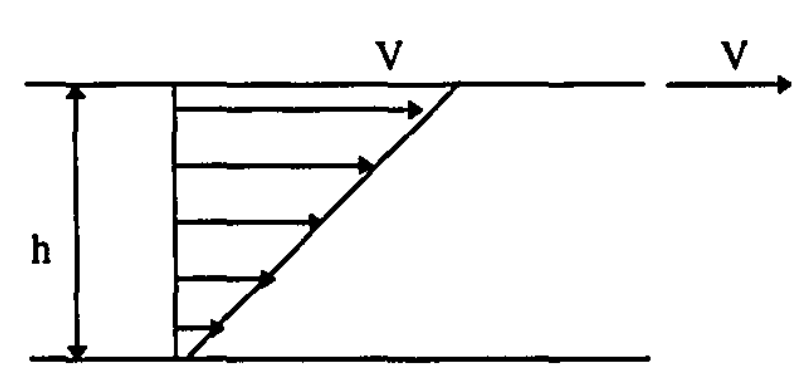

slip condition

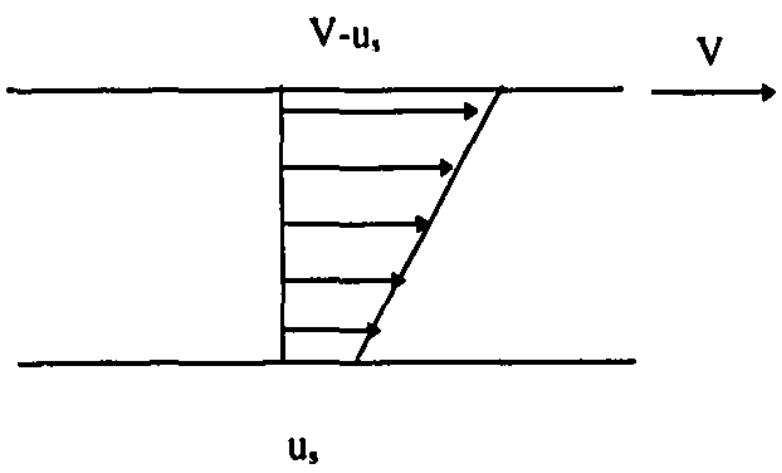

Fig. 3.1 Geometry of the sliding plate rheometer. 


$$
\dot{\gamma}_{n}=\frac{V}{h}=\dot{\gamma}+\frac{2 u_{1}}{h}
$$

where $\dot{\gamma}_{n}$ is the nominal shear rate, $\mathrm{V}$ is the velocity of the moving plate, $\dot{\gamma}$ is the true shear rate in the melt, $u_{r}$ is the slip velocity, and $h$ is the spacing between the plates.

$A$ plot of $\gamma_{n}$ vs. $1 / \mathrm{h}$ at constant shear stress consists of a straight line whose slope is $2 u_{s}$, if $u_{s}$ is a function of $\sigma$ only. On a $\log -\log$ plot of $u_{1} v s$. $\sigma$, most of the data for a constant temperature and constant surface conditions often fall on a single line, which suggests the following stcady state model:

$$
\begin{array}{ll}
u_{s}=0 & \sigma<\sigma_{c} \\
u_{s}=a \sigma^{m} & \sigma>\sigma_{c}
\end{array}
$$

where $\sigma_{\mathrm{c}}$ is the critical shear stress for the onset of slip, "a" is the slip coefficient which is a function of temperature, and the exponent $m$ is practically independerit of temperature. If the polymer also follows a power-law model:

$$
\frac{2 u_{s}}{h}=\dot{\gamma}_{n}-\left(\frac{\sigma_{w}}{K}\right)^{1 / n}
$$

Hatzikiriakos and Dealy [6] also conducted capillary rheometer studies on wall slip for the same HDPE resin. Despite the fact that according to the authors, pressure has a negligible effect on the viscosity and density of HDPE, the Bagley plots obtained exhibited curvature. After applying the Bagley end correction and modifying the Mooney technique, they estimated the slip velocity at an axial distance $\mathrm{z}_{\mathbf{0}}$ :

$$
\dot{\gamma}_{A s}\left(z_{0}\right)=\dot{\gamma}_{A}-\frac{8 u_{s}\left(z_{0}\right)}{D} \quad\left[\sigma_{w}\left(z_{o}\right)=\text { const }\right]
$$

where $\dot{\gamma}_{A s}$ is the apparent wall shear rate corrected for wall slip, assumed to be only a function of wall shear stress, and D is the capillary diameter. The Rabinowitch correction is later applied to obtain the true wall shear rate and viscosity. For a polymer obeying the 
power-law model for viscosity in the range where slip occurs, the slip velocity can the evaluated directly from the basic capillary flow data:

$$
\frac{8 u_{s}\left(z_{0}\right)}{D}=\dot{\gamma}_{A}-\left(\frac{4 n}{(3 n+1)}\right)\left(\frac{\sigma_{w}\left(z_{0}\right)}{K}\right)^{1 / n}
$$

In the same paper [6], a complete slip velocity model is developed, taking into account the temperature, pressure and molecular structure of the polymer. The reader is referred to references $[4,6]$ for complete details. We present here only the final expression:

$$
u_{s}=\xi_{o}\left(\frac{C_{1}^{0}\left(T-T_{o}\right)}{C_{2}^{0}+\left(T-T_{o}\right)}\right)\left(\frac{\sigma_{w}}{\sigma_{c 1} I^{1 / 4}}\right)^{m}\left[1-c_{2} \tanh \left(\frac{1}{R T}\left(E+c_{3} \frac{\sigma_{n}}{\sigma_{w}}\right)\right)\right]
$$

where $\xi_{0}$ is an empirical constant, $\sigma_{\mathrm{n}}$ is the compressive stress acting normal to the interface, $\sigma_{\mathrm{cl}}$ is the critical shear stress for the onset of slip, I is the polydispersity, $\sigma_{\mathrm{w}}$ is the wall shear stress, $m$ is a constant that depends only on the type of polymer, $C_{1}{ }^{0}$ and $C_{2}{ }^{0}$ are empirical constants in the WLF equation that are fitted to experimental data, $T$ is the absolute temperature, $T_{0}$ is a reference temperature, $c_{2}$ and $c_{3}$ are empirical constants, $l:$ is the activation energy, and $R$ is the gas constant.

In a paper previously mentioned [4], Hatzikiriakos and Dealy applied two of the above models to the low and high-flow-rate branches of oscillatory flow in capillaries. For the low-flow-rate branch, the slip velocity was associated with adhesive failure at the fluid/wall interface, and the slip model used was equation 3.6. The slip velocity in the high-flow-rate branch was assumed to be the result of cohesive failure or "disentanglement" of molecules, and was modeled by the power-law (equation 3.2).

In a later publication on the effects of interfacial conditions on wall slip and sharkskin melt fracture of HDPE, Hatzikiriakos and Dealy [29] performed their experiments in capillary and slit rheometers. The model used for slip in a capillary was again equation 3.6. For a slit rheometer (fig. 3.2 , width to height ratio $>10$ ): 


$$
\sigma_{w}=K\left[\left(\frac{2 n+1}{3 n}\right) \dot{\gamma}_{A}^{s}\right]^{n}
$$

for a polymer whose viscosity obcys a power-law model. The slip velocity can be oblained as follows where $\mathrm{H}$ is the height in figure 3.2:

$$
\frac{6 u_{s}}{H}=\dot{\gamma}_{A}^{s}-\left(\frac{3 n}{2 n+1}\right)\left(\frac{\sigma_{w}}{K}\right)^{1 / n}
$$

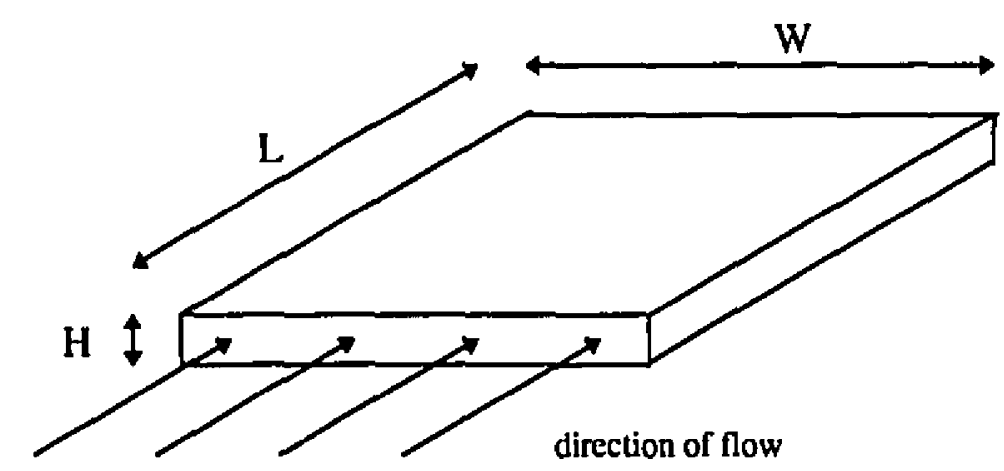

Fig. 3.2 Geometry of a slit for rheometer experiments.

Equation 3.6 can also be used as a theoretical model for slip velocity in a slit if $\left(c_{3} / 2\right) L / W$ replaces $c_{3} L / D$. The equation is thus approximately valid for a flow geometry other than the one used to determine the constants.

Finally, a more recent model has been proposed by Hatzikiriakos [8] for the numerical prediction of wall slip and sharkskin melt fracture in capillary flow, for HDPE and LLDPE. The theoretical slip velocity is derived from a rate activation theory and includes a hyperbolic sine term in place of the $\sigma_{w}{ }^{m}$ term in the original power law:

$$
u_{s}=\frac{2 a K T}{N h} \exp \left(\frac{-\Delta G_{o}}{R T}\right) \sinh \left[\frac{E}{R T}\left(\frac{\sigma_{w}}{\sigma_{c}}-1\right)\right]
$$


where a is the slip coefficient, which depends on the type of polymer, temperature and pressure. $\mathrm{K}$ is Boltzman's constant, $\mathrm{h}$ is Planck's constant, $\mathrm{R}$ is the molar gas constant, $\mathrm{T}$ is the absolute temperature, $\Delta G_{o}$ is the energy barrier that a molecule has to overcome in order to change its position, $\mathrm{E}$ is the minimum amount of energy that the shear stress has to overcome for slip to occur, and $\mathrm{N}$ is the number of macromolecule/wall bonded sites (assumed to be equal to the number of entanglements).

An advantage of this model is that it provides for a smooth transition from the no-slip (o) the slip condition at the critical shear stress $\sigma_{\mathrm{c}}$, which is not possible with the simple power-law model. This feature is important when investigating the sitc for initiation of wall slip and surface melt fracture. An example curve for $u_{s} v s . \sigma_{w}$ is shown in figure 3.3.

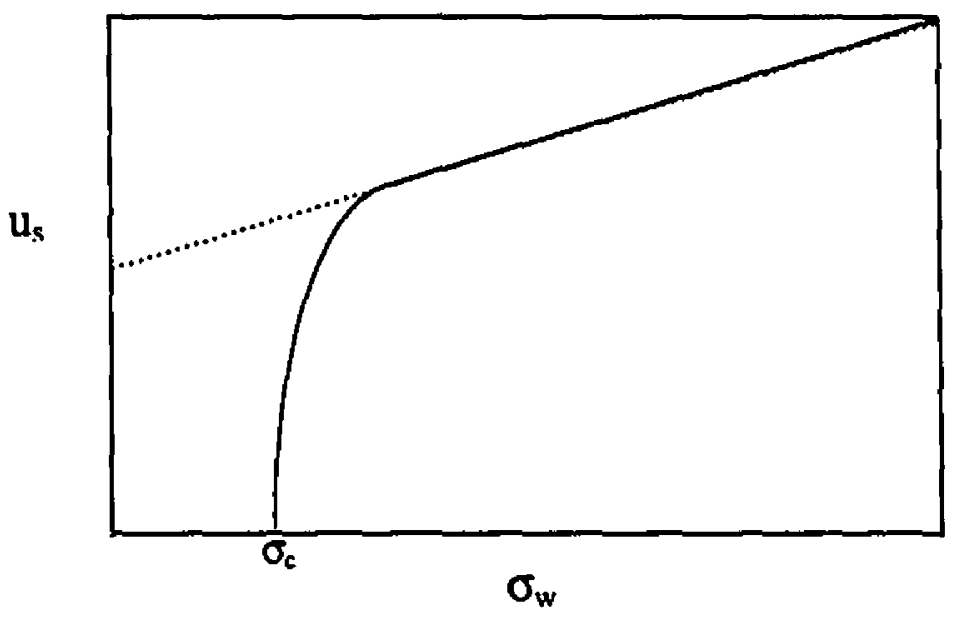

Fig. $3.3 \quad$ Slip velocity predicted by equation 3.9 (log scalcs).

There has been some controversy over the evidence of slip measured by Ramamurthy (LLDPE) [30], Kalika and Denn (LLDPE) [28] and Hatzikiriakos and Dealy (HDPI) [5, 6]. Piau et al. [9] showed that the method used by Ramamurthy, based on a Mooney diagram, representing the wall shear rate variations as a function of the capillary radius, must take entry effects into account for a correct cvaluation of the slip velocity. 
Ramamurthy used capillaries of various diameters, but with a unique length to diameter (L/D) ratio of 20 , so no entrance corrections were made to calculate the stress values. In $\Lambda$ ppendix $A$ of [9], Piau et al. show that wall slip velocities calculated from flow curves for a serics of capillary dies may result exclusively from entrance effects.

Kalika and Denn [28] used several L/D ratios but a single capillary diameter, so no gap dependence of the flow curve was reported. For all the dies used, and in accordance with the work of Ramamurthy [30], the flow curves displayed a discontinuity in the range of shear rates where sharkskin is usually seen. However, this discontinuity was observed at $2.6 \times 10^{5} \mathrm{~Pa}$ and not at $10^{5} \mathrm{~Pa}$, the value reported by Ramamurthy. Kalika and Denn attributed this discontinuity to a loss of adhesion between the polymer and the wall. By fitting the power-law parameters in the low shear rate region, where no sharkskin is observed, they calculated non-negligible slip velocities by using the deviation of the flow curve from the power-law regime. However, there is doubt as to whether a power-law regime is established in the low shear rate region.

El Kissi and Piau [11] also mention Hatzikiriakos and Dealy's work [5, 6] on wall slip of HDPE. They report that the gap dependent flow curves were used to argue that slip at the wall is taking placc, and to quantify it. However they believe that it is essential to give experimental proof of the existence of slip. For example, it is possible to perform direct slip visualizations by observations of the flow inside the capillary, or slip velocity measurements using laser doppler velocimetry. In particular, in the case of Kalika and Denn [28] and Hatzikiriakos and Dealy studies [6], the high values calculated for the slip velocity (up to $3 \mathrm{~cm} / \mathrm{s}$ ) could have been measured by appropriate experimental means, although it is not an easy task.

\subsection{Transient Models}

Transient shear experiments were performed by Hatzikiriakos and Dealy in a sliding plate rheometer with HDPE [5] to study the effect of shear history on slip. Lim and Schowalter [31] had suggested that the transition from dynamic slip to stick is gradual and shows 
characteristics of relaxation in the oscillating region of the flow curve for slit flow. To take this behavior into account, Hatzikiriakos and Dealy $|5|$ incorporated a slip relaxation term into an expression that is consistent with steady state observations:

$$
u_{s}+\lambda_{s}\left(\frac{d u_{s}}{d t}\right)=a \sigma^{m}
$$

where $\lambda_{s}$ is a "slip relaxation time". For steady slip flow the second term on the left handside is zero, and equation 3.2 is recovered.

For exponential shear, the nominal strain varies with time as follows:

$$
\gamma_{n}(t)=A\left(e^{\alpha t}-1\right)
$$

where $\mathrm{A}$ is the "strain scale factor" and $\alpha$ is the "exponential rate constant". From their experiments, Hatzikiriakos and Dealy obtained a mean relaxation time for HDPl: which was used for later calculation for oscillatory shear.

For oscillatory shear, the nominal shear strain as a function of time is given by:

$$
\gamma_{n}(t)=\gamma_{0} \sin (\omega t)
$$

where $\gamma_{0}$ is the nominal strain amplitude and $\omega$ is the frequency. The nominal shear rate $\left(\mathrm{d} \gamma_{\mathrm{N}} / \mathrm{dt}\right)$ is:

$$
\dot{\gamma}_{n}(t)=\gamma_{0} \omega \cos (\omega t)
$$

The dynamic slip model (equation 3.10) was applied to this flow, and its predictions were compared with actual shear stress waveforms. A constitutive cquation was needed to account for the viscoelasticity of the melt, i.e. to relate stress to the actual deformation of the polymer. A linear viscoelastic constitutive equation was chosen; the authors used a Maxwell model with one relaxation time:

$$
\sigma+\lambda\left(\frac{d \sigma}{d t}\right)=\eta_{0} \dot{\gamma}
$$


where $\eta_{0}$ is the zero shear viscosity. Combining equations $3.1,3.13$ and 3.14 we obtain:

$$
\sigma+\lambda\left(\frac{d \sigma}{d t}\right)=\eta_{o}\left[\gamma_{o} \omega \cos (\omega t)-\frac{2 u_{s}}{h}\right]
$$

The system of two equations (3.10 and 3.15) is solved with the following initial conditions:

$$
\text { at } \mathrm{t}=0, \quad \sigma=0 \text { and } \mathrm{u}_{\mathrm{s}}=0 \text {. }
$$

The solution to these equations compared well quantitatively with experimental data. Hatzikiriakos and Dealy concluded that the inclusion of the unsteady term in the dynamic slip model is essential to reproduce the results of this type of experiment. They also suggested that melt slip is a physicochemical process in which the polymer-wall interface undergoes continuous change during successive cycles.

\subsection{Effect of Substrate}

In their sliding plate rheometer experiments with HDPE, Hatzikiriakos and Dealy [5] also studied the effect of a layer of fluorocarbon at the interface on both the slip velocity and the critical shear stress for the onset of slip. They used two types of fluoropolymer. Dynamar 9613 (3M) was applied in solution form with subsequent evaporation of solvent and resulted in a significant decrease in the critical shear stress and increase in slip velocity. The other fluoropolymer (DFL) was applied as an aerosol and was sprayed on the surface. It had no effect on the critical shear stress but reduced notably the slip velocity.

It thus appears that depending on the situation, a fluoropolymer can act either as a slip promoter or as an adhesion promoter. To help understand the mechanism of action of fluoropolymer additives, Stewart and Dealy [32] performed microscopic examination of the surfaces. They noticed that the solution application gave a smooth surface on which the polymer could slip, but that the spray resulted in a porous surface. Since it was shown that the method of applying the coating had an effect on its interaction with the melt, it 
was suggested that the nature of the interface could play an important role in the slip of polymers.

During their study of the effect of surface coatings on the wall slip of L.LDPPS. Hatzikiriakos and Dealy [7] concluded that slip is a result of adhesive failure at the interface. This was confirmed, since the critical shear stress for the onset of slip scaled well with the work of adhesion of the interface. They used three fluoropolymer coatings on the plates of a sliding plate rheometer, and all significantly increased the slip velocity and decreased the critical shear stress.

In a paper previously mentioned [29], Hatzikiriakos and Dealy tried to resolve the debate in the literature as to whether or not fluoropolymers act as adhesion promoters or slip facilitators in die flow. They studied the effects of interfacial conditions on wall slip and sharkskin melt fracture of HDPE in capillary and slit rheometers. Two fluoropolymers (Dynamar 9613 and DFL) were used to modify the interface. One of these increased slip while the other (DFL) did not seem to have a major effect on the slip velocity in capillary flow experiments. The DFL sprayed coating had previously been found to decrease the slip velocity at ambient pressure in sliding plate experiments [5]. However, both materials improved extrudate appearance. From these results, it scems that both adhesion promoters and slip promoters can improve extrudate appearance. The mechanism proposed by the authors states that the presence of an adhesion promoter or slip promoter at the interface decreases the extensional strain rate just upstream of the exit, thus eliminating exit fracture.

Ramamurthy [30] noticed that certain metals, like brass, improve the appearance of polyethylene films in film blowing. Hatzikiriakos and Dealy [29] studied the effect of brass vs. stainless steel in their slit flow experiments and observed that the slip velocity was slightly reduced in the presence of brass. However, this reduction was within experimental error, and the result was not deemed to be conclusive. 


\section{Scope and Objectives of this Work}

The objectives of this work were as follows:

1. To look for experimental evidence that slip occurs during injection molding.

2. To investigate the possible relationship between flow marks and wall slip.

3. To investigate the feasibility of incorporating slip models in a $2.5 \mathrm{D}$ (Hele-Shaw) injection molding model. 


\section{Experimental Aspects}

\subsection{Experimental Material}

One material was mainly used in this work. It is an LLDPE high stability resin from Dow (Dowlex 2049) that had been partially characterized in terms of slip and rheology at McGill in a previous study [33]. The recommended processing temperature range is between 200 and $250^{\circ} \mathrm{C}$. The rheology of unfilled materials is simpler than that of filled materials. Exploratory injection molding experiments were conducted to confirm that flow marks were generated for this material. Exploratory experiments were also conducted with an injection grade HDPE from Exxon (Exxon 6706), that was characterized at the Industrial Materials Institute (IMI) in terms of rheology and physical properties. Since slip occurs mostly at high shear stresses, one way to achieve this is by using an extrusion grade of polymer in injection molding. Dowlex 2049 (Melt Index M.I.=1.0 g/10 min., ASTM D1238, Method E)) is in fact a blown film grade, but was chosen since its rheological and slip behavior was partially known. Preliminary injection molding experiments confirmed that a higher density of flow marks was generated for Dowlex 2049 parts compared to Exxon 6706 parts (M.I.=7.0 g/10 min.). The bulk properties of the two resins are given in table 5.1, and table 5.2 provides molecular weight information for the LLDPE resin.

Table 5.1 Polyethylene resins used in exploratory studies

\begin{tabular}{|c|c|c|}
\hline Resin & Density $\left(\mathrm{g} / \mathrm{cm}^{3}\right)$ & Melt Index $(\mathrm{g} / 10 \mathrm{~min})$. \\
\hline LLDPE Dowlex 2049 & .926 & 1.0 \\
\hline HDPE Exxon 6706 & .952 & 7.0 \\
\hline
\end{tabular}

Table 5.2 Molecular weight information for resin used in experimental studies.

\begin{tabular}{|c|c|c|}
\hline Resin & Molecular Weight $(\mathrm{g} / \mathrm{mol})$ & Polydispersity $\left(\mathbf{M}_{w} / \mathbf{M}_{\mathbf{n}}\right)$ \\
\hline LLDPE Dowlex 2049 & 119600 & 3.82 \\
\hline
\end{tabular}




\subsection{Characterization of Resin}

To perform the simulation of the mold filling stage so it can be compared to experimental results, the following properties are needed:

1) viscosity (Carreau-WLF model)

$$
\begin{aligned}
& \eta=\frac{\eta_{0} A_{t}}{\left(1+P_{2} A_{t} \dot{\gamma}\right)^{P_{3}}} \\
& \log \left(A_{t}\right)=\frac{8.86\left(T_{\text {ref }}-T_{s}\right)}{\left(101.6+T_{\text {ref }}-T_{s}\right)}-\frac{8.86\left(T-T_{s}\right)}{\left(101.6+T-T_{s}\right)}
\end{aligned}
$$

3) where $\eta_{0}$ is the zero-shear viscosity, $P_{2}$ is the relaxation time, $P_{3}$ is the power law index, $T_{\text {ref }}$ is the reference temperature, $T_{s}$ is the standard temperature and $\dot{\gamma}$ the effective shear rate

4) critical shear stress for the onset of slip $\sigma_{c}$

5) slip velocity $u_{s}$

6) heat capacity $C_{p}$

7) thermal conductivity $k$

8) density $\rho$

9) no-flow temperature.

\subsubsection{Rheological Properties and Slip Behavior}

Rheological measurements were carried out on an Instron, piston-driven, constant-speed, capillary rheometer located at McGill. The temperature control system for the rheometer barrel consisted of three distinct heating zones monitored by three J-type rheometer barrel thermocouples. Three Omega digital PID controllers were used to control the heating zones of the capillary rheometer to a precision of $\pm 1^{\circ} \mathrm{C}$ [34]. Rheological measurements were made at 160,200 and $240^{\circ} \mathrm{C}$ to cover the injection molding temperature range. Circular dies of various diameters and L/D were used, all made from 420 stainless steel (Table 5.3). Small L/D ratios were used in order to obtain an accurate value of the Bagley correction and to avoid pressure effects on viscosity. Measurements were also carried out with orifices $(L / D \approx 0)$ to verify the Bagley correction. At least two diameters were used to 
obtain the flow curve gap dependence, which is required to obtain the critical shear stress for the onset of slip and to calculate the slip velocity.

Table 5.3 Capillary dies used in this work

\begin{tabular}{|c|c|}
\hline Diameter & L/D ratios \\
\hline $0.030^{\prime \prime}(0.0762 \mathrm{~cm})$ & $\approx 0,5,10,20$ \\
\hline $0.054^{\prime \prime}(0.1372 \mathrm{~cm})$ & $\approx 0,5,10,20$ \\
\hline
\end{tabular}

\subsubsection{Thermal Properties}

\subsubsection{Heat Capacity Measurements}

Heat capacity measurements were carried out using a power compensation device (PerkinElmer DSC-7 Differential Scanning Calorimeter) located at IMI. Dowlex 2049 samples were placed into sample holders and sealed. A scanning rate of $-20^{\circ} \mathrm{C} / \mathrm{min}$. was used for two temperature ranges: $260-120^{\circ} \mathrm{C}$ and $170-30^{\circ} \mathrm{C}$, considering the solidification during injection molding. The fast scanning rate of $20^{\circ} \mathrm{C} / \mathrm{min}$. is suggested in order to increase sensitivity (larger signal) with small loss of resolution, and to shorten the experiment time. The heat flux was recorded as a function of temperature. Empty sample holders were cooled at the same rate to obtain the baseline. The heat flux was measured in the same temperature range for sapphire samples having known heat capacities. The heat capacity is calculated from the difference in heat flow between a blank (empty pan) run and a sample pan run under identical conditions, including heating rate:

$$
C_{p}=K_{c} x \frac{\text { Heat Flow (Sample) - Heat Flow (Blank) }}{\text { Heating Rate }}
$$

where $K_{c_{p}}$ is a constant calibrated with sapphire. This calculation is automatically obtained by the DSC software. Each experiment was repeated once to verify reproducibility. 


\subsubsection{Thermal Conductivity Measurements}

Thermal conductivity measurements were carried out using a K-System II apparatus located at IMI, over a temperature range of 220 to $30^{\circ} \mathrm{C}$. The K-System measurement of thermal conductivity of polymer melts is based on the transient "line-source method" [35]. It is an improved design where the heater and measurement wires are encased in a steel hypodermic tube so that the whole unit is in the form of a probe. It is then easily inserted into the moiten polymer. Since the power output of the probe heater is too small to achieve and maintain melt temperatures, an external source such as a heated barrel is necessary to heat up the sample to its initial steady state temperature.

After the heated barrel has attained the desired temperature level, pellets are introduced through the top. Care has to be taken to avoid air bubbles in the sample. After the sample has melted, the probe is inserted axially down the center of the barrel and the temperature is monitored until steady state is attained. A small constant voltage is then applied to the probe heater for 10 to 20 seconds. The probe temperature transient is recorded during this period on a data-acquisition system. These data are used to calculate the thermal conductivity at that temperature. The heater can then be set to a different temperature for the next measurement. Six measurements were made at each temperature: 230, 210, 190, $170,150,125,115,105,80,6040$ and $25^{\circ} \mathrm{C}$. The probe used for the measurements was $50 \mathrm{~mm}$ long and had a resistance of $28.58 \mathrm{ohms}$. The voltage was $2.00 \mathrm{~V}$.

\subsubsection{PVT Measurements}

Pressure-Volume-Temperature (PVT) data were obtained using a PVT-Gnomix (Version 6.02) apparatus also located at IMI. Cylindrical samples were prepared for the experiments using a Ray-Ran injection molding press for test samples (melt temperature $=$ $220^{\circ} \mathrm{C}$ and mold temperature $=40^{\circ} \mathrm{C}$ ). The solid state density was evaluated by means of the loss-in-weight method (equation 5.3) at $0.922 \mathrm{~g} / \mathrm{cm}^{3}$ for molded samples (the theoretical density is $0.926 \mathrm{~g} / \mathrm{cm}^{3}$ for this resin.): 


$$
\rho_{\text {sumple }}=\frac{W_{\text {air }}}{\left(W_{\text {air }}-W_{\text {athenot }}\right)} \times \rho_{\text {esthenot }}
$$

where $\mathrm{W}_{\text {atr }}$ is sample weight in air and $\mathrm{W}_{\text {ethanol }}$ is sample weight in ethanol.

In this method, the polymer is contained in a sample cell together with a confining lluid, leading to a hydrostatic state of stress even for solid samples. The sample must be inert 10 the confining fluid. Volume changes of the sample are calculated from the combined volume changes of the sample and the confining fluid by subtracting the known volume change of the fluid at each pressure and temperature [36]. Mercury (Hg) was used as the confining fluid. Measurements were carricd out at constant pressures of 10,60 and 120 $\mathrm{MPa}$ over a temperature range from 220 to $70^{\circ} \mathrm{C}$ (scanning rate of $-3^{\circ} \mathrm{C} / \mathrm{min}$.). Calculations of specific volumes ( $1 /$ density) were made automatically by the PVT-Gnomix system software.

\subsection{Injection Molding}

\subsubsection{Equipment}

Injection molding experiments were performed on an instrumented edge-gated plate mold $(40 \times 10 \times 0.24 \mathrm{~cm})$, mounted on a 400 ton Husky injection press located at IMI. $\Lambda$ sketch of the plate mold is provided in appendix $A$, showing the locations of the four pressure transducers (Hunkar Laboratories Inc.). Position \#1 is in the runner, and positions \#2, \#3 and \#4 are in the cavity. Since most of the injections resulted in short shots, due to the high viscosity of the resin, no readings were obtained from pressure transducer \#4. The capacity of \#1 is 36220psi (1000lbs load cell on ejector pin of 3/16" dia.) and that of $\# 2$, \#3 and \#4 is 81490 psi (1000lbs load cell on cjector pin of 1/8" dia.).

Polyethylene is transparent to infrared wavelengths below a thickness of $7 \mathrm{~mm}$. The maximum thickness of the molded plates was $3.175 \mathrm{~mm}(0.125 ")$, so temperature measurements could not be made by infrared sensometry. Thermocouples are too slow in response to be accurate in injection molding measurements. To overcome this difficulty, two SENSOTRONTM melt cavity pressure/temperature transducers for use in an injection 
molding machine were ordered. SENSOTRONTM's patented Silicon-on-Sapphire melt pressure sensors are in direct contact with the melt, which gives them very fast response times, in the order of 100 to 500 microseconds. The sapphire diaphragm, located at the tip of the transducer, is $\mathbf{2 0 0}$ times harder than stainless steel, thus making it practically abrasion proof. $A$ silicon RTD (Resistance Thermistor Differential) is located on the sapphire diaphragm, which gives an accurate measurement of melt temperature in the same device, thus reducing the number of mounting wells required [37]. The delivery time for these components unfortunately exceeded time available for this work, considering the fact that the mold had to be modified to install the transducers because of insufficient space between the cooling channels. Therefore, injection molding experiments had to be conducted without temperature measurements.

\subsubsection{Molding Conditions}

Table 5.4 lists fourteen molding conditions. Experiments \#2, 3 and 7 were designed to study the effect of injection speed. Injection speed is given as a percentage of the total hydraulic oil flow available to the injection cylinder the setting controls the electric current to the hydraulic injection valve to increase or decrease the speed of the injection piston). In experiments $\# 2,4$ and 5, we studied the effect of mold thickness. The effect of mold temperature was examined in experiments \#1,2 and 6 and melt temperature in $\# 2,9$ and 10. Two gates were used in experiments \#3 and 11 with the same molding conditions. Finally, the effect of a wall coating was studied in experiments $\# 2,3,8$ and 12 (Teflon ${ }^{\mathrm{TM}}$ ) and $\# 2,3,13$ and 14 (silicon oil). Datz for each run were collected only after twenty (20) consecutive moldings after any changes in the settings, to allow equilibrium to be achieved. The injection shot size was adjusted to compensate for the volume differences when mold thickness effects were studied. At low injection speed, it was also adjusted not to exceed the maximum injection time. 
Table 5.4 Injection molding conditions for Dowlex 2049

\begin{tabular}{|c|c|c|c|c|c|c|}
\hline Experiment & Gate & $\begin{array}{c}\text { Injection } \\
\text { Speed }\end{array}$ & $\begin{array}{c}\text { Mold } \\
\text { Thickness }\end{array}$ & $\begin{array}{c}\text { Mold } \\
\text { Temperature }\end{array}$ & $\begin{array}{c}\text { Melt } \\
\text { Temperature }\end{array}$ & Conting \\
\hline$\# 1$ & Edge & $70 \%$ & $2.4 \mathrm{~mm}$ & $65^{\circ} \mathrm{C}$ & $220^{\circ} \mathrm{C}$ & No \\
\hline$\# 2$ & Edge & $70 \%$ & $2.4 \mathrm{~mm}$ & $35^{\circ} \mathrm{C}$ & $220^{\circ} \mathrm{C}$ & No \\
\hline$\# 3$ & Edge & $100 \%$ & $2.4 \mathrm{~mm}$ & $35^{\circ} \mathrm{C}$ & $220^{\circ} \mathrm{C}$ & No \\
\hline$\# 4$ & Edge & $70 \%$ & $1.6 \mathrm{~mm}$ & $35^{\circ} \mathrm{C}$ & $220^{\circ} \mathrm{C}$ & No \\
\hline$\# 5$ & Edge & $70 \%$ & $3.2 \mathrm{~mm}$ & $35^{\circ} \mathrm{C}$ & $220^{\circ} \mathrm{C}$ & No \\
\hline$\# 6$ & Edge & $70 \%$ & $2.4 \mathrm{~mm}$ & $15^{\circ} \mathrm{C}$ & $220^{\circ} \mathrm{C}$ & No \\
\hline$\# 7$ & Edge & $20 \%$ & $2.4 \mathrm{~mm}$ & $35^{\circ} \mathrm{C}$ & $220^{\circ} \mathrm{C}$ & No \\
\hline$\# 8$ & Edge & $70 \%$ & $2.4 \mathrm{~mm}$ & $35^{\circ} \mathrm{C}$ & $220^{\circ} \mathrm{C}$ & Teflon \\
\hline$\# 9$ & Edge & $70 \%$ & $2.4 \mathrm{~mm}$ & $35^{\circ} \mathrm{C}$ & $240^{\circ} \mathrm{C}$ & No \\
\hline$\# 10$ & Edge & $70 \%$ & $2.4 \mathrm{~mm}$ & $35^{\circ} \mathrm{C}$ & $200^{\circ} \mathrm{C}$ & No \\
\hline$\# 11$ & Pin & $100 \%$ & $2.4 \mathrm{~mm}$ & $35^{\circ} \mathrm{C}$ & $220^{\circ} \mathrm{C}$ & No \\
\hline$\# 12$ & Edge & $100 \%$ & $2.4 \mathrm{~mm}$ & $35^{\circ} \mathrm{C}$ & $220^{\circ} \mathrm{C}$ & Teflon \\
\hline$\# 13$ & Edge & $70 \%$ & $2.4 \mathrm{~mm}$ & $35^{\circ} \mathrm{C}$ & $220^{\circ} \mathrm{C}$ & Silicon \\
\hline$\# 14$ & Edge & $100 \%$ & $2.4 \mathrm{~mm}$ & $35^{\circ} \mathrm{C}$ & $220^{\circ} \mathrm{C}$ & Silicon \\
\hline
\end{tabular}

\subsubsection{Coating Application}

Two types of coating were used in this work: Teflon ${ }^{\mathrm{TM}}$ solutions (2) and silicone oil. The Tefon ${ }^{\mathrm{TM}}$ solutions were provided by the Dupont company. One is called SF-50 and is a copolymer of $50 \%$ Hexafluoropropylene (HFP) and 50\% Tetrafluorocthylene (TFE) in a perfluoro(2-butyltetrahydrofurane) solvent. The second is named SF-25 and is a copolymer of 25\% HFP and 75\% TFE in a perfluorophenanthrene solvent The silicone oil is a clear silicone liquid from Dow Coming (200 fluid), a dimethylpolysiloxane with a Newtonian kinematic viscosity of $50 \mathrm{cs}$ (1 stokes $\left.=10^{-4} \mathrm{~m}^{2} / \mathrm{s}\right)$.

The mold was initially cleaned with a commercial oven cleaner (Easy-Off), rinsed with acetone and water, and allowed to dry in air. Both Teflon ${ }^{\text {TM }}$ solutions were applied in a 
thin uniform coating by spray-gun and heated to $200^{\circ} \mathrm{C}$ and $270^{\circ} \mathrm{C}$ respectively to evaporate the solvent. The oil was applied by a paintbrush in a thin coating.

\subsection{Microscopy}

The surface appearance of the molded plates was monitored by visual observation, stereoscopic microscopy and scanning electron microscopy (SEM). For enlargements between 10X and 70X and a summary surface evaluation, Bausch \& Lomb Stereoscopic Microscope was used. For higher enlargement (up to 1000X), SEM was used (JEOL JSM-6100 Scanning Microscope). Polymeric samples were coated for SEM with an AuPd coating (Hummer V (Technics) Anodic Sputtering Coater). 


\section{Theoretical and Numerical Aspects}

\subsection{Description of Plasfill [38]}

Plasfill is a finite-element program that simulates the mold filling stage of the injection molding process. The program was developed at the Industrial Matcrials Institute (National Research Council Canada). Plasfill predicts and displays graphically the following results as functions of time:

1) position of the flow front

2) distribution of the pressure in the filled domain

3) temperature distribution throughout the filled domain and in the gapwise direction (2.5D formulation)

4) distribution of velocity

5) distribution of shear rate and shear stress (at the wall or average values).

The above results can be used to optimize mold design and processing conditions. The current capabilities of the Plasfill software include:

1) quick calculation of the flow front advancement

2) detailed analysis that couples the material properties with the flow front advancement

3) flow rate control injection with constant and variable flow rate

4) pressure control injection with constant and variable gate pressure

5) differential core-cavity temperature through a full-gap analysis.

The viscosity $\eta$ is modeled by a generalized Newtonian model (Carreau-WLF equation) and is assumed to depend only on shear rate and temperature. This viscosity model can be reduced to the Newtonian model or power-law model by appropriate choice of parameters. The density, $\rho$, heat capacity, $C_{p}$, and thermal conductivity, $k$, are assumed to be constant during the filling stage.

Users of Plasfill must provide as input data: 

1) matcrial propertics
2) mold configuration and location of the gate(s)
3) molding conditions.

Output results can be vicwed graphically using Plasview.

\subsubsection{General Assumptions for Simulation of Mold Filling Stage}

The analysis of the filling stage involves unsteady-state free surface flow, coupled with transient cooling. In the case of thin cavities, variations in the width direction can be neglected. It is also justifiable to assume that the polymer melt is incompressible and that body forces can be neglected [39].

In several publications, Gao, Nguyen $[40,41,42]$, and Girard and Salloum [40, 41] have stated the general assumptions for simulation of the mold filling stage in Plasfill for 3D thin parts:
1) $2 \mathrm{D}$ flow
2) matcrial is incompressible and purely viscous
3) inertia is negligible compared to viscous forces
4) heat conduction in the flow direction is neglected
5) thermal convection in gapwise direction is neglected.

The generalized Hele-Shaw equations provide a good approximation of this type of flow. Hele-Shaw equations are combined with the Navier-Stokes (momentum) equation, the continuity equation and the energy equation to obtain the flow of a polymer in a thin channel:

$$
\begin{array}{ll}
\mathrm{x} \text { - momentum } & \frac{\partial p}{\partial x}=\frac{\partial}{\partial z}\left(\eta \frac{\partial u}{\partial z}\right) \\
\mathrm{y} \text { - momentum } & \frac{\partial p}{\partial y}=\frac{\partial}{\partial z}\left(\eta \frac{\partial v}{\partial z}\right)
\end{array}
$$




$$
\begin{array}{ll}
\text { z-momentum } & \frac{\partial p}{\partial z}=0 \\
\text { continuity cquation } & \frac{\partial}{\partial x} \rho u+\frac{\partial}{\partial y} \rho v+\frac{\partial}{\partial z} \rho w=0
\end{array}
$$

where $\mathrm{x}$ and $\mathrm{y}$ are the coordinates in the horizontal plane, $z$ is the coordinate in the gapwise direction (fig. 6.1), $u, v$ and $w$ are respectively the $x, y$ and $z$ components of the velocity, $p$ is the pressure, and $\eta$ is the viscosity.

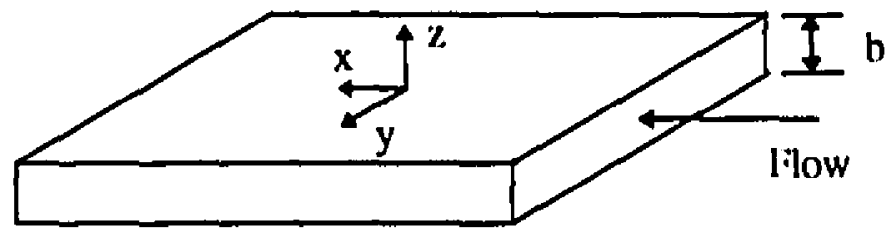

Fig. $6.1 \quad$ Coordinate axis for mold filling in Plasfill.

The energy equation is given by the following expression:

$$
\rho C_{p}\left(\frac{\partial T}{\partial t}+u \frac{\partial T}{\partial x}+v \frac{\partial T}{\partial y}\right)=\frac{\partial}{\partial z}\left(k \frac{\partial T}{\partial z}\right)+\Phi_{v}
$$

where $T$ is the temperature, $\rho$ is the density, $C_{p}$ is the heat capacity, $k$ is the thermal conductivity and $\Phi_{v}$ is the viscous dissipation rate per unit volume. The work associated with melt compression has been neglected.

We derive the pressure equation using a full gap analysis, where $b$ is the thickness of the mold. Integration of the momentum equations 6.1 and 6.2 twice, with the boundary conditions that the velocity vanishes on $z=0$ and $z=b$ (no-slip casc) yieids:

$$
u=-\frac{\partial p}{\partial x}\left(S_{1}(z)-\frac{S_{1}(0)}{S_{0}(0)} S_{0}(z)\right)
$$




$$
\begin{aligned}
& \qquad \begin{aligned}
& v=-\frac{\partial p}{\partial y}\left(S_{1}(z)-\frac{S_{1}(0)}{S_{0}(0)} S_{0}(z)\right) \\
& \text { where } \quad S_{1}(z)=\int_{z}^{b} \frac{\xi}{\eta} d \xi
\end{aligned} \\
& \text { and } \quad S_{0}(z)=\int_{z}^{b} \frac{1}{\eta} d \xi
\end{aligned}
$$

Integration of the continuity equation (6.4) over the thickness of the mold, using the assumption that $w=0$ on $z=0$ and $z=b$, gives:

$$
\begin{gathered}
\int_{0}^{b} \frac{\partial}{\partial x}(\rho u) d z+\int_{0}^{b} \frac{\partial}{\partial y}(\rho v) d z=0 \\
\frac{\partial}{\partial x} \int_{0}^{b} \rho u d z+\frac{\partial}{\partial y} \int_{0}^{b} \rho v d z=0
\end{gathered}
$$

Substitution of equations 6.6 and 6.7 into 6.11 gives:

$$
\frac{\partial}{\partial x}\left(s \frac{\partial p}{\partial x}\right)+\frac{\partial}{\partial y}\left(s \frac{\partial p}{\partial y}\right)=0
$$

where

$$
S=\int_{0}^{b} \rho S_{1}(z) d z+\frac{S_{1}(0)}{S_{0}(0)} \int_{0}^{b} \rho S_{0}(z) d z
$$

is the fluidity.

In injection mold filling, we use the assumption that the density $\rho$ is constant. The fluidity term $S$ becomes:

$$
\begin{aligned}
& S=S_{2}(0)-\frac{S_{1}(0)^{2}}{S_{0}(0)} \\
& \text { where } \\
& S_{2}(z)=\int_{z}^{b} \frac{\xi^{2}}{\eta} d \xi
\end{aligned}
$$

This form for $S$ is obtained through integration by parts of $S_{1}(z)$ and $S_{0}(z)$ : 


$$
\int_{0}^{b} m d n=\left.m n\right|_{0} ^{b}-\int_{0}^{b} n d m
$$

with $\quad m=\int_{z}^{b} \frac{\xi^{\prime}}{\eta} d \xi^{\prime} \quad$ and $d n=d \xi \quad$ for $S_{1}(z)$

$$
m n=\left(\int_{z}^{b} \frac{\xi^{\prime}}{\eta} d \xi^{\prime} \times \xi\right)_{0}^{b}=(0 \times b)-\int_{0}^{b} \frac{\xi^{\prime}}{\eta} d \xi^{\prime} \times 0=0
$$

$$
\int_{0}^{b} m d n=-\int_{0}^{b} n d m=-\int_{0}^{b}\left(\xi \times d\left(\int_{2}^{b} \frac{\xi^{\prime}}{\eta} d \xi^{\prime}\right)\right)
$$

$$
\int_{0}^{b} m d n=-\int_{0}^{b} n d m=-\int_{0}^{b}\left(\xi x-\frac{\xi}{\eta} d \xi\right)=\int_{0}^{b} \frac{\xi^{2}}{\eta} d \xi=S_{2}(0)
$$

For $\mathrm{S}_{0}(\mathrm{z})$, the integration by parts is done with:

$$
\begin{gathered}
m=\int_{z}^{b} \frac{1}{\eta} d \xi^{\prime} \text { and } d n=d \xi \\
m n=\left(\int_{z}^{b} \frac{1}{\eta} d \xi^{\prime} \times \xi\right)_{0}^{b}=(0 \times b)-\int_{0}^{b} \frac{1}{\eta} d \xi^{\prime} \times 0=0 \\
\int_{0}^{b} m d n=-\int_{0}^{b} n d m=-\int_{0}^{b}\left(\xi \times d\left(\int_{z}^{b} \frac{1}{\eta} d \xi^{\prime}\right)\right) \\
\int_{0}^{b} m d n=-\int_{0}^{b} n d m=-\int_{0}^{b}\left(\xi \times-\frac{1}{\eta} d \xi\right)=\int_{0}^{b} \frac{\xi}{\eta} d \xi=S_{1}(0)
\end{gathered}
$$

Equation 6.12 is used to solve for the pressure distribution in the mold. Boundary conditions for the pressure equation are:

1) at the flow front, $p=0$

2) at the gate, either $p$ or the flow rate $Q$ is specificd

3) on the mold walls, $\partial \mathrm{p} / \partial \mathrm{n}=0$ (pressure gradient in the normal direction).

Initial and boundary conditions for the energy equation are: 
1) at $\mathrm{t}=0, \mathrm{~T}=\mathrm{T}_{\text {melt }}$

2) at the gate, $T=T_{\text {melt }}$

3) at the flow front, $T$ is constant over the gap and equal to the entering melt temperature (to reproduce the fountain flow effect on temperature)

4) at $\mathrm{z}=0,\left.\quad k \frac{\partial T}{\partial z}\right|_{z=0}=h_{0}\left(T-T_{\infty}\right)=\left.q\right|_{z=0}$

5) at $x=b,\left.\quad k \frac{\partial T}{\partial z}\right|_{z=b}=h_{b}\left(T-T_{\infty}\right)=\left.q\right|_{z=b}$

where $h_{0}$ and $h_{b}$ are the heat transfer coefficients at walls $z=0$ and $z=b$ respectively, and $T_{\infty}$ is the cooling fluid temperature. Heat transfer coefficients $h_{0}$ and $h_{b}$ can vary due to different cooling arrangements in each part of the mold.

\subsubsection{Numerical Procedure}

The pressure equation is solved first, using the finite element method. The advantage of this method is that it can handle complex geometries and arbitrary boundary shapes by the use of local coordinates. Gao, Nguyen, and Girard and Salloum [40] used 3-node linear elements to approximate the pressure. The mesh that is used in the simulation is shown in appendix A. The Galerkin method is applied to discretize the pressure equation (6.12), which results in a linear algebraic system of the form:

$$
[K][p]=[R]
$$

where $[K]$ is the stiffness matrix and $[R]$ is a function vector evaluated from the boundary conditions. The pressure field is obtained by inverting the above equation:

$$
[\mathrm{p}]=[\mathrm{K}]^{-1}[\mathrm{R}]
$$

A control volume approach is used to track the flow front advancement [43]. This approach uses a fixed mesh system with the flow front passing through it. To locate the flow front as a function of time, a fill factor $F$ (between 0 and 1 ) is associated with each element (where $0=$ empty and $1=$ filled). For every time step, the calculation of the 
pressure distribution is achieved to obtain the velocity distribution in the filled domain. The flow rate information, based on the velocity ficld, allows evaluation of the fill factor $\mathrm{F}$ for each element by applying the principle of conservation of mass. An iterative procedure is performed to the end of the filling phase.

The velocity and temperature problems are solved as scparate systems, in order to minimize the size of the matrices [44]. The energy equation is solved using a hybrid method [42]. The equation is discretized using the linite difference method. The time derivative of temperature is approximated by backward finite difference:

$$
\frac{\partial T}{\partial t}=\frac{1}{\Delta t}\left(T_{t}-T_{t-\Delta t}\right)
$$

and the $\mathrm{z}$-derivative by central difference:

$$
\frac{\partial}{\partial z} k \frac{\partial T}{\partial z}=\frac{1}{\Delta z^{2}}\left([k T]_{z+\Delta z}-2[k T]_{z}+[k T]_{z-\Lambda z}\right)
$$

An inner iteration on temperature is worthwhile. The viscous heating term is updated using the viscosity corresponding to the latest temperature ficld and iterated to convergence before the velocity field is resolved. The viscous dissipation term and the convection term are evaluated using results from the previous time step. This method allows the calculation of the temperature as a function of time $t$ and position $z$ from node to node. 


\subsection{Incorporation of Slip Models}

$\Lambda$ the present time, the problem that arises from the dynamic three-phase boundary condition is avoided in Plasfill by using gapwise average velocities $\bar{u}$ and $\bar{v}$. These average velocities are obtained using the no-slip condition at $z=0$ and $z=b$. The resulting velocity profile is planar in the thickness direction and allowed to slip during the advancement of the flow front. The incorporation of a slip model would modify the pressure distribution and consequently, the values of gapwise average velocities $\bar{u}$ and $\bar{v}$.

During this work, formulations of steady state and transient slip models suitable for incorporation into Plasfill were developed. These models are based on the previous work of Hatzikiriakos and Dealy, which was presented in chapter 3, and adapted for use in injection molding. Due to uncertainties about the models, they were not incorporated into Plasfill.

\subsubsection{General Equations for Simulation of Mold Filling with Wall Slip}

Allowing for slip, the boundary conditions for $\mathrm{x}$ - momentum and $\mathrm{y}$ - momentum (equations 6.1 and 6.2 ) in the full-gap analysis are:

- $\quad$ at $\mathrm{z}=\mathrm{b}, \mathrm{u}=\mathrm{u}_{\mathrm{s}_{\mathrm{b}}}$

- at $\mathrm{z}=0, \mathrm{u}=\mathrm{u}_{\mathrm{s}_{0}}$

- at $z=b, v=v_{s b}$

- at $\mathrm{z}=0, \mathrm{v}=\mathrm{v}_{\mathrm{S} 0}$

where $b$ is the thickness of the mold cavity, $u_{S}$ is the slip velocity in the $x$ - direction, and $v_{S}$ is the $y$ - component of the slip velocity.

Integration of the $\mathrm{x}$ - momentum equation over the full mold thickness gives:

$$
\frac{\partial u}{\partial z}=\frac{\partial p}{\partial x} \frac{z}{\eta}+\frac{C}{\eta}
$$




$$
\begin{aligned}
& u_{s_{b}}-u=\frac{\partial p}{\partial x} \int_{i}^{b} \frac{\xi}{\eta} d \xi+C \int_{z}^{b} \frac{1}{\eta} d \xi \quad \text { with the rirst boundary condition } \\
& C=\frac{u_{s_{b}}-u_{s_{0}}}{\int_{0}^{b} \frac{1}{\eta} d \xi}-\frac{\partial p}{\partial x} \frac{\int_{0}^{b} \frac{\xi}{\eta} d \xi}{\int_{0}^{b} \frac{1}{\eta} d \xi} \quad \text { with the second boundary condition }
\end{aligned}
$$

We obtain, for the velocity:

$$
u=-\frac{\partial p}{\partial x}\left(S_{1}(z)-\frac{S_{1}(0)}{S_{0}(0)} S_{0}(z)\right)+u_{s_{b}}-\left(\frac{\left(u_{s_{b}}-u_{s_{0}}\right)}{S_{0}(0)} S_{0}(z)\right)
$$

where $S_{1}(z)$ and $S_{0}(z)$ are defined by equations 6.8 and 6.9 .

The y - momentum equation can be integraled the same way, giving:

$$
v=-\frac{\partial p}{\partial y}\left(S_{1}(z)-\frac{S_{1}(0)}{S_{0}(0)} S_{0}(z)\right)+v_{s_{0}}-\left(\frac{\left(v_{s_{0}}-v_{s_{0}}\right)}{S_{0}(0)} S_{0}(z)\right)
$$

By following the same development given in section 6.1 .1 , the continuity equation is obtained:

$$
\frac{\partial}{\partial x}\left(S \frac{\partial p}{\partial x}-b u_{s_{b}}+\frac{S_{1}(0)}{S_{0}(0)}\left(u_{s_{b}}-u_{s_{0}}\right)\right)+\frac{\partial}{\partial y}\left(S \frac{\partial p}{\partial y}-b v_{s_{b}}+\frac{S_{1}(0)}{S_{0}(0)}\left(v_{s_{p}}-v_{s_{0}}\right)\right)=0
$$

where $S$ is defined by equation 6.14 . 


\subsubsection{General Models for the Slip Velocity}

\subsubsection{Steady-State Slip Model}

The first model to be implemented was a steady-state slip model given by:

$$
U_{s}=f\left(\sigma_{w \mid z=0}\right) \text { and } U_{s}=f\left(\sigma_{w \mid z=b}\right)
$$

$x$ and $y$ components of the slip velocity are as follows:

$$
\begin{array}{rr}
u_{s}=U_{s} \times \frac{-\frac{\partial p}{\partial x}}{|\nabla p|} & v_{s}=U_{s} \times \frac{-\frac{\partial p}{\partial y}}{|\nabla p|} \\
\text { where } & |\nabla p|=\sqrt{\left(\frac{\partial p^{2}}{\partial x}+\frac{\partial p^{2}}{\partial y}\right)}
\end{array}
$$

The slip function $f\left(\sigma_{w}\right)$ proposed by Hatzikiriakos [45] for linear polyethylene is:

$$
f\left(\sigma_{w}\right)=\frac{2 \alpha K T}{N h} \exp \left(\frac{-\Delta G_{0}}{R T}\right) \sinh \left(\frac{E}{R T}\left(\frac{\sigma_{w}}{\sigma_{c}}-1\right)\right)
$$

where $T$ (in Kelvin) and $\sigma_{w}$ are the values obtained from the previous calculation step at cach wall (i.c. $z=0$ and $z=b$ ). The other terms are constants defined as follows:

$\alpha$ is a length scale $=2.07 \mathrm{~nm}$ (HDPE) or $1.9 \mathrm{~nm}$ (LLDPE)

$\mathrm{K}$ is the Boltzmann's constant $=1.380 \times 10^{-23} \mathrm{~J} /$ molec. $\mathrm{K}$

$\mathrm{h}$ is Planck's constant $=6.62 \times 10^{-34} \mathrm{~J} . \mathrm{s}$

$\mathrm{R}$ is the molar gas constant $=8.314 \mathrm{~J} / \mathrm{mol} . \mathrm{K}$

$\Delta \mathrm{G}_{\mathrm{o}}$ is the energy of activation $=37500 \mathrm{~J} / \mathrm{mol}$ (HDPE) or $45600 \mathrm{~J} / \mathrm{mol}$ (LLDPE)

$E$ is the work of adhesion $=7840 \mathrm{~J} / \mathrm{mol}$

$N$ is the number of bonded sites with the wall $=100$ (scales with $M_{w}$ )

$\sigma_{\mathrm{c}}$ is the critical shear stress for the onset of slip $=100 \mathrm{kPa}$.

The shear stresses at the walls are related to the deformation in the melt by the viscosity: 


$$
\sigma_{\omega}=\left.(\eta(\dot{\gamma}, T) \dot{\gamma})\right|_{w}
$$

where $\dot{\gamma}$ in the Hele-Shaw formulation is defined as:

$$
\dot{\gamma}_{w}=\left.\sqrt{\left(\frac{\partial u}{\partial z}\right)^{2}+\left(\frac{\partial v}{\partial z}\right)^{2}}\right|_{w}
$$

The viscosity $\eta_{w}$ is modeled by a generalized Newtonian model and depends on the shear rate and the temperature at the respective walls.

\subsubsection{Dynamic Slip Model}

The second model to be implemented would be a dynamic slip model, and two approaches were considered. The first approach is a scalar treatment of the slip velocity. The slip velocity is considered as a scalar to calculate its magnitude through the use of the material derivative and an equation derived from the original equation for transient slip (equation 3.10). The orientation of the slip velocity is assumed to be the same as the one for the flow stream, by relating the $x$ and $y$ components of the slip velocity to the pressure gradients, $\partial \mathrm{p} / \partial \mathrm{x}$ and $\partial \mathrm{p} / \partial \mathrm{y}$, calculated by the Hele-Shaw cquations.

The second approach is a vector treatment of the slip velocity. With this mothod, the magnitude and the orientation of the slip velocity are calculated simultancously through the material derivative and the use of the transient slip equation, by treating the slip as a vector component. In this approach, the orientation of the slip velocity can differ from the one for the flow stream and is not directly related to the pressure gradients.

The first approach, the scalar treatment of the slip velocity, is developed the following way:

At each wall $(\mathrm{z}=0$ and $\mathrm{z}=\mathrm{b})$ :

$$
U_{s}+\lambda_{s} \frac{D U_{s}}{D t}=f\left(\sigma_{w \mid z=0}\right) \quad \text { and } \quad U_{s}+\lambda_{s} \frac{D U_{s}}{D t}=f\left(\sigma_{w \mid z=b}\right)
$$




$$
\text { or } \quad \begin{array}{r}
U_{1}+\lambda_{1}\left(\frac{\partial U_{1}}{\partial t}+u_{1} \frac{\partial U_{1}}{\partial x}+v_{1} \frac{\partial U_{1}}{\partial y}\right)=f\left(\sigma_{w \mid z=0}\right) \\
U_{1}+\lambda_{1}\left(\frac{\partial U_{1}}{\partial t}+u_{1} \frac{\partial U_{1}}{\partial x}+v_{1} \frac{\partial U_{1}}{\partial y}\right)=f\left(\sigma_{m \mid z=b}\right)
\end{array}
$$

where $U_{3}$ is the magnitude of the slip velocity, $u_{4}$ and $v_{6}$ are respectively the $x$ and $y$ components of the slip velocity and $\lambda_{r}$ is a "slip relaxation time". The function $f\left(\sigma_{w}\right)$ is given by equation 6.38 like in the stcady-state model.

The matcrial derivative is applied to obtain $\mathrm{U}_{\mathrm{s}}$ at each wall, and the $\mathrm{x}$ and $\mathrm{y}$ components of the slip velocity are determined as follows:

$$
\begin{aligned}
& u_{s}=U_{s} \times \frac{-\frac{\partial p}{\partial x}}{|\nabla p|} \quad v_{s}=U_{s} \times \frac{-\frac{\partial p}{\partial y}}{|\nabla p|} \\
& \text { where } \quad|\nabla p|=\sqrt{\left(\frac{\partial p^{2}}{\partial x}+\frac{\partial p^{2}}{\partial y}\right)}
\end{aligned}
$$

Equations 6.42 and 6.36 are coupled and must be solved by an iterative procedure.

The second approach is the vector treatment of the slip velocity:

At the two walls $(z=0$ and $z=b)$ :

$$
\begin{aligned}
& \overline{u_{s}}+\lambda_{s} \frac{D \overline{u_{s}}}{D t}=f\left(\left.\underline{\sigma}\right|_{\mathrm{z}=0}\right) \text { and } \overline{u_{s}}+\lambda_{s} \frac{D u}{D t}=f\left(\left.\underline{\sigma}\right|_{z=b}\right) \\
& u_{s}+\lambda_{1}\left(\frac{\partial u_{s}}{\partial t}+u_{s} \frac{\partial u_{s}}{\partial x}+v_{s} \frac{\partial u_{s}}{\partial y}\right)=f\left(\sigma_{x=1<=0}\right) \\
& u_{s}+\lambda_{s}\left(\frac{\partial u_{s}}{\partial t}+u_{s} \frac{\partial u_{s}}{\partial x}+v_{s} \frac{\partial u_{s}}{\partial y}\right)=f\left(\sigma_{x i \mid z=b}\right) \\
& v_{s}+\lambda_{s}\left(\frac{\partial v_{s}}{\partial t}+u_{s} \frac{\partial v_{s}}{\partial x}+v_{s} \frac{\partial v_{s}}{\partial y}\right)=f\left(\sigma_{x=1 z=0}\right) \\
& v_{s}+\lambda_{s}\left(\frac{\partial v_{s}}{\partial t}+u_{s} \frac{\partial v_{s}}{\partial x}+v_{s} \frac{\partial v_{s}}{\partial y}\right)=f\left(\sigma_{x \mid z=b}\right)
\end{aligned}
$$


where $u_{s}$ and $v_{s}$ are respectively the $x$ and $y$ components of the slip velocity, and $\lambda_{s}$ is the slip relaxation time.

In this case, the $\mathrm{x}$ and $\mathrm{y}$ components of the slip velocity are given by the above equations and are not direclly related to the pressure gradients, $\partial p / \partial x$ and $\partial p / \partial y$. lirom the continuum properties of the melt, we had:

$$
\begin{gathered}
\sigma_{x z \mid \text { wall }}=\left.\left(\eta \gamma_{x z}^{\prime}\right)\right|_{\text {wall }}=\left.\left(\eta \frac{\partial u}{\partial z}\right)\right|_{\text {wall }} \\
\sigma_{y z \mid \text { wall }}=\left.\left(\eta \gamma_{y z}\right)\right|_{\text {wall }}=\left.\left(\eta \frac{\partial v}{\partial z}\right)\right|_{\text {wall }}
\end{gathered}
$$

For this approach, a critical shear stress for the onset of slip cepends on the state of stress, through a criterion similar to the von Mises or Tresca criteria for yicld stress. $\Lambda \mathrm{l}$ this time, it is believed that the second approach would give more realistic results but would be more tedious to incorporate into a 2D-now formulation.

Even if a transient slip model is used, it could not be coupled to a viscoclastic constitutive equation since Plasfill does not allow for this. It has been shown that in injection molding simulations the predicted stress profiles are significantly influenced by the constitutive equation used and by relaxation effects [15]. However, these effects are taken into account only whe" it is desired to predict the orientation of molecules and/or residual stresses. It is be. $\mathrm{d}$ that this would also improve the simulation of stip. Injection molding is not a steady-state operation, and viscoclasticity and transient slip should be of importance. Good reproduction of experimental results may not be possible until viscoelasticity and transient slip models are included. Unfortunately, to add viscoelastic effects to the formulation would increase considerably the computational time and cost [46], and an approximate solution with purely viscous fluid properties is often sufficient for industrial needs, where the filling of the mold is the primary concern. 


\subsubsection{Numerical Implementation}

The continuity equation with the occurrence of slip is given by equation 6.34 :

$$
\frac{\partial}{\partial x}\left(S \frac{\partial p}{\partial x}-b u_{s_{b}}+\frac{S_{1}(0)}{S_{0}(0)}\left(u_{s_{b}}-u_{s_{0}}\right)\right)+\frac{\partial}{\partial y}\left(S \frac{\partial p}{\partial y}-b v_{s_{b}}+\frac{S_{1}(0)}{S_{0}(0)}\left(v_{s_{b}}-v_{s_{0}}\right)\right)=0
$$

The pressure is expanded as follows:

$$
p(x, y,)=\sum_{i=1}^{n} p_{i} \Phi_{i}(x, y)
$$

where $p_{i}$ is the nodal pressure to be determined, and $\Phi_{i}$ is the trial function associated with node $i$. For a triangular linear element, the trial function is given by:

$$
\Phi_{i}(x, y)=\frac{a_{i}+b_{i} x+c_{i} y}{2 \Delta}
$$

where $\Delta$ is the area of the triangle, and

$$
\begin{aligned}
& a_{i}=x_{j} y_{k}-x_{k} y_{j} \\
& b_{i}=y_{j}-y_{k} \\
& c_{i}=x_{j}-x_{k}
\end{aligned}
$$

Galerkin's method is applied by multiplying the pressure equation by $\Phi_{\mathrm{i}}$ and integrating over the domain $\Omega$ :

$$
\iint_{\Omega}\left(\frac{\partial}{\partial x}\left(S \frac{\partial p}{\partial x}-b u_{s_{0}}+\frac{S_{1}(0)}{S_{0}(0)}\left(u_{s_{s}}-u_{s_{0}}\right)\right)+\frac{\partial}{\partial y}\left(S \frac{\partial p}{\partial y}-b v_{s_{s}}+\frac{S_{1}(0)}{S_{0}(0)}\left(v_{s_{s}}-v_{s_{0}}\right)\right)\right) \Phi_{i} d \Omega=0
$$

When integration by parts and divergence theorem is applied, we get: 


$$
\begin{aligned}
& \oint_{\delta \infty}\left\{\left(S \frac{\partial p}{\partial x}-b u_{x_{v}}+\frac{S_{1}(0)}{S_{0}(0)}\left(u_{s_{b}}-u_{s_{0}}\right)\right) n_{x}+\left(S \frac{\partial p}{\partial y}-b w_{s_{p}}+\frac{S_{1}(0)}{S_{0}(0)}\left(v_{s_{b}}-v_{w_{0}}\right)\right) n_{y}\right\} \boldsymbol{\Phi}_{i} d l \\
& +\iint_{\Omega}\left\{\left(b u_{s_{b}}-\frac{S_{1}(0)}{S_{0}(0)}\left(u_{s_{b}}-u_{s_{3}}\right)\right) \frac{\partial \Phi_{i}}{\partial x}+\left(b v_{s_{b}}-\frac{S_{1}(0)}{S_{0}(0)}\left(v_{s_{b}}-v_{s_{10}}\right)\right) \frac{\partial \Phi_{i}}{\partial y}\right\} d \Omega \\
& -\iint_{\Omega}\left(S \frac{\partial p}{\partial x} \frac{\partial \Phi_{i}}{\partial x}+S \frac{\partial p}{\partial y} \frac{\partial \Phi_{1}}{\partial y}\right) d \Omega=0
\end{aligned}
$$

The first integral represents the contribution from the boundary. When the pressure is given, i.c. a Dirichlet condition, this term is not evaluated sinee $\Phi_{i}$ is zero where pressure is imposed and:

$$
\left(s \frac{\partial p}{\partial x}-b u_{s_{b}}+\frac{S_{1}(0)}{S_{0}(0)}\left(u_{s_{b}}-u_{s_{0}}\right)\right) n_{x}+\left(S \frac{\partial p}{\partial y}-b v_{s_{b}}+\frac{S_{1}(0)}{S_{0}(0)}\left(v_{s_{b}}-v_{s_{0}}\right)\right) n_{y}=0
$$

along the solid boundary due to the non-penetrating condition. The third integral in equation 6.49 gives rise to the stiffness matrix.

With the finite element discretization of the domain $\Omega$, equation 6.49 can be rewritten as a summation over elements as follows:

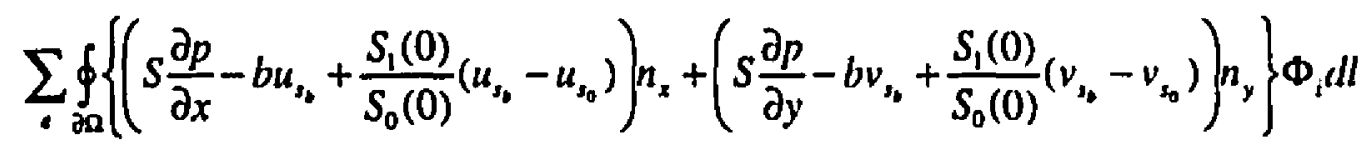

$$
\begin{aligned}
& +\sum_{\varepsilon} \iint_{\Omega}\left\{\left(b u_{s_{b}}-\frac{S_{1}(0)}{S_{0}(0)}\left(u_{s_{b}}-u_{s_{0}}\right)\right) \frac{\partial \Phi_{i}}{\partial \mathrm{x}}+\left(b v_{s_{b}}-\frac{S_{1}(0)}{S_{0}(0)}\left(v_{s_{b}}-v_{s_{0}}\right)\right) \frac{\partial \Phi_{i}}{\partial y}\right\} d \Omega \\
& -\sum_{a} \iint_{\mathfrak{a}}\left(S \frac{\partial p}{\partial x} \frac{\partial \Phi_{i}}{\partial x}+S \frac{\partial p}{\partial y} \frac{\partial \Phi_{i}}{\partial y}\right) d \Omega=0
\end{aligned}
$$

The clement stiffness matrix is given by: 


$$
K_{i j}=\iint_{\Omega_{i}} S\left(\frac{\partial \Phi_{i}}{\partial x} \frac{\partial \Phi_{j}}{\partial x}+\frac{\partial \Phi_{i}}{\partial y} \frac{\partial \Phi_{j}}{\partial y}\right) d \Omega
$$

and $\quad K_{i j}^{e}=\frac{b_{i} b_{j}+c_{i} c_{j}}{4 \Delta^{2}} \iint_{\Omega_{i}} S d \Omega \quad$ for a triangular linear element.

Values of the nodal pressures $p_{i}$ are obtained by solving the following equation:

$$
\sum_{e} K_{i j}^{e} p_{j}^{e}=\sum_{e} F_{i}^{e}
$$

where

$$
\begin{aligned}
& F_{i}^{e}=\oint_{\partial \Omega_{0}}\left\{\left(S \frac{\partial p}{\partial x}-b u_{s_{0}}+\frac{S_{1}(0)}{S_{0}(0)}\left(u_{s_{b}}-u_{s_{0}}\right)\right) n_{x}+\left(S \frac{\partial p}{\partial y}-b v_{s_{b}}+\frac{S_{1}(0)}{S_{0}(0)}\left(v_{s_{0}}-v_{s_{0}}\right)\right) n_{y}\right\} \Phi_{i} d l \\
& +\iint_{\Omega_{0}}\left\{\left(b u_{s_{0}}-\frac{S_{1}(0)}{S_{0}(0)}\left(u_{s_{0}}-u_{s_{0}}\right)\right) \frac{\partial \Phi_{i}}{\partial \mathrm{x}}+\left(b v_{s_{b}}-\frac{S_{1}(0)}{S_{0}(0)}\left(v_{s_{b}}-v_{s_{0}}\right)\right) \frac{\partial \Phi_{i}}{\partial y}\right\} d \Omega
\end{aligned}
$$

Equation 6.54 can be restated as the following global matrix equation:

$$
[K]\{p\}=\{F\}
$$

Evaluation of the nodal pressures $p_{i}$ at an $m+1$ iteration is carried out as follows:

$$
\begin{aligned}
& p^{m+1}=p^{m}+\Delta p^{m+1} \\
& {[K]^{m}\left\{p^{m}+\Delta p^{m+1}\right\}=\{F\}^{m}} \\
& {[K]^{m}\left\{\Delta p^{m+1}\right\}=\{F\}^{m}-[K]^{m}\left\{p^{m}\right\}} \\
& {[K]^{m}\left\{\Delta p^{m+1}\right\}=\{R\}^{m}}
\end{aligned}
$$

where $\{R\}$ is the weighted residual that must go towards zero, and is expressed as: 


$$
\begin{aligned}
\{R\} & =\oint_{\partial \Omega}\left\{\left(S \frac{\partial p}{\partial x}-b u_{s_{b}}+\frac{S_{1}(0)}{S_{0}(0)}\left(u_{s_{b}}-u_{s_{0}}\right)\right) n_{x}+\left(S \frac{\partial p}{\partial y}-b v_{s_{p}}+\frac{S_{1}(0)}{S_{0}(0)}\left(v_{s_{b}}-v_{s_{b}}\right)\right) n_{y}\right\} \Phi_{i} d l \\
& +\iint_{\Omega}\left\{\left(b u_{s_{b}}-\frac{S_{1}(0)}{S_{0}(0)}\left(u_{s_{b}}-u_{s_{0}}\right)\right) \frac{\partial \Phi_{i}}{\partial x}+\left(b v_{s_{b}}-\frac{S_{1}(0)}{S_{0}(0)}\left(v_{s_{t}}-v_{s_{b}}\right)\right) \frac{\partial \Phi_{i}}{\partial y^{\prime}}\right\} d \Omega \\
& -\iint_{\Omega}\left(S \frac{\partial p}{\partial x} \frac{\partial \Phi_{i}}{\partial x}+S \frac{\partial p}{\partial y} \frac{\partial \Phi_{i}}{\partial y}\right) d \Omega
\end{aligned}
$$

For a triangular linear element, $\{R\}$ becomes:

$$
\begin{aligned}
& \{R\}=\oint_{\partial n}\left\{\begin{array}{l}
\left(s \sum_{j=1}^{n} \frac{p_{j} b_{j}}{2 \Delta}-b u_{s_{b}}+\frac{S_{1}(0)}{S_{0}(0)}\left(u_{s_{b}}-u_{s_{0}}\right)\right) n_{x} \\
+\left(S \sum_{j=1}^{n} \frac{p_{j} c_{j}}{2 \Delta}-b v_{s_{b}}+\frac{S_{1}(0)}{S_{0}(0)}\left(v_{s_{b}}-v_{s_{0}}\right)\right) n_{y}
\end{array}\right\} \frac{a_{1}+b_{j} x+c_{j} y}{2 \Delta} d l \\
& +\iint_{\Omega}\left\{\left(b u_{s_{b}}-\frac{S_{1}(0)}{S_{0}(0)}\left(u_{s_{b}}-u_{s_{0}}\right)\right) \frac{b_{i}}{2 \Delta}+\left(b v_{s_{b}}+\frac{S_{1}(0)}{S_{0}(0)}\left(v_{s_{b}}-v_{s_{0}}\right)\right) \frac{c_{i}}{2 \Delta}\right\} d \Omega \\
& -\frac{b_{i} \sum_{j=1}^{n} p_{j} b_{j}+c_{i} \sum_{j=1}^{n} p_{j} c_{j}}{4 \Delta^{2}} \iint_{\Omega} S d \Omega
\end{aligned}
$$

\subsection{Validation of Computer Model Predictions}

Although slip was not incorporated into the Hele-Shaw Plasfill formulation at this time, the predictions of the computer simulations are compared to experimental results in chapter 10. In any event, it may not be appropriate to describe flow marks and other types of defect in terms of slip. Results predicted by the simulations are compared with experimental data (flow front location, pressure distributions) to establish the critical conditions for the occurrence of flow marks during injection molding. 


\section{Resin Properties}

\subsection{Viscosity and Slip Behavior}

The quantities measured in a piston-driven capillary rheometer are the piston force and piston speed. The driving pressure is related to the piston force, $F_{d}$, as follows:

$$
P_{d}=\frac{F_{d}}{\pi R_{b}^{2}}
$$

where $R_{b}$ is the radius of the barrel [27].

The wall shear stress is related to the driving pressure $P_{d}$ through equation 7.2:

$$
\sigma_{w}=\frac{\left(P_{d}-P_{e}\right)}{2(L / R)}
$$

where $\mathrm{P}_{\mathrm{c}}$ is the correction for end effects. This correction can be obtained in two ways: Bagley plots [47] or the usc of an orifice. In this work, both methods were applied and compared, giving similar results. The apparent wall shear rate is defined as:

$$
\dot{\gamma}_{A} \equiv \frac{4 Q}{\pi R^{3}}
$$

where $\mathrm{R}$ is the capillary radius, and $\mathrm{Q}$ is the flow rate calculated from the piston speed and cross-sectional area of the barrel. The true wall shear rate is obtained by multiplying the apparent wall shear rate by the Rabinowitch correction:

$$
\dot{\gamma}_{w}=\left(\frac{3+b}{4}\right) \dot{\gamma}_{A}
$$

where $b$ is defined as:

$$
b \equiv \frac{d(\log \dot{\gamma})}{d\left(\log \sigma_{w}\right)}
$$


For a power-law fluid, $\mathrm{b}$ is equal to $\mathrm{l} / \mathrm{n}$. An alternative procedure to obtain the true shear rate is to use the Schummer technique, which gives a good approximation of the true viscosity curve [27]. Schummer et al. proposed a horizontal shift corresponding to:

$$
\dot{\gamma}^{*}=x^{*} \dot{\gamma}_{1}
$$

where $\mathrm{x}^{*}$ is the shift factor and is set equal to 0.83 , giving a viscosity that differs from the true value of the shifted shear rate by no more than $3 \%$.

The Rabinowitch correction can not be applied before a correction for slip is made when slip occurs. As mentioned in a previous chapter (chap. 3), wall slip can be determined when a gap dependence is observed in the flow curve. In this work, two diameters were used in order to detect this gap dependence $(D=0.030$ " $(0.762 \mathrm{~mm})$ and $D=0.054$ " $(1.372 \mathrm{~mm})$ ). However, at all temperatures, no gap dependence was observed in any of the curves. Figure 7.1 shows the flow curves for an L/D of 20.

The absence of a gap dependence is in contradiction with previous work [48, 49]. However, the gap dependence observed by Sentmanat [48] was for a smaller diameter $\left(\mathrm{D}=0.010^{\prime \prime}(0.254 \mathrm{~mm})\right.$ vs. $\left.\mathrm{D}=0.054^{\prime \prime}\right)$ and slip velocity calculations from these data did not result in a single curve, as it should when slip velocity is only a function of shear stress. As well, Hatzikiriakos [49] shows an obvious gap dependence only for the smallest diameter $\left(D=0.020^{\prime \prime}(0.508 \mathrm{~mm})\right.$ vs. $D=0.030^{\prime \prime}$ and $\left.D=0.050^{\prime \prime}\right)$, and again the calculated slip velocities do not collapse onto a single curve, particularly at low shear stresses. The smallest diameter of $\mathrm{D}=0.010$ " was not used in the present work because of the exceedingly long time necessary to reach steady-state flow conditions and the risk of thermal degradation.

The gap dependence for a similar resin, FC1010, (M.I. $=1.0 \mathrm{~g} / 10 \mathrm{~min} ., \mathrm{M}_{\mathrm{W}}=1.43 \times 10^{5}$, $M_{W} / M_{n}=3.9$ ) was also not detected by El Kissi and Piau [11]. These authors tested the slip hypothesis by studying the flow of an LLDPE through capillarics of various geometries. The results obtained showed that experimental methods for determining slip velocity did not give conclusive evidence of the existence of slip at the wall for the flow of 
the LI.DPP: used, under conditions that would normally give rise to sharkskin (shear stresses higher than 0.17MPa for $\mathrm{FC} 1010$ ).

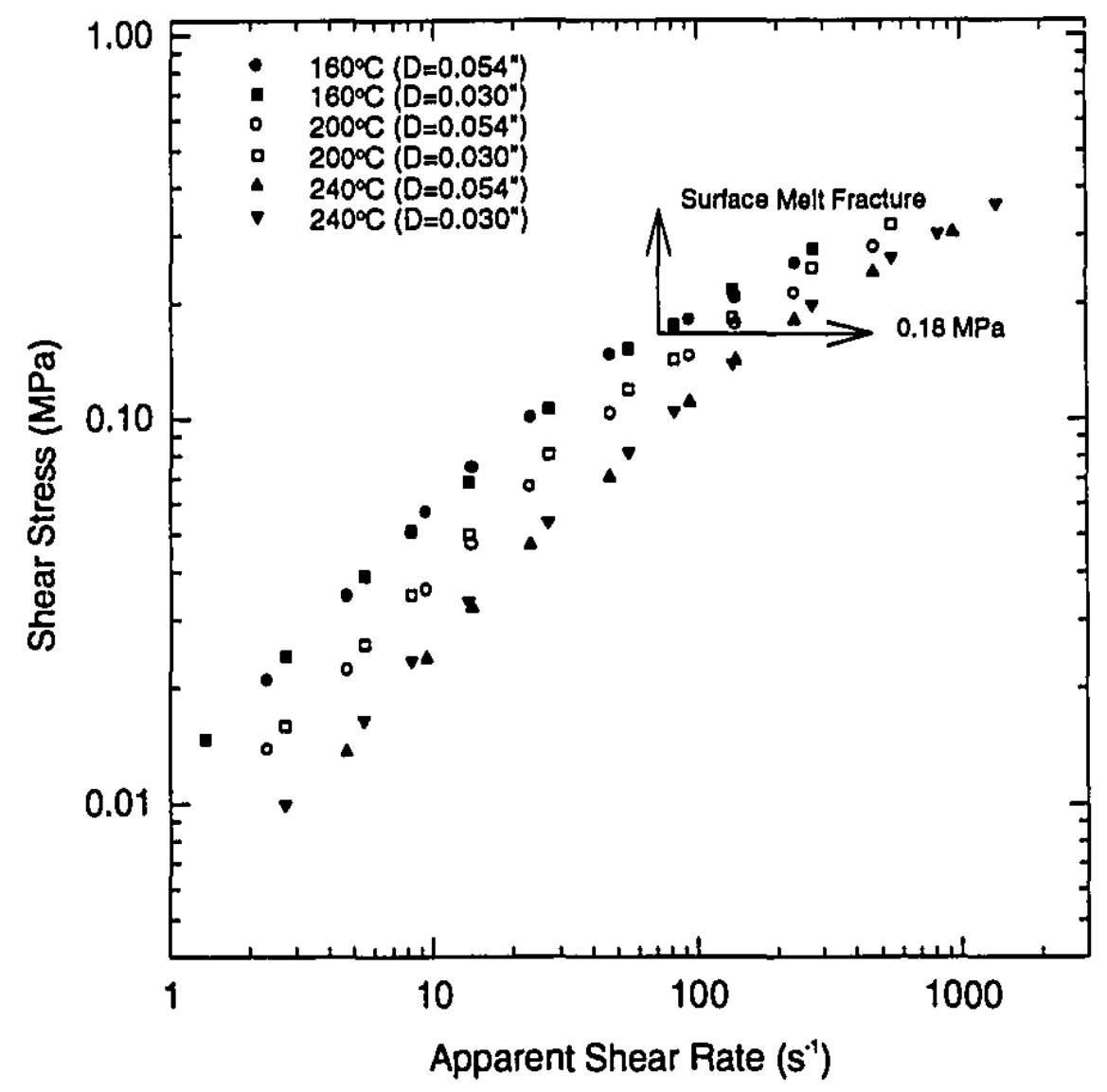

Fig. 7.1 Flow curves of Dowlex 2049 at three temperatures $(\mathrm{L} / \mathrm{D}=20)$

The present author draws a similar conclusion regarding the study of LLDPE Dowlex 2049, where surface melt fracture (or sharkskin) was observed to occur around $0.18 \mathrm{MPa}$. The critical shear stress for the onset of slip was determined to be $0.1 \mathrm{MPa}$ by Hatzikiriakos et al. Incidentally, the value of $0.18 \mathrm{MPa}$ for the occurrence of sharkskin is lower than the one obtained by Hatzikiriakos [49], who observed that at values of wall 
shear stress of about $0.18 \mathrm{MP}^{2}$ the extrudate surface appeared to be matte, while sharkskin occurred above $0.25 \mathrm{MPa}$.

Since no evidence of slip was found, the Rabinowitch correction was applied with no further correction to the flow curve. Instead of using the Schummer approximation, the local value of $\mathrm{b}$ was computed at each temperature for each set of data points and a graph of $1 / \mathrm{b}$ vs. wall shear stress was plotted. Experimental points for $\sigma$ show some scatter, and this scatter is amplified when the local derivative is taken. $\Lambda$ second order polynomial was fitted to the data, and this value of $b$ was used in the calculation. The polynomial used is as follows:

$$
\frac{1}{b}=0.8087-2.561 \sigma_{w}+3.539 \sigma_{w}^{2}
$$

with $\sigma_{\mathrm{W}}$ in $\mathrm{MPa}$. The plot is shown in figure 7.2. If we compare this curve with the Schummer approximation $(1 / \mathrm{b}=0.83)$, we see that his approach is mostly valid at low shear stresses.

Once the true wall shear rate is obtained, the viscosity can be calculated:

$$
\eta=\frac{\sigma_{w}}{\dot{\gamma}_{w}}
$$

The viscosity of Dowlex 2049 is presented in figures 7.3 and 7.4. 


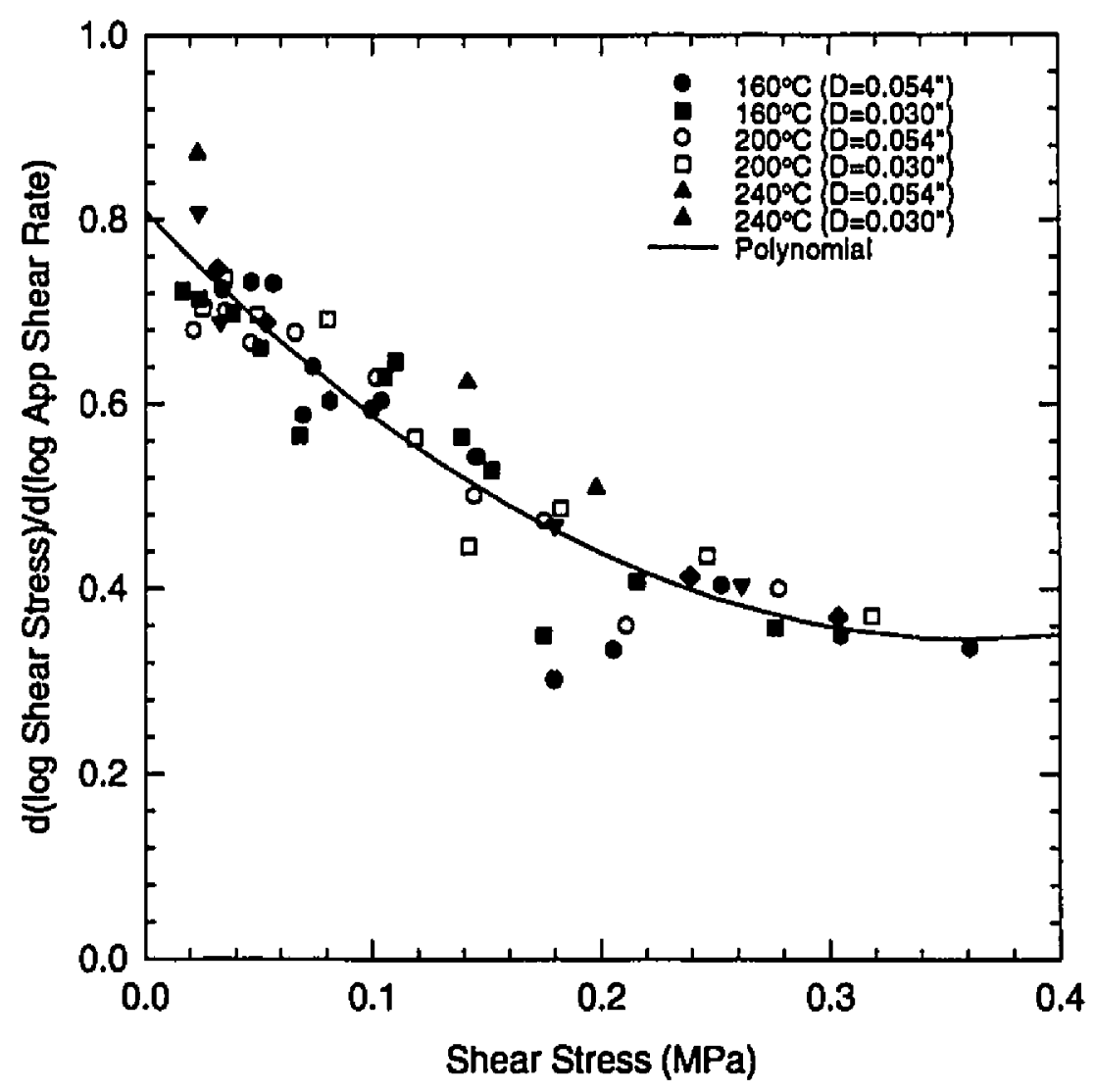

Fig. $7.21 / \mathrm{b}$ vs. Wall Shcar Stress for Dowlex $2049(\mathrm{~L} / \mathrm{D}=20)$

In order to verify the precision of the viscosity measurements, the principle of timesuperposition can be used. For a given polymer, the viscosity curves obtained at several temperatures can be superposed by shifting along the axes on a log-log plot. This implies the existence of a "shift factor":

$$
\frac{\eta(\gamma)}{a_{T}} \text { vs. } \dot{\gamma} a_{T}
$$

This factor can be determined by measuring the effect of temperature on the zero shear rate viscosity as foliows: 


$$
a_{T}=\frac{\eta_{o}(T)}{\eta_{o}\left(T_{o}\right)}
$$

where $T_{0}$ is the reference temperature and $\eta_{0}(T)$ is the zero shear rate (or Newtonian) viscosity at the temperature $T$. An empirical relation for $\eta_{0}(T)$ is the Arrhenius equation, from which the shift factor can be calculated:

$$
\frac{\eta_{o}(T)}{\eta_{0}\left(T_{0}\right)}=\exp \left[\frac{E_{a}}{R T}\left(\frac{1}{T}-\frac{1}{T_{a}}\right)\right]
$$

where $E_{a}$ is an "activation energy for flow" [27]. For a reference temperature of 473K, an activation energy of $26.1 \mathrm{~kJ} / \mathrm{mol}$ was found to fit the data. The resulting curve is presented in figure 7.3.

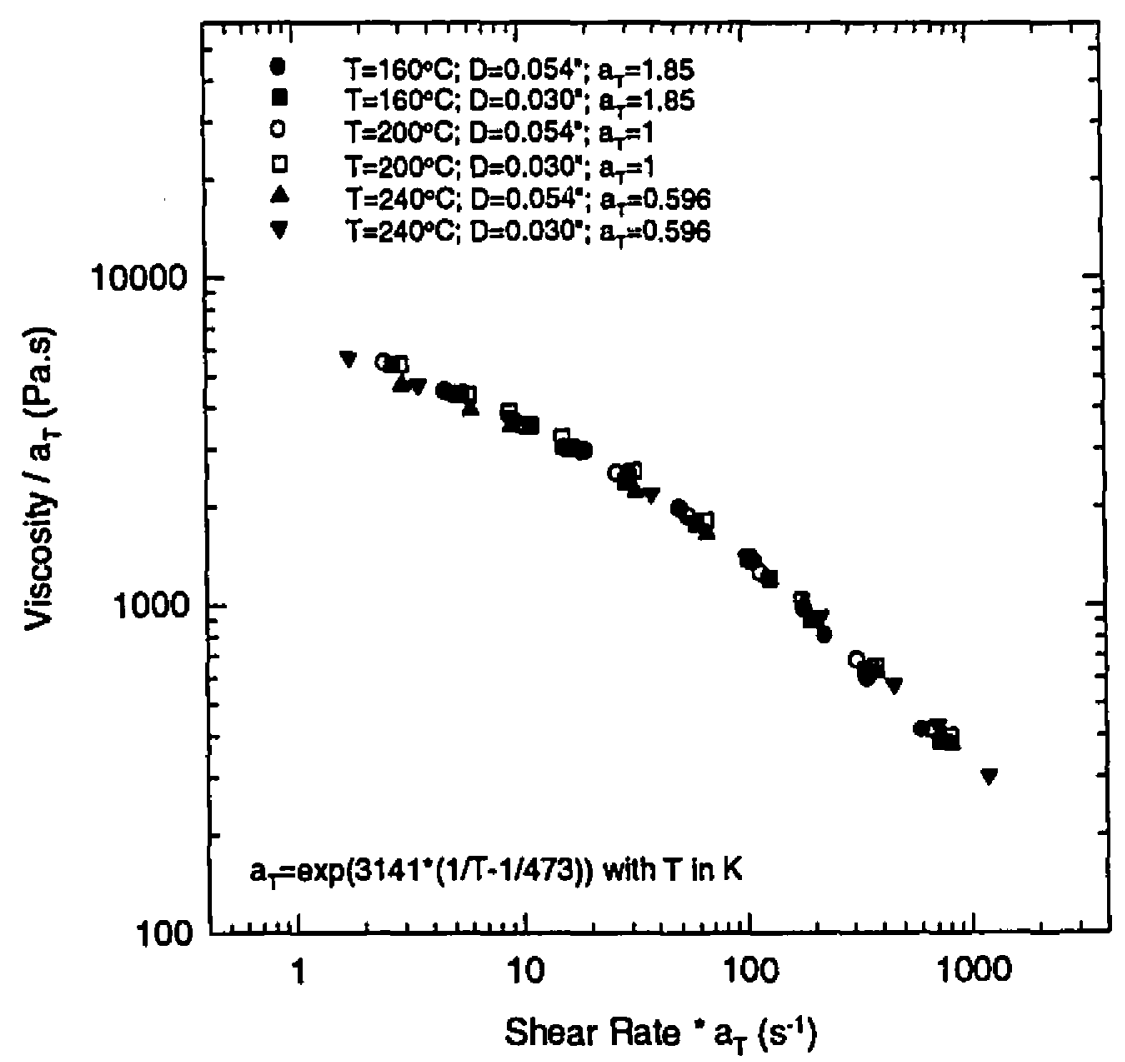

Fig. 7.3 Principle of time-superposition applied to Dowlex 2049 (L/D=20) 


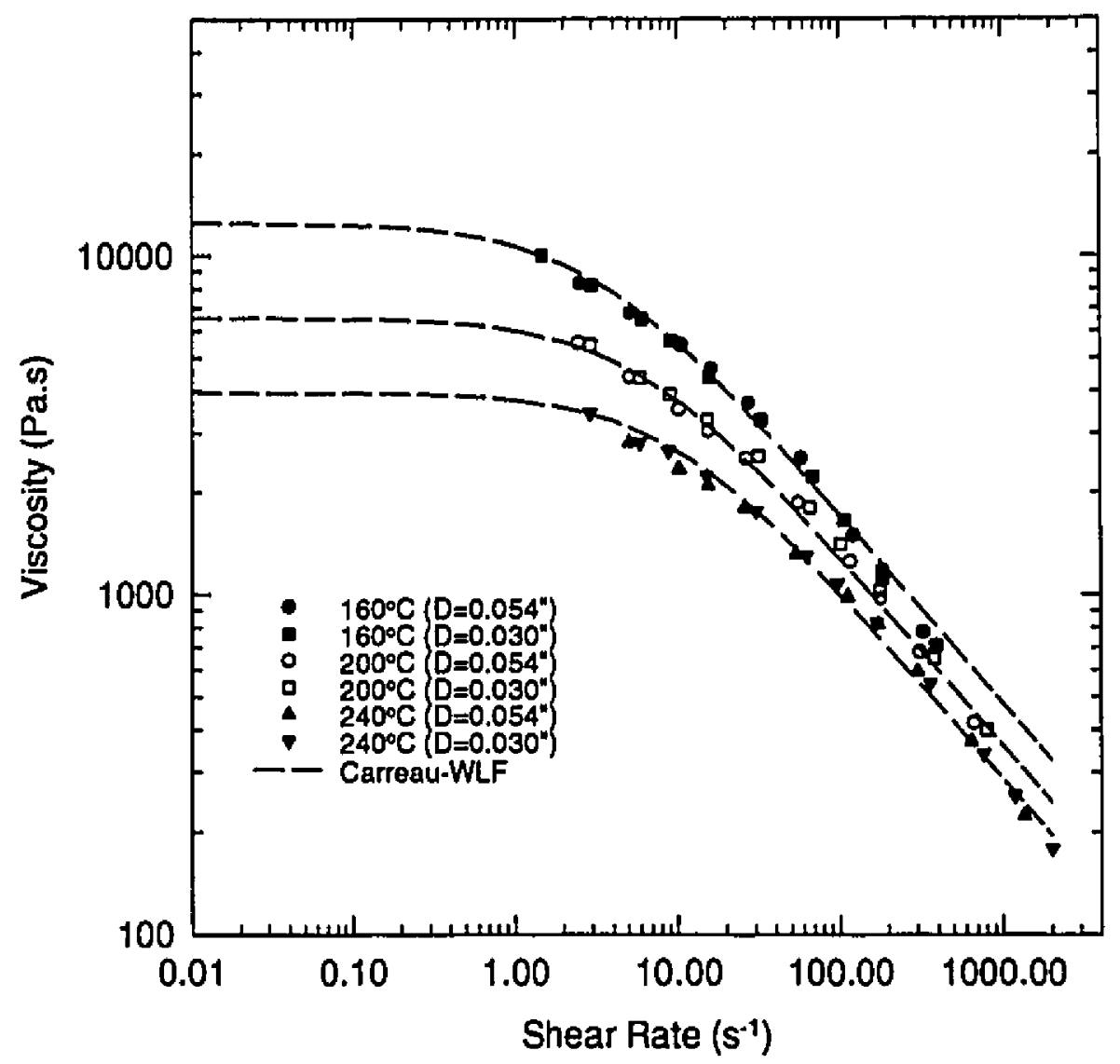

Fig. 7.4 Viscosity curves of Dowlex 2049 for three temperatures (L/D=20, 2 die diameters).

For simulation in Plasfill, the Carreau-WLF parameters must be specified to the program. The expression is given by:

$$
\begin{aligned}
& \eta=\frac{\eta_{o} A_{t}}{\left(1+P_{2} A_{t} \dot{\gamma}\right)^{P_{s}}} \\
& \log \left(A_{t}\right)=\frac{8.86\left(T_{\text {ref }}-T_{s}\right)}{\left(101.6+T_{\text {ref }}-T_{s}\right)}-\frac{8.86\left(T-T_{s}\right)}{\left(101.6+T-T_{s}\right)}
\end{aligned}
$$

where $P_{2}$ is the relaxation time, $P_{3}$ is related to the power law index $n$ as follows: 


$$
P_{3}=1-n
$$

$\mathrm{T}_{\mathrm{ref}}$ is the reference temperature, $\mathrm{T}_{\mathrm{a}}$ is the standard temperature and $\dot{\gamma}$ the true shear ralte. Table 7.1 gives the values of the fitted parameters of Carreau-Wlff model for Dowlex 2049, and the curve is shown in figure 7.4:

Table 7.1 Fitted Carreau-WLF parameters for Dowlex 2049

\begin{tabular}{|c|c|}
\hline$\eta_{0}$ & $6555 \mathrm{~Pa} . \mathrm{s}$ \\
\hline $\mathbf{P}_{2}$ & $0.1764 \mathrm{~s}$ \\
\hline $\mathbf{P}_{3}$ & 0.56 \\
\hline $\mathbf{T}_{\text {ref }}$ & $2000^{\circ} \mathrm{C}$ \\
\hline $\mathbf{T}_{\mathbf{s}}$ & $-83^{\circ} \mathrm{C}$ \\
\hline
\end{tabular}

The shift factor in this model is given by the WLF equation. In table 7.2, we compare the fitted shift factors obtained by the Arthenius and the WLI" equations, and note that they are similar:

Table 7.2 Shift factors calculated for Dowlex 2049

\begin{tabular}{|c|c|c|}
\hline Temperature & Arrhenius & WLF \\
\hline $160^{\circ} \mathrm{C}$ & 1.850 & 1.869 \\
\hline $200^{\circ} \mathrm{C}$ & 1.0 & 1.0 \\
\hline $240^{\circ} \mathrm{C}$ & 0.596 & 0.602 \\
\hline
\end{tabular}




\subsection{Thermal Properties}

\subsubsection{Heat Capacity}

Results of heal capacity $\left(C_{p}\right)$ measurements in the melt phase are shown in figure 7.5. Data sets 1,2,3 and 4 are results of individual experiments for two temperature ranges $(260)-120)^{10} \mathrm{C}$ and $\left.17(0)-105 \mathrm{C}\right)$ :

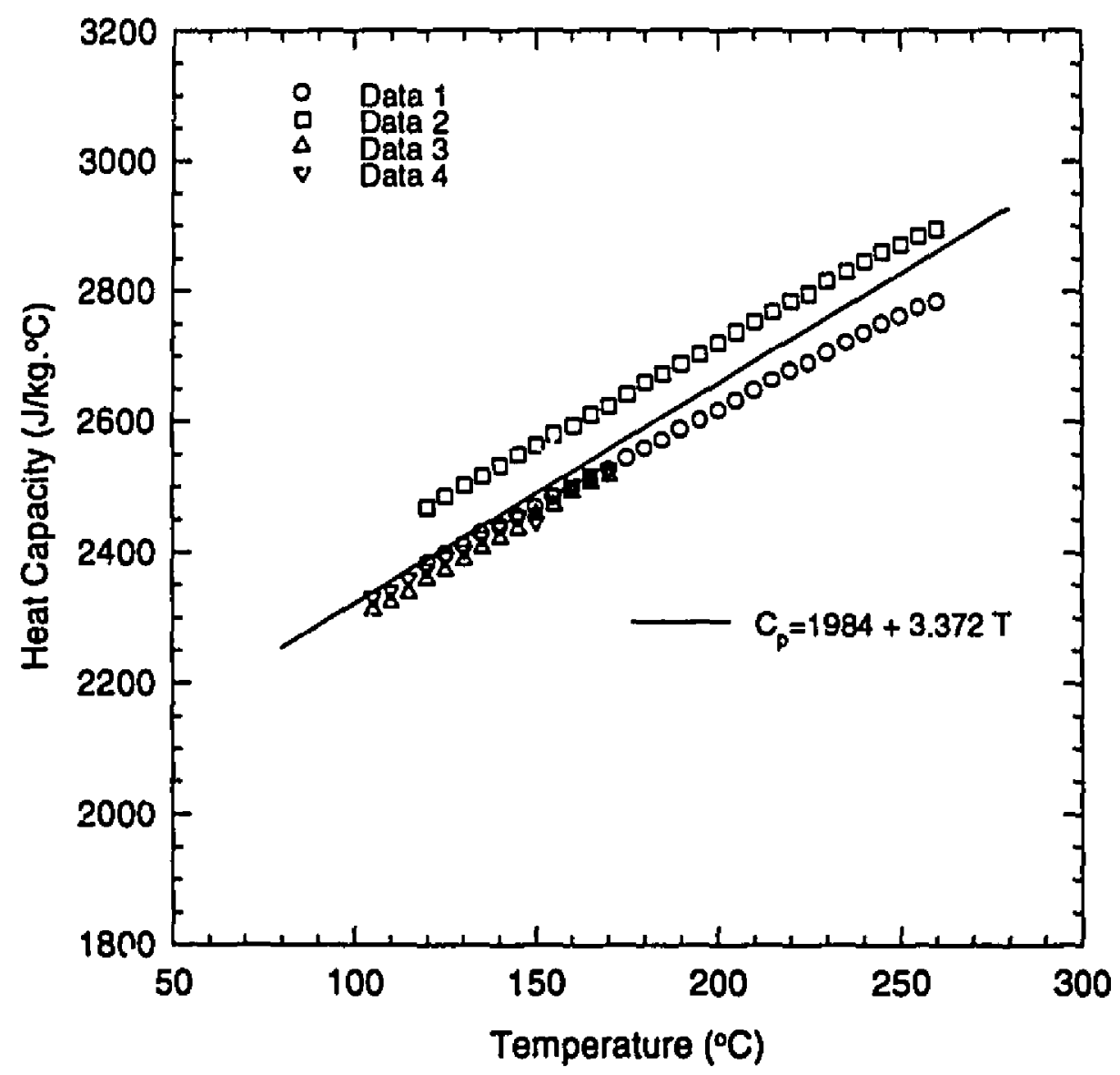

liig. 7.5 Heat Capacity as a function of temperature for Dowlex 2049.

The reproducibility of the data was within $4 \%$, which is the usual range for DSC measurements. The resulls were fitted using a linear expression:

$$
C_{f}=1984+3.372 T
$$


with $\mathrm{C}_{\mathrm{p}}$ in $\mathrm{J} /\left(\mathrm{kg} .{ }^{\circ} \mathrm{C}\right.$ ) and $\mathrm{T}$ in " $\mathrm{C}$ (correlation lactor $\mathrm{R}^{2}=0.906$ ). Since Plasfill reguires a constant value for the heat capacity, the injection melt cemperature was used to cilleulate a value of $C_{p}$ for the simulations. $\wedge t 220^{\circ} C_{,} C_{p}=2726 \mathrm{~J} /\left(\mathrm{kg}\right.$. $\left.{ }^{\prime C}\right)$.

\subsubsection{Thermal Conductivity}

The results of thermal conductivity (k) measurements in the melt phase are shown in figure 7.6. Data sets 1 and 2 are results of individual experiments for the same temperature range $\left(230-125^{\circ} \mathrm{C}\right)$ :

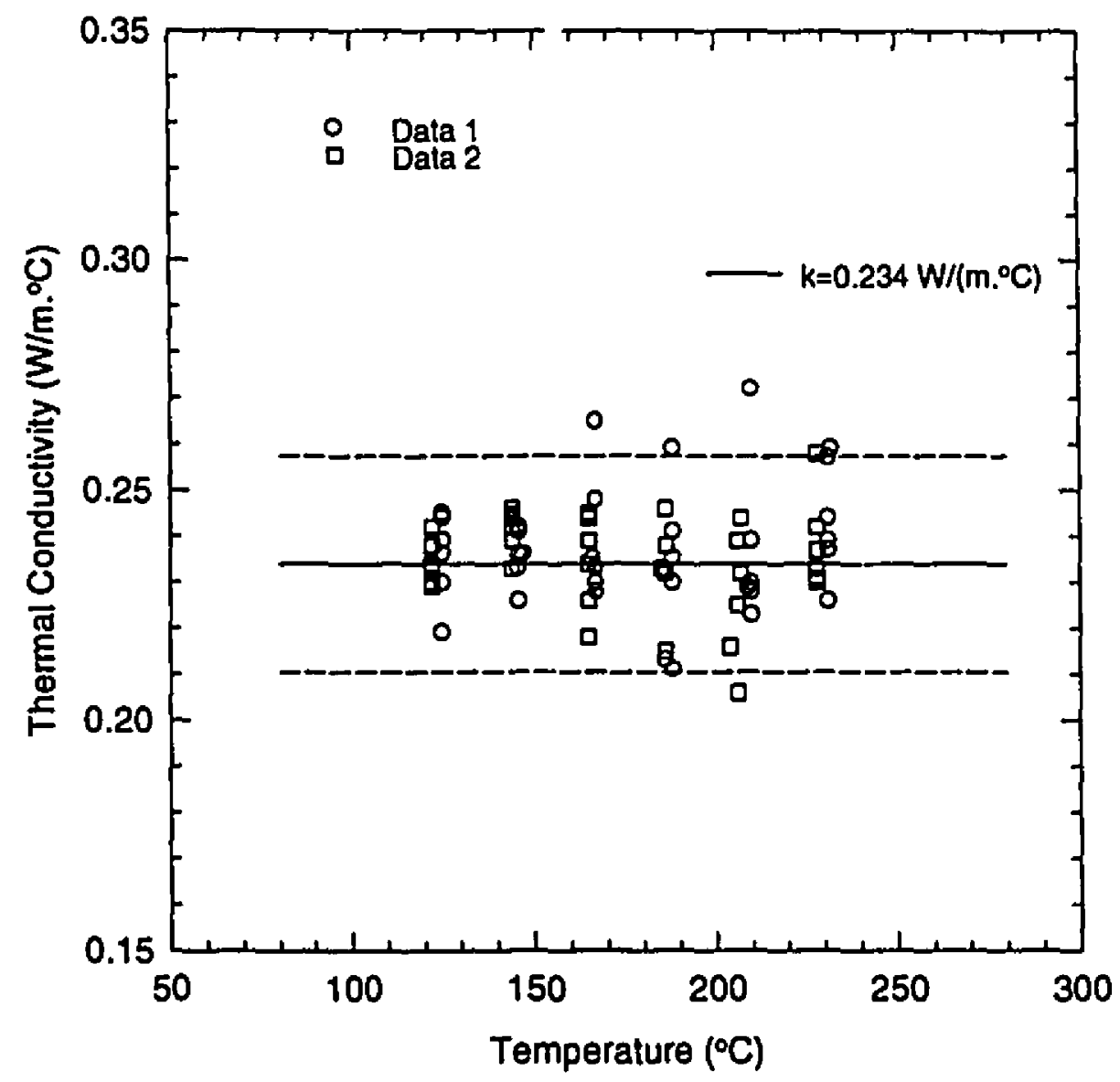

Fig. 7.6 Thermal conductivity as a function of temperature for Dowlex 2049 . 
A lot of scatter is evident. İrrors arise from the improper placement of the probe, by inhomogeneous samples, or if the set up is not at steady state prior to taking the reading. In general, however, reproducibility of the results was better than $10 \%$. All the data collected are shown here.

The results were fitted using a constant value of thermal conductivity, which was:

$$
k=0.234 \mathrm{~W} /\left(\mathrm{m}^{\circ} \mathrm{C}\right)
$$

This was used directly in the Plasfill simulations. $\Lambda$ confidence interval of $10 \%$ is shown by the dashed lines in figure 7.6.

\subsection{Density}

The results of Pressure-Volume-Temperature (PVT) measurements in the melt and the solid phases are shown in figure 7.7.

The temperature of crystallization $\left(T_{c}\right)$ as a function of pressure was fitted using a linear expression:

$$
T_{c}=113.52+0.0281 P
$$

with $P$ in bars and $T_{c}$ in ${ }^{\circ} \mathrm{C}$.

For $\mathrm{TZT}_{\mathrm{c}}$ (melt phase), the specific volume, $\mathrm{V}$, was fitted by the following equation:

$$
\begin{aligned}
& V=\frac{1}{\rho}=\frac{a}{P+b}+\frac{c T}{P+d} \\
& \text { with } \mathrm{a}=55000, \mathrm{~b}=48700, \mathrm{c}=1.35 \text { and } \mathrm{d}=1398
\end{aligned}
$$

with $P$ in bars and $T_{c}$ in ${ }^{\circ} \mathrm{C}$.

Since a constant density is used in Plasfill (pressure effects are assumed to be negligible during filling), $\rho$ was calculated at atmospheric pressure and the melt temperature for the simulations. At $220^{\circ} \mathrm{C}, p=739.7 \mathrm{~kg} / \mathrm{m}^{3}$. 


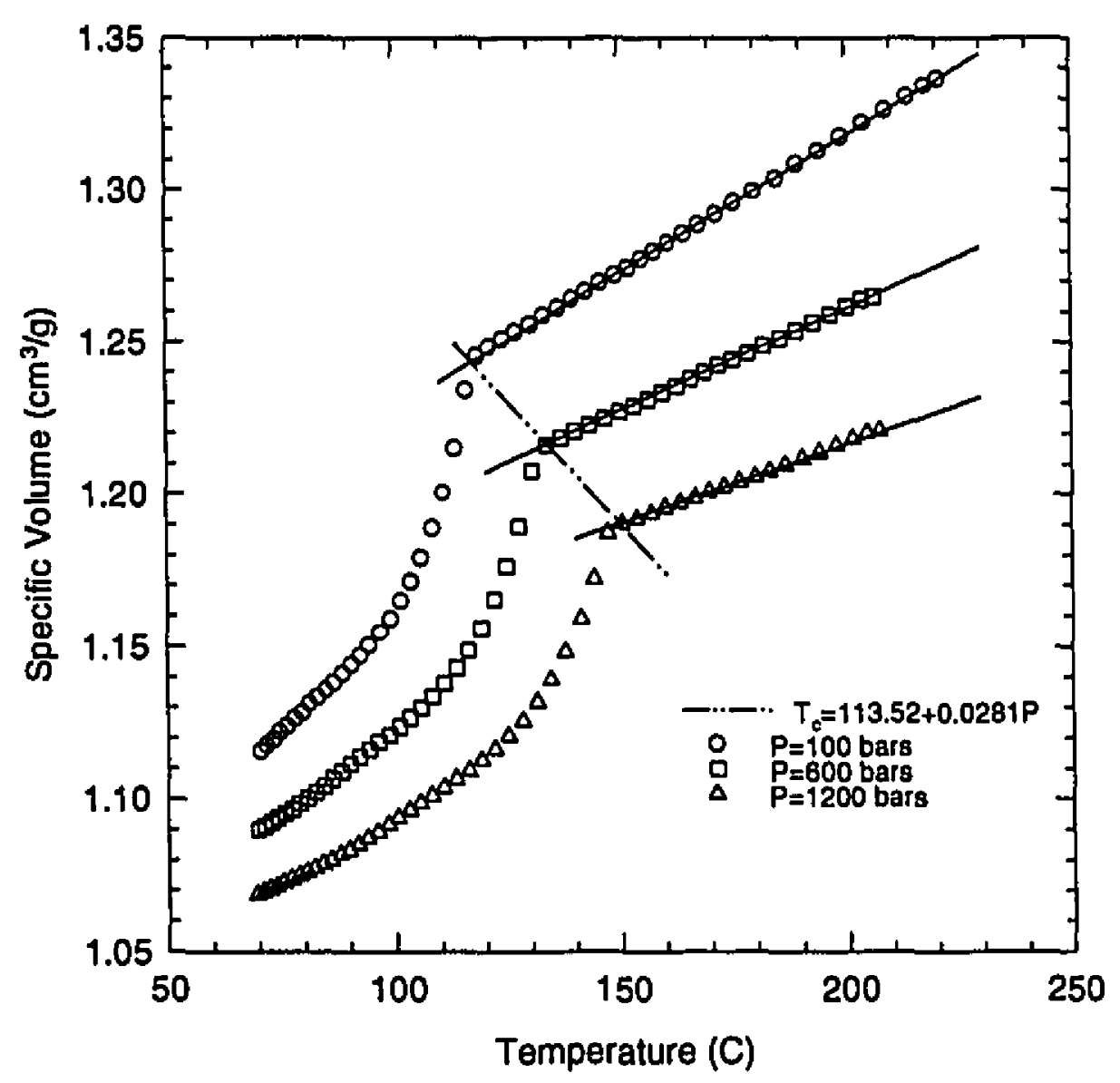

Fig. 7.7 Specific volume as a function of temperature and pressure (Dowlex 2049). 


\section{Experimental Results of Injection Molding}

Before presenting the effects of each variable studied, we describe in this section the types of defect observed in Dowlex 2049 molded plates. The two sides of the mold are not the same: on one side, small regularly spaced dots and lines are machined into the surface. This side is referred to later as "textured", and it had been made at IMI for a study of shrinkage during injection molding. The other side of the mold is smooth.

On the textured side, near the gate, an entirely dull surface is observed on the molded plate, and this defect can cover quite a large percentage of the plate. We refer to this type of defect as a "patch". This region is followed by irregularly spaced "flow lines" of a few millimeters width. The last part of the plate is generally free of defects.

Variations in surface appearance are less distinct on the smooth (untextured) side of the plate. A close examination shows that the surface corresponding to the patches of the other side is less glossy. This is confirmed by microscopic examination (section 8.6). Sometimes, small patches can be observed clearly.

Flow lines are said to "alternate", since the end of a line on one side generally corresponds to the start of one on the opposite side. However, flow lines are sometimes very difficult to detect on the smooth side of the plate, and no alternate lines corresponding to the oppositc side can be found. Figure 8.1 is a sketch of the various types of defects observed.

In this chapter, the influence of each variable is also discussed in terms of percentage of fill and pressure reading at the gate. However, difficulties encountered in the calibration of the pressure sensors resulted in low pressure readings. As a result, only comparative pressure readings can be provided. 


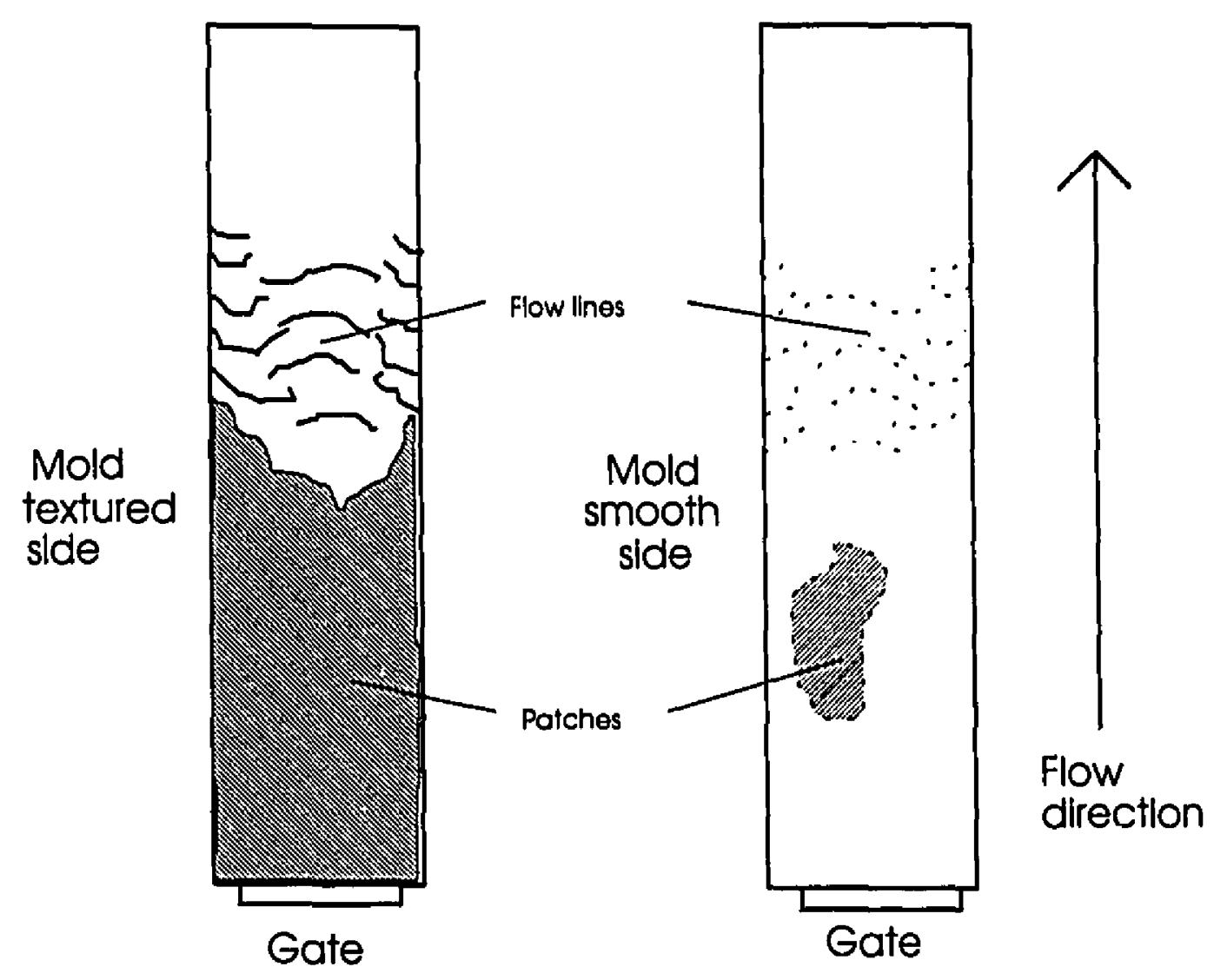

Fig. 8.1 Defects found on Dowlex 2049 molded plates.

\subsection{Effect of Mold Thickness}

As expected, the percentage of fill is higher for a larger mold thickness, since there is less flow resistance (it is normally assumed that for standard injection molding the solid layer, or skin, is approximately $0.25 \mathrm{~mm}$ thick, regardless of the nominal wall thickness of the part [50]). For a reference case of a 0.093" thick plate, percentages of fill obtained are $97 \%>78 \%>21 \%$ for decreasing thickness. (Conditions are presented in table 5.4). Pressure readings at the gate are larger for the smaller thickness for the same reason. However, no changes can be observed in the type of surface defect or the relative severity for each sample, except slightly wider flow lines as mold thickness increases. Mold thickness does not seem to have a great influence on patch and how mark generation. 


\subsection{Effect of Mold Temperature}

The percentage of fill is slightly higher for a higher mold temperature, since the solidified layer is smaller, and this results in less flow resistance $(83 \%>78 \%>73 \%$ for decreasing mold temperature). However, pressure readings at the gate do not vary much, being slightly lower for the higher mold temperature of $65^{\circ} \mathrm{C}$. Again, no obvious changes can be observed in the type of surface defect or its relative importance. Small patches can be seen more clearly on the smooth side of the plate for the lowest mold temperature $\left(15^{\circ} \mathrm{C}\right)$. In the range studied, mold temperature does not seem to have a great influence on patch and flow mark gencration.

\subsection{Effect of Melt Temperature}

As expected, percentage of fill is higher for a higher melt temperature, since viscosity decreases with temperature ( $89 \%>78 \%>64 \%$ for decreasing melt temperature). Pressure readings at the gate are similar for the intermediate and higher melt temperatures $\left(220\right.$ and $\left.240^{\circ} \mathrm{C}\right)$, but surprisingly, slightly lower for the lowest temperature $\left(200^{\circ} \mathrm{C}\right)$. No changes can be observed in the type of surface defect or its relative severity on each sample. Melt temperature, in the range studied, does not seem to be an important variable for the occurrence of patches and flow marks.

\subsection{Effect of Gate}

For similar molding conditions, comparing the pin and edge gates, no difference in the percentage of fill was found ( $81 \%$ for both). No sensor is installed at the pin gate, and pressures can not ve compared at that position, but readings in the cavity are similar for both conditions. Patches and flow marks are present in both cases; an interesting feature on one of the pin gate samples is that the normally uniform dull surface is broken in some regions by alternate flow marks. This indicates that patches are an advanced, or very dense stage of flow marks. 


\subsection{Effect of Injection Speed}

The percentage of fill increases with increasing injection speed $(81 \%>78 \%>66 \%)$. The pressure at the gate is larger for the lowest injection speed (20\% of maximum speed), probably because of more freezing at the gate. This condition also generates a different defect pattern; no patches are seen, and a few alternate flow marks cover only the first quarter of the plate. However, the other two conditions $(70 \%$ and $100 \%$ of maximum injection speed) are similar in terms of surface defects. We conclude that injection speed is the major factor controlling the occurrence of flow marks.

\subsection{Effect of Coating}

\subsubsection{Teflon ${ }^{\mathrm{TM}}$ SF-50 and SF-25}

The first Teflon ${ }^{\mathrm{TM}}$ coating (SF-50) did not resist the high shear stresses associated with injection molding and was almost completely removed after the first plate was molded. The experiment was repeated, with the same :esult. The second Teflon ${ }^{T M}$ coating (SF-25) lasted much longer. It was possible to mold at least twenty-five plates before any evidence of coating removal. However, no significant changes were noted in pressure, percentage of fill or occurrence of surface defect. This result is significant with regard to the possible relation between slip and flow marks.

\subsubsection{Silicone Oil}

Silicone oil had to be reapplied every two parts. The percentage of filling is lower when the coating is present $(72 \%<78 \%$ and $74 \%<81 \%)$. Pressure readings are also much lower, probably because of a lubrication effect. The most spectacular consequence of the oil is a major distortion of the flow front (seen because of short shots) and warpage of the part. Surface defects are amplified, but are somewhat different in nature than those usually observed. 


\subsection{Microscopic Observations of Molded Surfaces and Filled-LDPE sample}

\subsubsection{Dowlex 2049}

Figure 8.2, a stereoscopic photomicrograph, shows a 10X enlargement of the flow marks section. SLM observations of the dull region show that the resin surface is severely stretched and deformed in the direction of flow by the process. The macroscopic "smooth" area is also smooth on the microscopic scale. SEM photographs show the transition zone between smooth and dull surfaces (figures 8.3 and 8.4) and the end (or tail) of a dull surface (figures 8.5 and 8.6). The flow direction is from left to right in every pholograph.

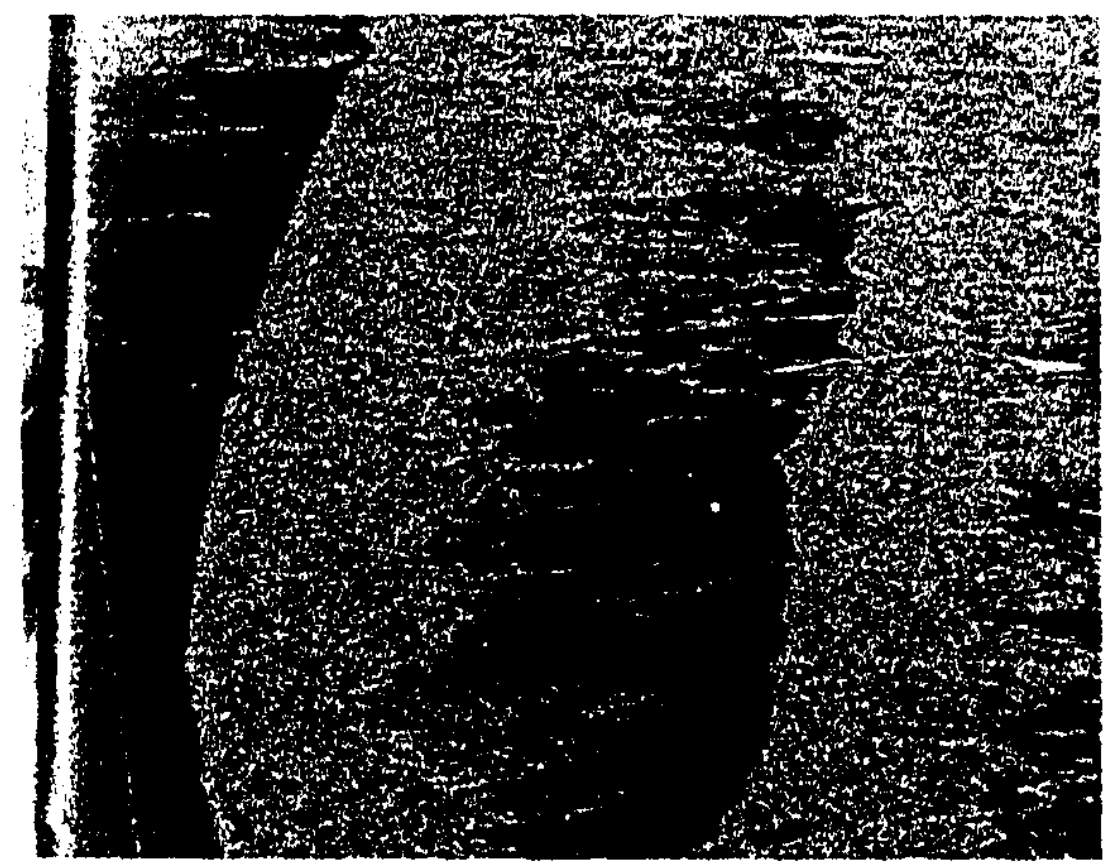

Fig. 8.2 Flow marks section on Dowlex 2049 sample (10X). 


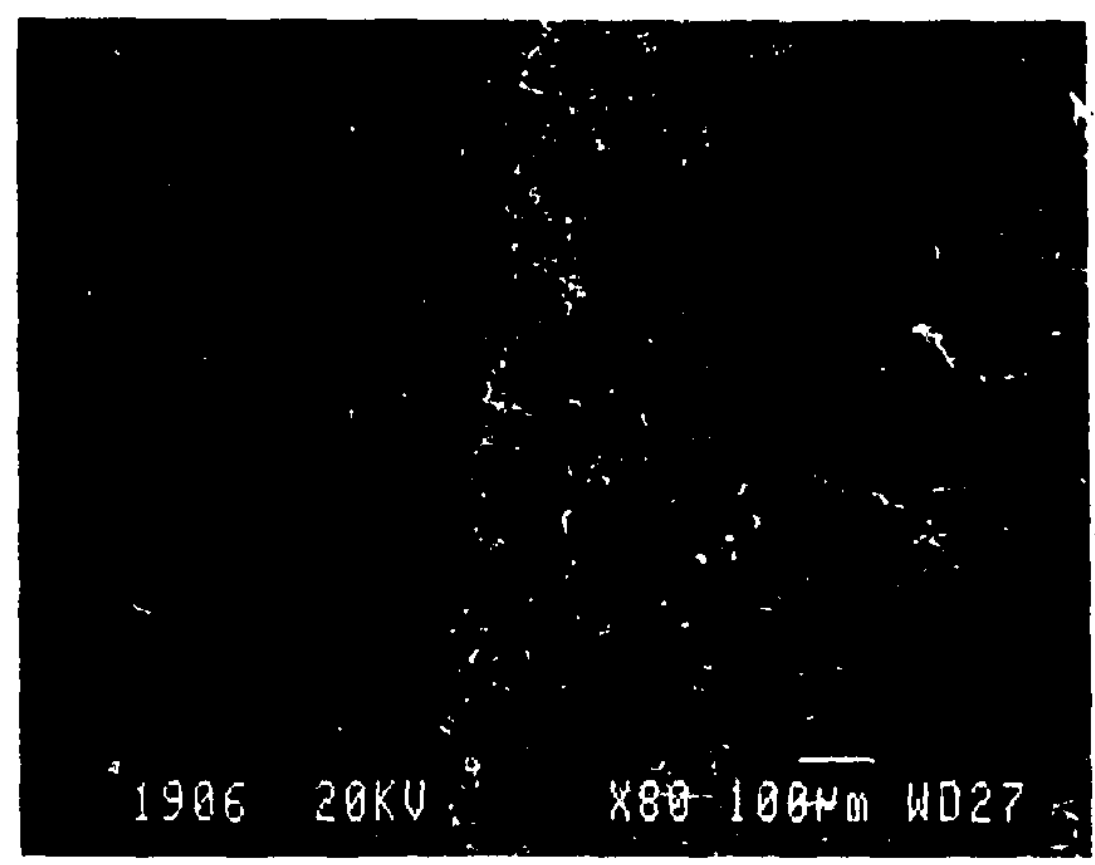

Fig. 8.3 Transition zone between smooth and dull surfaces (LLDPE, 80X).

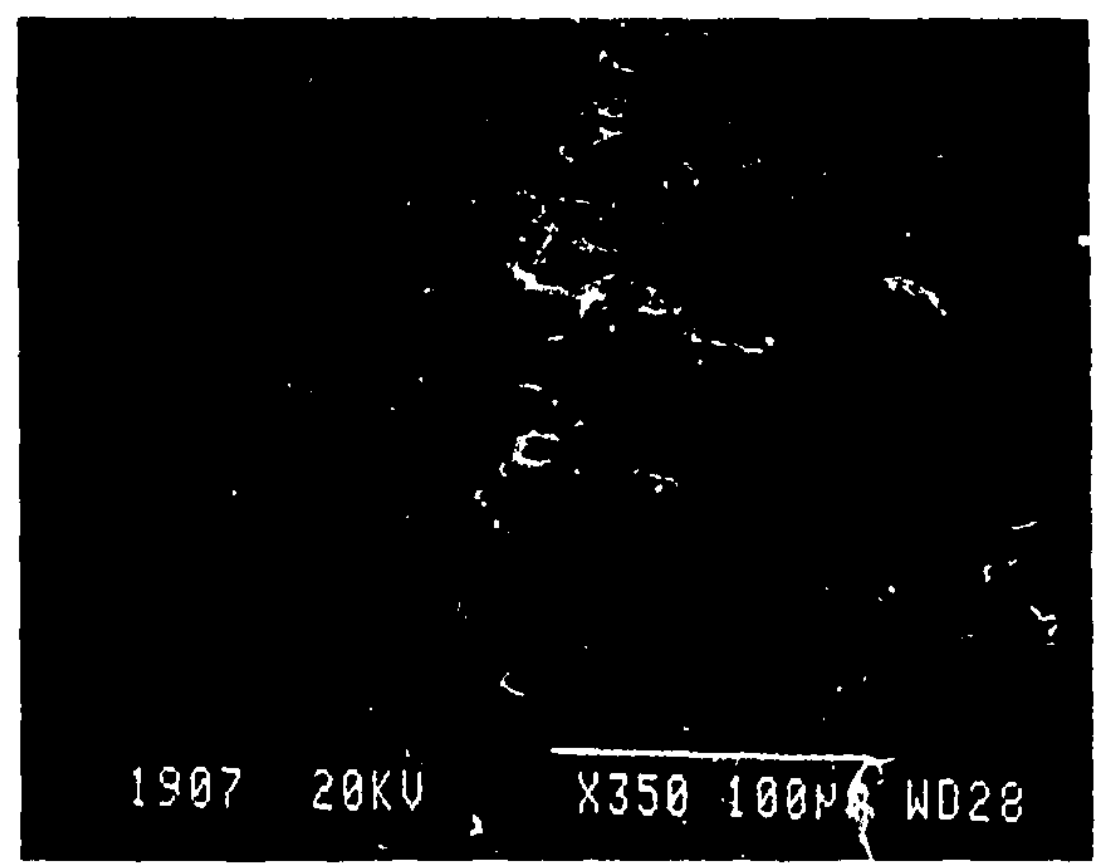

Fig. 8.4 Transition zone between smooth and dull surfaces (LLDPE, detail, 350X). 


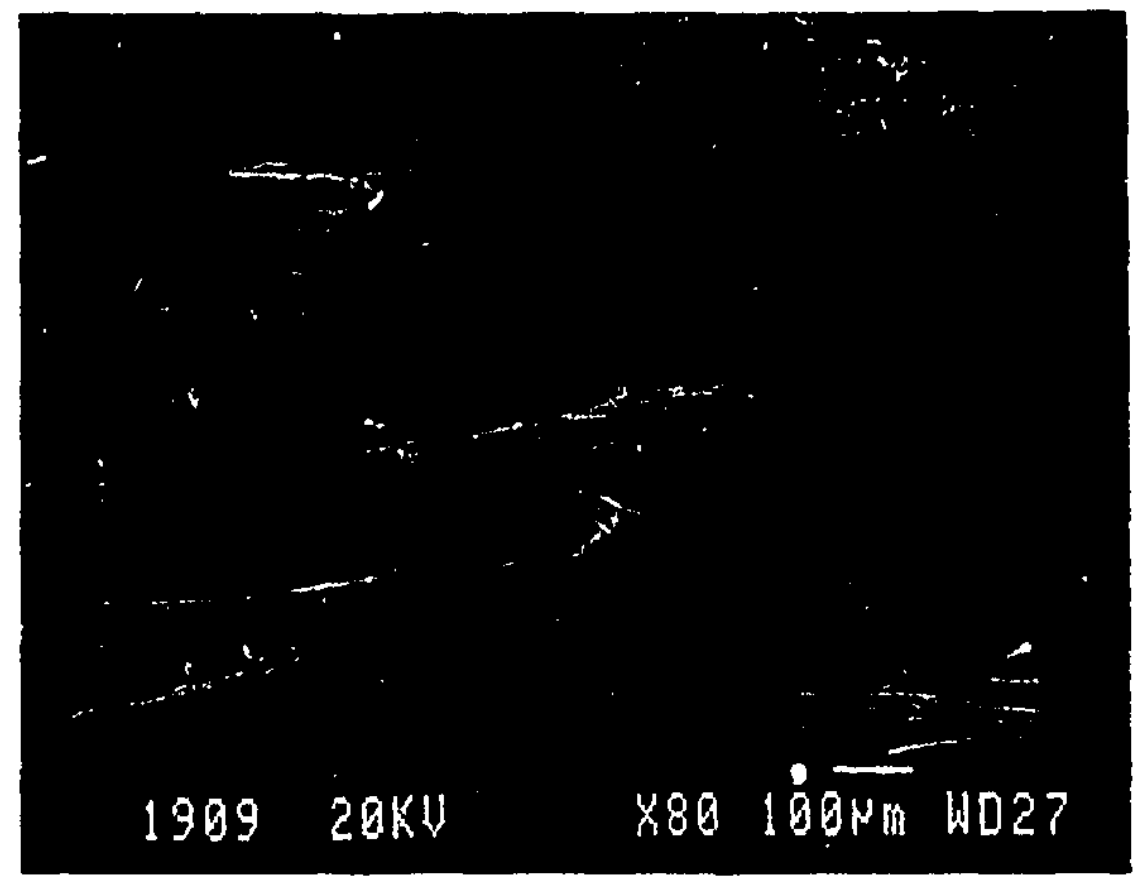

Fig. 8.5 End (or tail) of the dull region of a flow line (LLDPE, 80X).

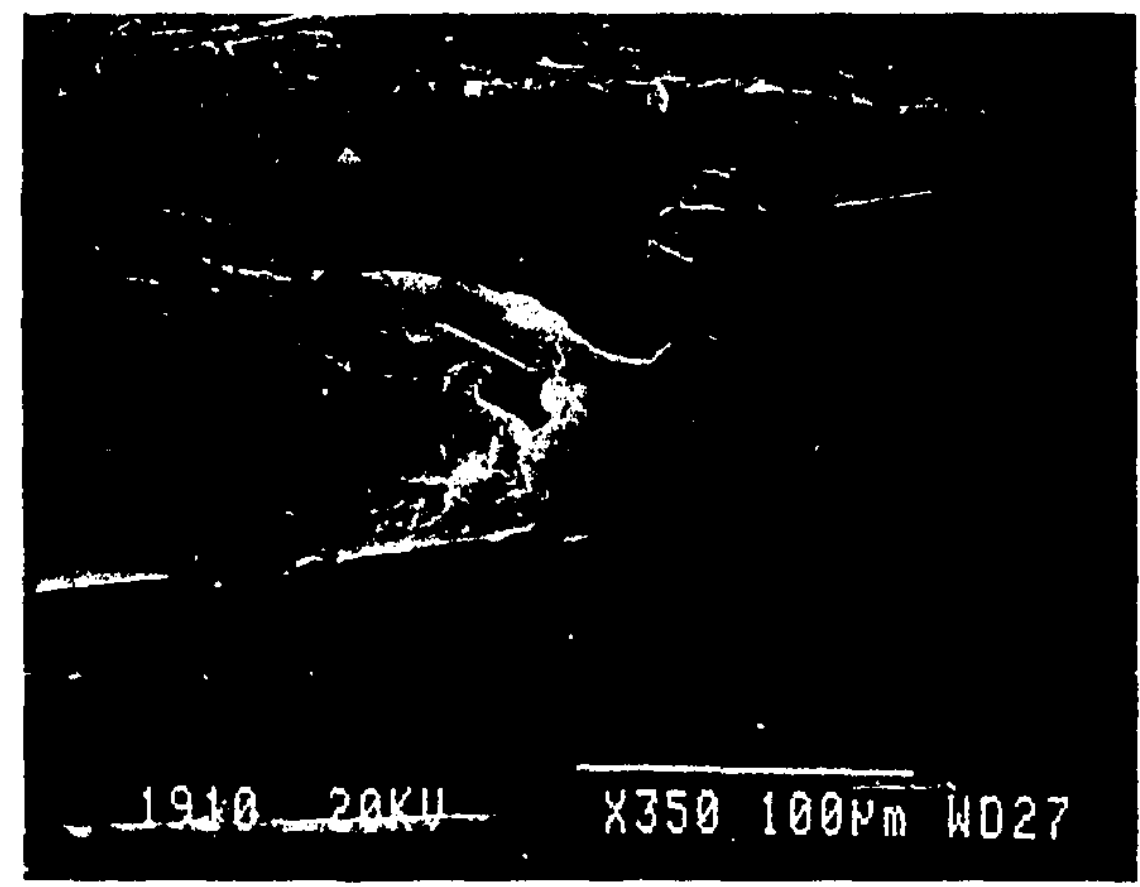

Fig. 8.6 End (or tail) of the dull region of a flow line (LLDPE, detail, 350X). 


\subsubsection{Exxon 6706}

Similar microscopic observations were made on HDPE Exxon 6706 plates previously molded in exploratory experiments. Figure 8.7 shows a $10 \mathrm{X}$ enlargement of the flow marks section. Features similar to those seen in the LLDPE Dowlex 2049 sample are found. SliM observations of the dull region show that the resin surface is even more severely stretched and deformed in the flow direction. The photographs show the transition zone between smooth and dull surfaces (figures 8.8, 8.9 and 8.10). The flow direction is again from left to right in every photograph. $\Lambda$ new feature can be noticed; small "islands" of torn material are detached from the bulk of the dull area. A detail is shown in figurc 8.11.

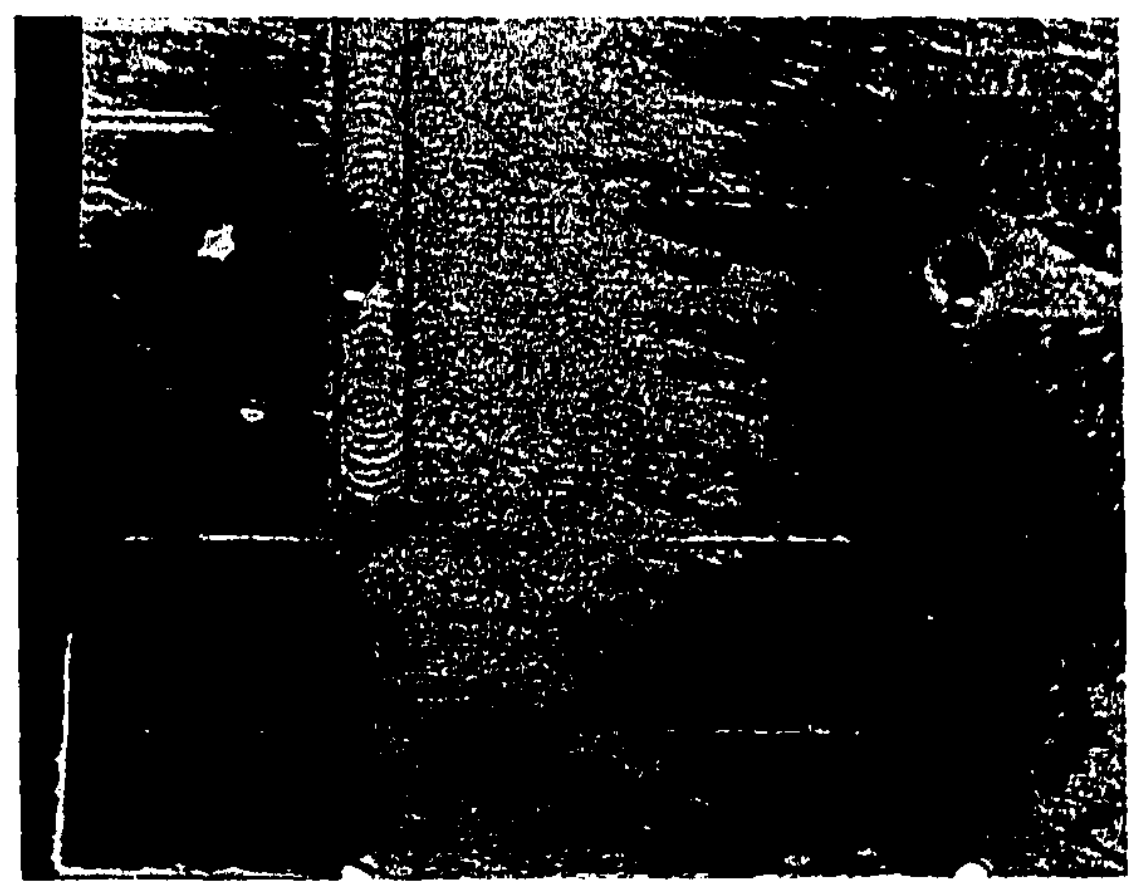

Fig. 8.7 Flow marks section on Exxon 6706 sample (10X). 


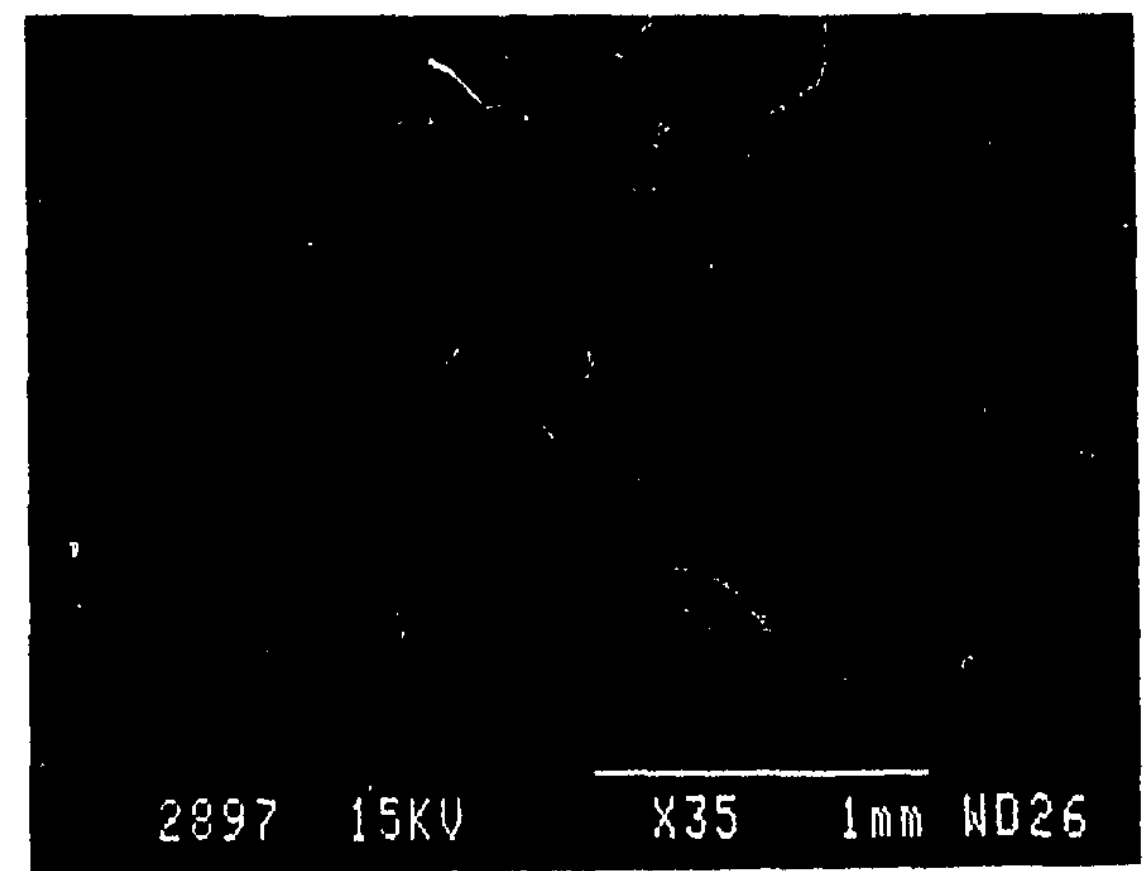

Fig. 8.8 Transition zone between smooth and dull surfaces (HDPE, 35X).

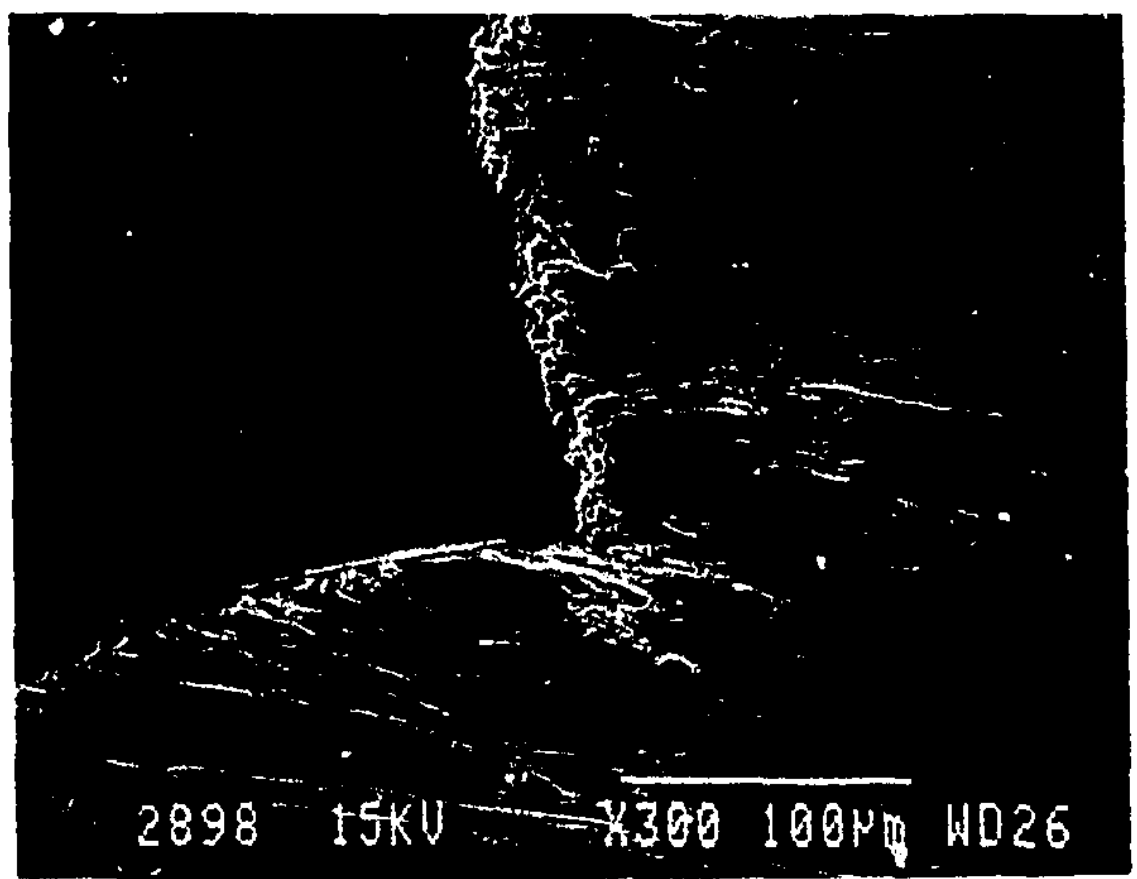

Fig. 8.9 Transition zone between smooth and dull surfaces (HDPE, detail, 300X). 


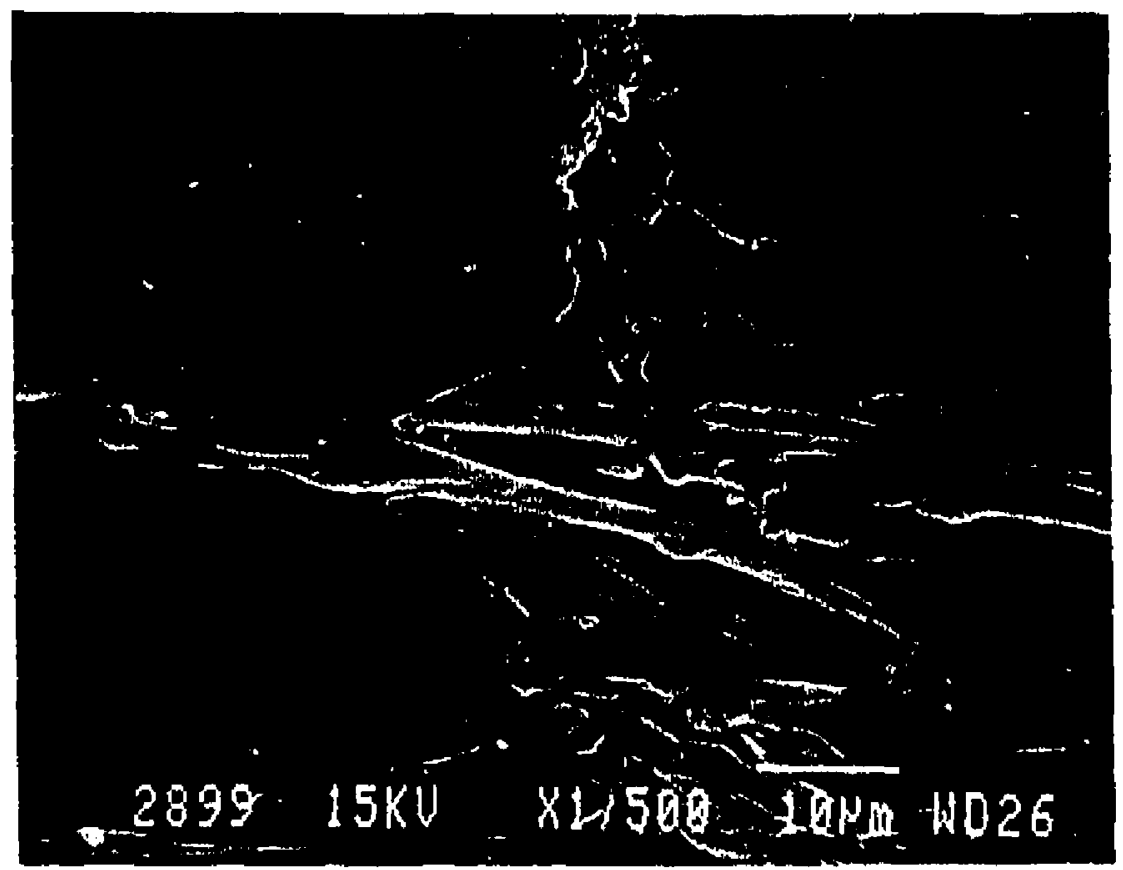

Fig. 8.10 Transition zone between smooth and dull surfaces (HDPE, dctail, 1500X).

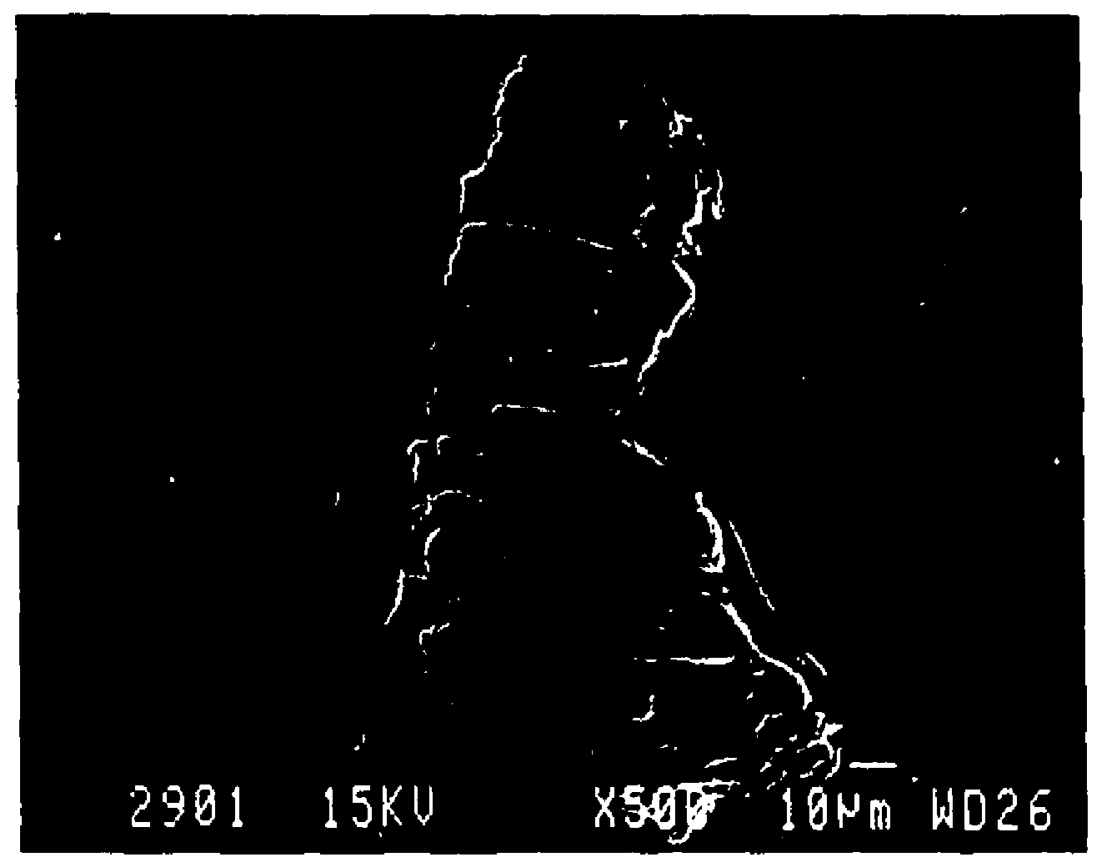

Fig. 8.11 Detail of a small thorn area (HDPE, 500X). 


\subsubsection{Filled-LDPE Sample}

$\Lambda$ small car component molded from filled L,DPl: was supplied by IYI. (St-Damien, Québec). the nature and the filler content are unknown. Only a few flow lines on one side of the part are seen near tine gate. SI:M photographs of that section show features similar to the ones seen in previous samples. litgures 8.12 and 8.13 show the transition zone between the smooth and dull regions. 'The flow direction is toward the left.

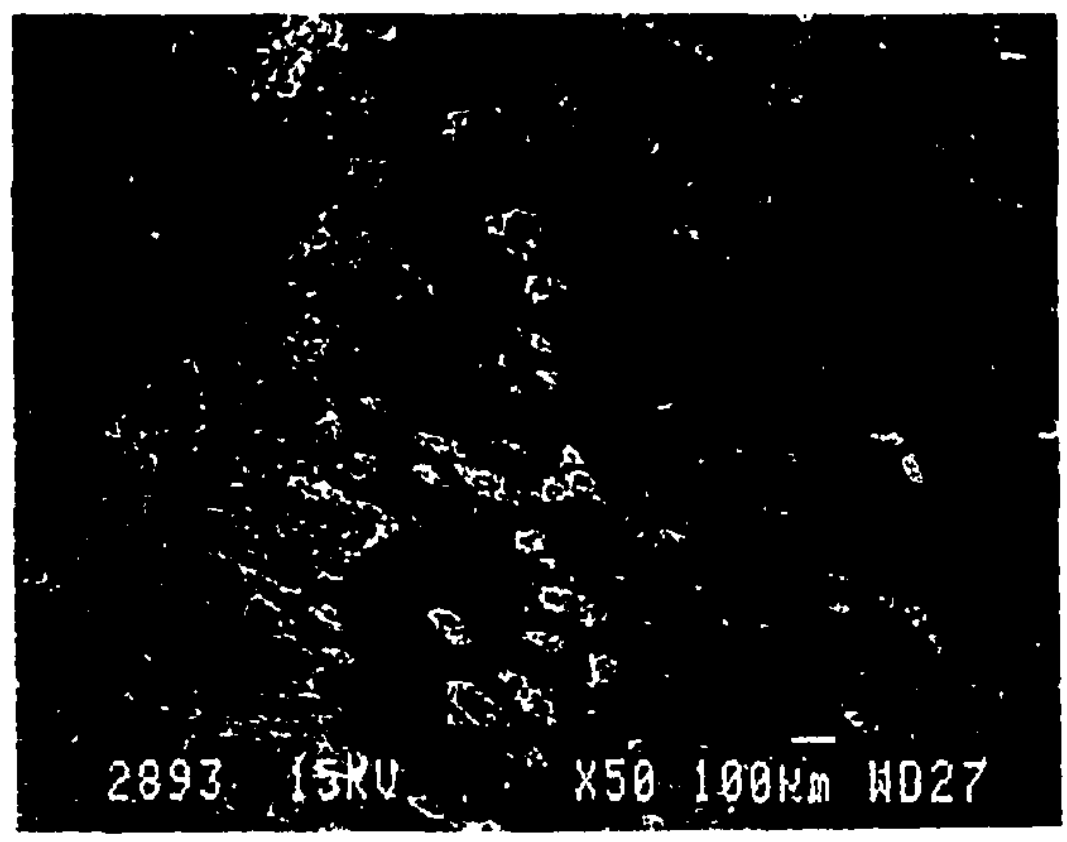

lïg. 8.12 Transition zone between smooth and dull surfaces (filled-I DPE, 50X). 


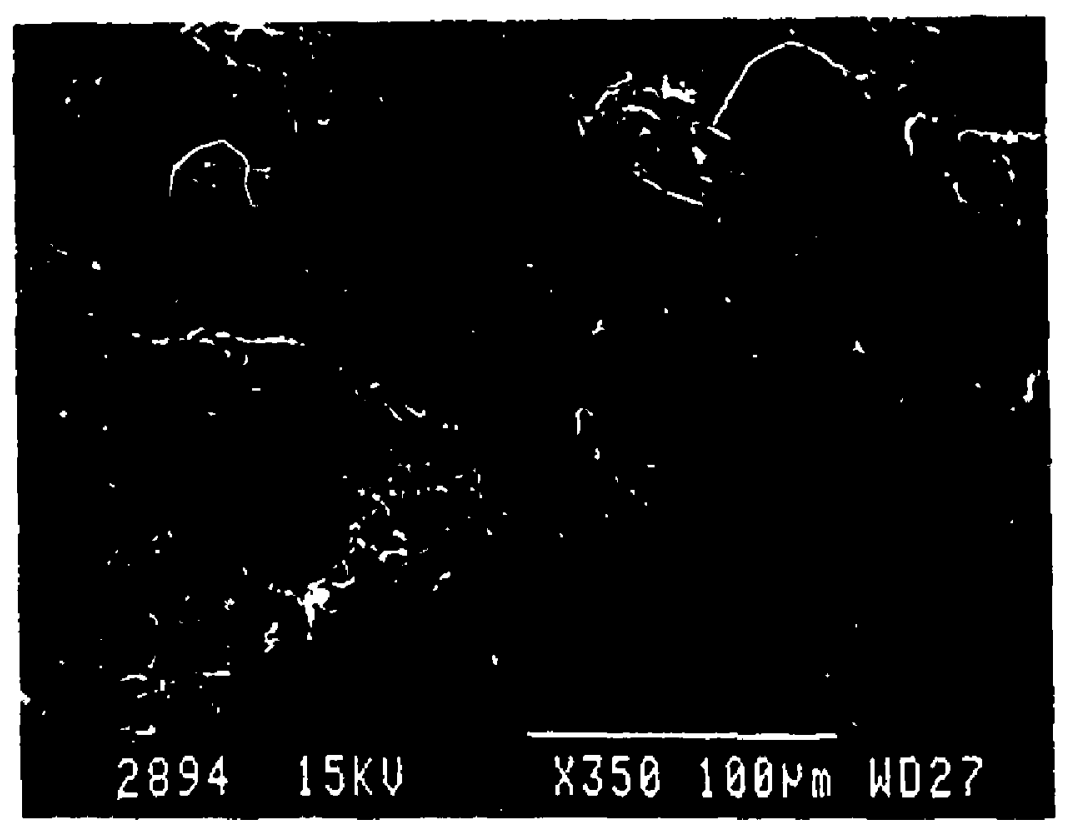

Fig. 8.13 Transition zone between smooth and dull surfaces (filled-I.I)Pl, detail, 350X). 


\section{Additional Experiments on the Effect of Injection Speed}

From the experiments described above, it was concluded that the major contributing factor to the occurrence of flow marks is the injection speed. Additional experiments were carried out at lower injection speeds to further explore the effect of this variable.

Since there was no evidence of slip in the Teflon ${ }^{\mathrm{TM}}$ experiments, and slip models were not incorporated in Plasfill, we also decided to extend our study to an injection molding grade resin, Ixxon 6706. It had been found in preliminary experiments that flow marks could be generated on these plates, but with less severity than for Dowlex 2049. Exxon 6706 is fully characterized regarding rheological and physical properties, but has not been studied in terms of slip.

Tables 9.1 and 9.2 show the physical and rheological properties of Exxon 6706 that were used in the Plasfill simulations. Viscosity data and a fitted Carreau-WLF model are shown in figure 9.1. For comparison, we also present Dowlex 2049 properties in tables 9.1 (at $220^{\circ} \mathrm{C}$ ) and 9.2 .

All additional experiments were conducted at a melt temperature of $220^{\circ} \mathrm{C}$ and a mold temperature of $40^{\circ} \mathrm{C}$. We started at the lowest injection speed $(10 \%$ of the maximum speed) and increased the speed by $10 \%$ until flow marks first appeared.

Table 9.1 Physical properties of Exxon 6706 and Dowlex 2049

\begin{tabular}{|c|c|c|}
\hline & 6706 & 2049 \\
\hline Heat Capacity $\left(\mathbf{C}_{\mathrm{p}}\right)$ & $2800 \mathrm{~J} /\left(\mathrm{kg} .{ }^{\circ} \mathrm{C}\right)$ & $2726 \mathrm{~J} /\left(\mathrm{kg} .{ }^{\circ} \mathrm{C}\right)$ \\
\hline Thermal Conductivity $(\mathrm{k})$ & $0.235 \mathrm{~W} /\left(\mathrm{m} .{ }^{\circ} \mathrm{C}\right)$ & $0.234 \mathrm{~W} /\left(\mathrm{m} .{ }^{\circ} \mathrm{C}\right)$ \\
\hline Bensity $(\rho)$ & $739 \mathrm{~kg} / \mathrm{m}^{3}$ & $739.7 \mathrm{~kg} / \mathrm{m}^{3}$ \\
\hline
\end{tabular}


Table 9.2 Fitted Carreau-WLF parameters for Exxon 6706 and Dowlex 2049

\begin{tabular}{|c|c|c|}
\hline & 6706 & 2049 \\
\hline$\eta_{0}$ & 733 Pa.s & 6555 Pa.s \\
\hline $\mathbf{P}_{2}$ & $0.00716 \mathrm{~s}$ & $0.1764 \mathrm{~s}$ \\
\hline $\mathbf{P}_{3}$ & 0.6928 & 0.56 \\
\hline $\mathbf{T}_{\text {ref }}$ & $207^{\circ} \mathrm{C}$ & $2000^{\circ} \mathrm{C}$ \\
\hline $\mathbf{T}_{\mathbf{s}}$ & $-59^{\circ} \mathrm{C}$ & $-83^{\circ} \mathrm{C}$ \\
\hline
\end{tabular}

$\therefore$

\subsection{Results for Dowlex 2049}

The onset of flow marks is observed at an injection speed of $20 \%$, which is the condition that was studied in the first set of experiments (condition \#7). No patches are seen, only a few alternate flow marks near the gaie, covering about one third of the plate. The sample molded at an injection speed of $15 \%$ is completely smooth. The percentage of fill and pressure increases with injection speed. These results are used in the next chapter to validate the Plasfill predictions.

\subsection{Results for Exxon 6706}

Plates molded at 10 and $20 \%$ of the maximum injection speed are free of surface defest. The onset of flow marks is noticed at an injection speed of $30 \%$. Surprisingly, this sample shows a large patch on the first quarter of the plate, followed by flow marks. The second half is smooth. Since Exxon 6706 is an injection grade, filling is almost complete even at a very low injection speed (99\% at a speed of $20 \%$, and $100 \%$ at $30 \%$ ). The pressures do not differ much for these conditions. These results are also used in the next chapter for model validation. 


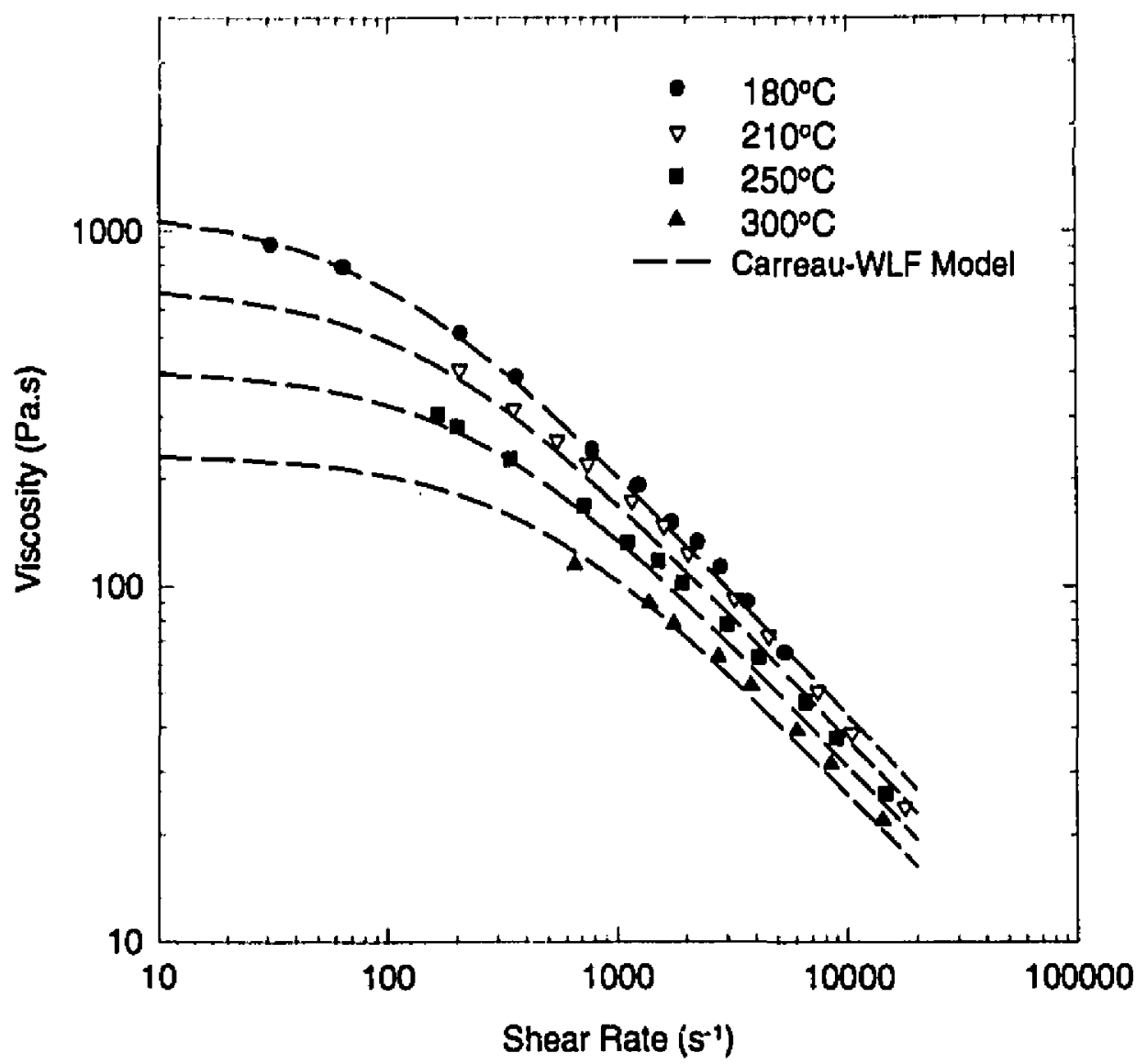

Fig. 9.1 Viscosity curves of Exxon 6706 . 


\section{Validation of Plasfill Predictions}

Four simulations, two for each linear PE studicd, were performed using Plasfill: 10 and $20 \%$ of the maximum injection specd for Dowlex 2049, and 20 and $30 \%$ of the maximum injection speed for Exxon 67n6.

\subsection{Validation Procedure}

Filling is under flow rate control. The applied flow rate is related to the time derivative of the screiv position:

$$
Q=\frac{d(p o s)}{d t} \bullet \text { area of the screw }
$$

wherc the surface area of the screw is $9 \pi \mathrm{cm}^{2}$. $\Lambda$ flow rate that is lincar with time is obtained in all four cases. Figure 10.1 shows the screw position for second condition studied, i.c. $20 \%$ of the maximum injection speed for Dowlex 2049. We apply a second-order polynomial to fit the data to calculate a corresponding flow rate:

$$
p o s=a+b x+c x^{2}
$$

where $x$ is the time in second, $a=53.43 \mathrm{~mm}, b=-4.455 \mathrm{~mm} / \mathrm{s}$ and $\mathrm{c}=0.1255 \mathrm{~mm} / \mathrm{s}^{2}$ in this example, and

$$
Q\left(\mathrm{~cm}^{3} / \mathrm{s}\right)=9 \pi(0.4455-0.0251 x)
$$

Ten steps flow rate can be entered in Plasfill for simulations, so the injection time is divided into ten equal intervals, and the average flow rate for each step is calculated. The ideal continuous and the stepped flow rates used in the model are shown in figure 10.2 for Dowlex 2049 and $20 \%$ of the maximum injection speed. 
It was found that the product of the calculated flow rate and the injection time exceeded by 15 to $25 \%$ the actual volume of the molded plates. In order to obtain agreement between experimental values and simulations, we used a correction factor $\alpha$, where $0.74 \leq \alpha \leq 0.83$ :

$$
Q_{\text {Piastit }}=\alpha \cdot Q_{\text {calculated }}
$$

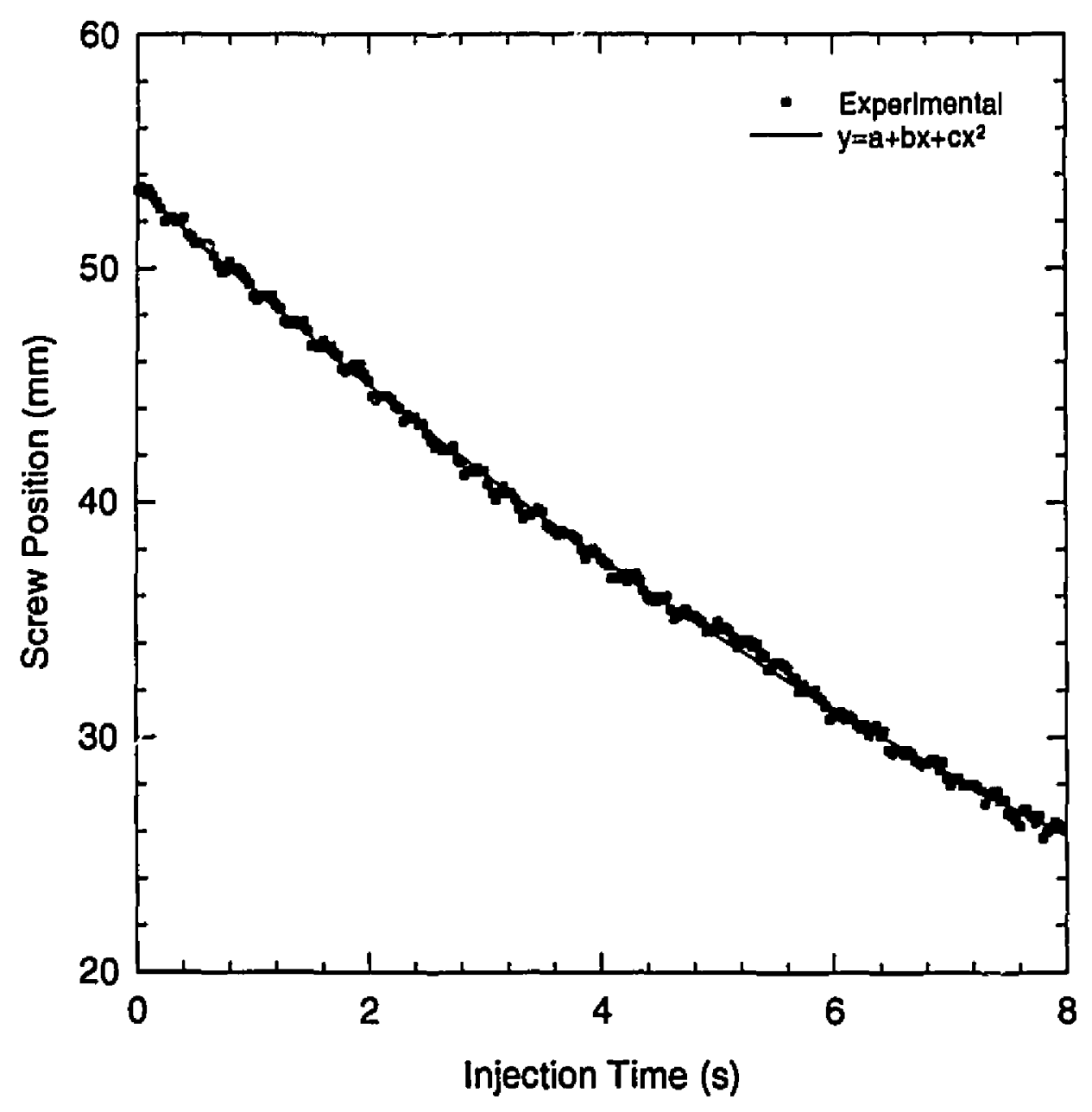

Fig. 10.1 Actual screw position and second-order polynomial (20\% of maximum injection speed, Dowlex 2049). 


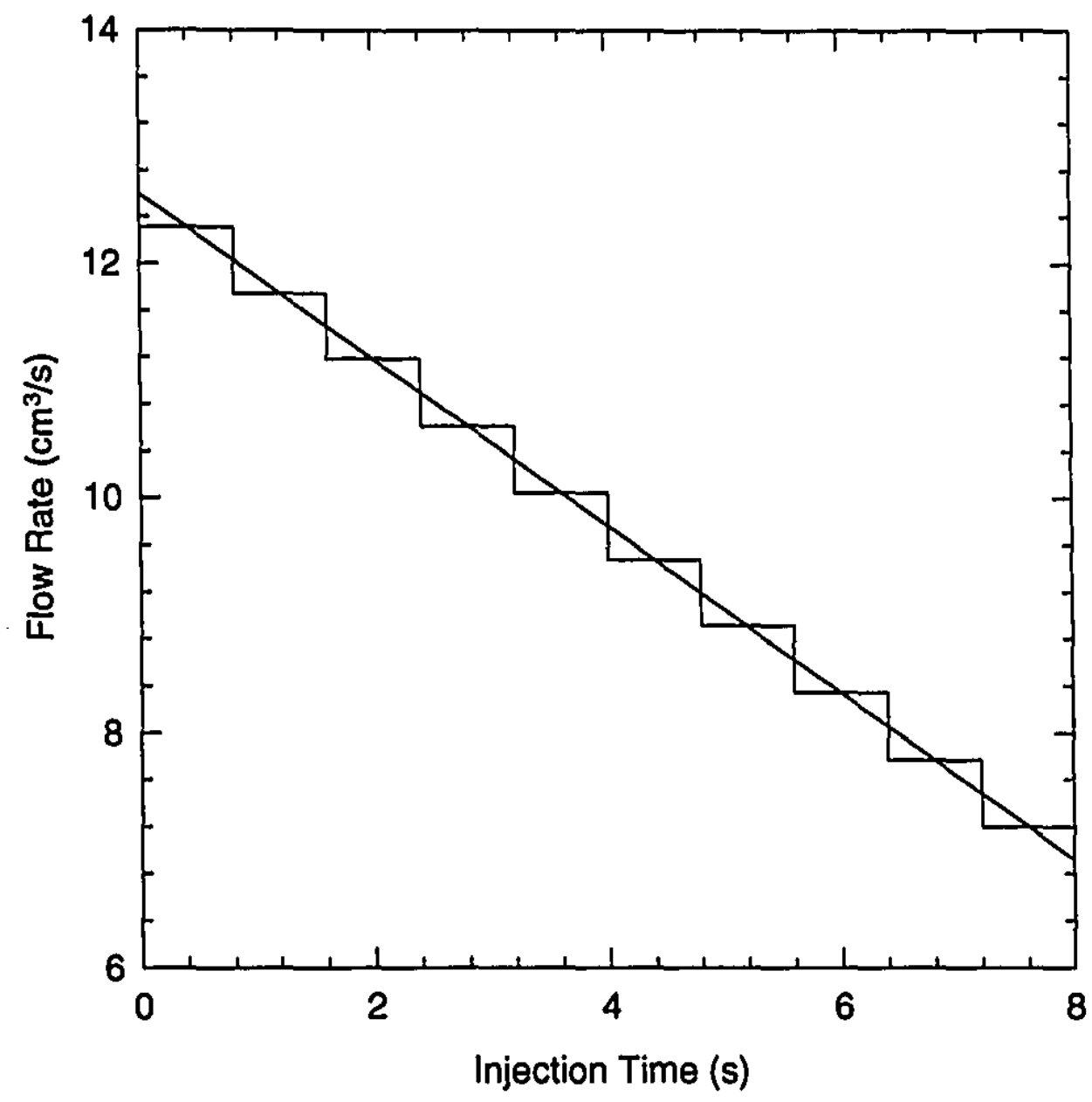

Fig. 10.2 Linear and step flow rates calculated from screw position.

At this time, it is not understood why $\alpha$ is significantly less than one. We noticed that there was some loss at the shut-off valve during injection molding experiments, and part of the discrepancy can be explained by this loss. However, air-shots (injection without a mold) showed that these losses were probably no more than $10 \%$ of the total volume. It is possible that melt compressibility plays a role, but further studies are needed to explain the value of $\alpha$. 
lior all simulations, we used a melt temperature of $220^{\circ} \mathrm{C}$ and a mold temperature of $40^{\circ} \mathrm{C}$, corresponding to the experimental conditions. Heat transfer coefficients of $2000 \mathrm{~W} /\left(\mathrm{m}^{2}{ }^{\circ}{ }^{\circ} \mathrm{C}\right)$ wert: applied at each wall. This value is in accordance with experimental work of Kamal et al. [51], who estimated heat transfer cocfficients during injection molding of HDPE. They determined two heat transfer coefficients each based on a different measured temperature:

- melt temperature indicated by the mold surface thermocouple

- melt temperature indicated by the heat flux sensor thermocouple.

In the first case, they obtained an average value of $2380 \mathrm{~W} /\left(\mathrm{m}^{2}{ }^{\circ}{ }^{\circ} \mathrm{C}\right)$ and in the second, 1030 $\mathrm{W} /\left(\mathrm{m}^{2}{ }^{\circ} \mathrm{C}\right)$ for HDPE. They suggested that measured heat transfer coefficients based on heat flux sensor temperature (the second case) are in the same range as coefficients suggested by comparing numerical simulation results for injection molding and measured temperature and pressure data under similar conditions for thermoplastic materials, i.e. $850-1130 \mathrm{~W} /\left(\mathrm{m}^{2}{ }^{\circ} \mathrm{C}\right)$. However, a second reference [52! suggests that $\mathrm{h}=2560 \mathrm{~W} /\left(\mathrm{m}^{2}{ }^{\circ} \mathrm{C}\right)$ for thermoplastics. Our own value of $2000 \mathrm{~W} /\left(\mathrm{m}^{2} .^{\circ} \mathrm{C}\right)$, however seems to be reasonable. Unfortunately, since no temperature readings were recorded during the experiments, we could not make an independent evaluation of the heat transfer coefficient.

\subsection{Effect of Injection Speed}

\subsubsection{Simulations for Dowlex 2049}

\subsubsection{1 $10 \%$ of Maximum Injection Speed}

lirom the screw position vs. time, we calculaie the flow rate:

$$
Q\left(c m^{3} / s\right)=9 \pi(0.2950-0.0120 x)
$$

The following flow rate profile was used for the simulation $(\alpha=0.76$, total injection time $=10$ sec.): 
Table 10.1 Imposed variable flow rate for $10 \%$ of maximum injection speed (1)owlex 2049)

\begin{tabular}{|c|c|c|}
\hline Time Step & Flow rate $\left(\mathrm{cm}^{3} / \mathrm{s}\right)$ & Duration (s) \\
\hline $\mathbf{1}$ & 6.2 & 1.0 \\
\hline $\mathbf{2}$ & 6.0 & 1.0 \\
\hline $\mathbf{4}$ & 5.7 & 1.0 \\
\hline $\mathbf{5}$ & 5.5 & 1.0 \\
\hline 6 & 5.2 & 1.0 \\
\hline 7 & 5.0 & 1.0 \\
\hline 8 & 4.7 & 1.0 \\
\hline 9 & 4.4 & 1.0 \\
\hline 10 & 4.2 & 1.0 \\
\hline
\end{tabular}

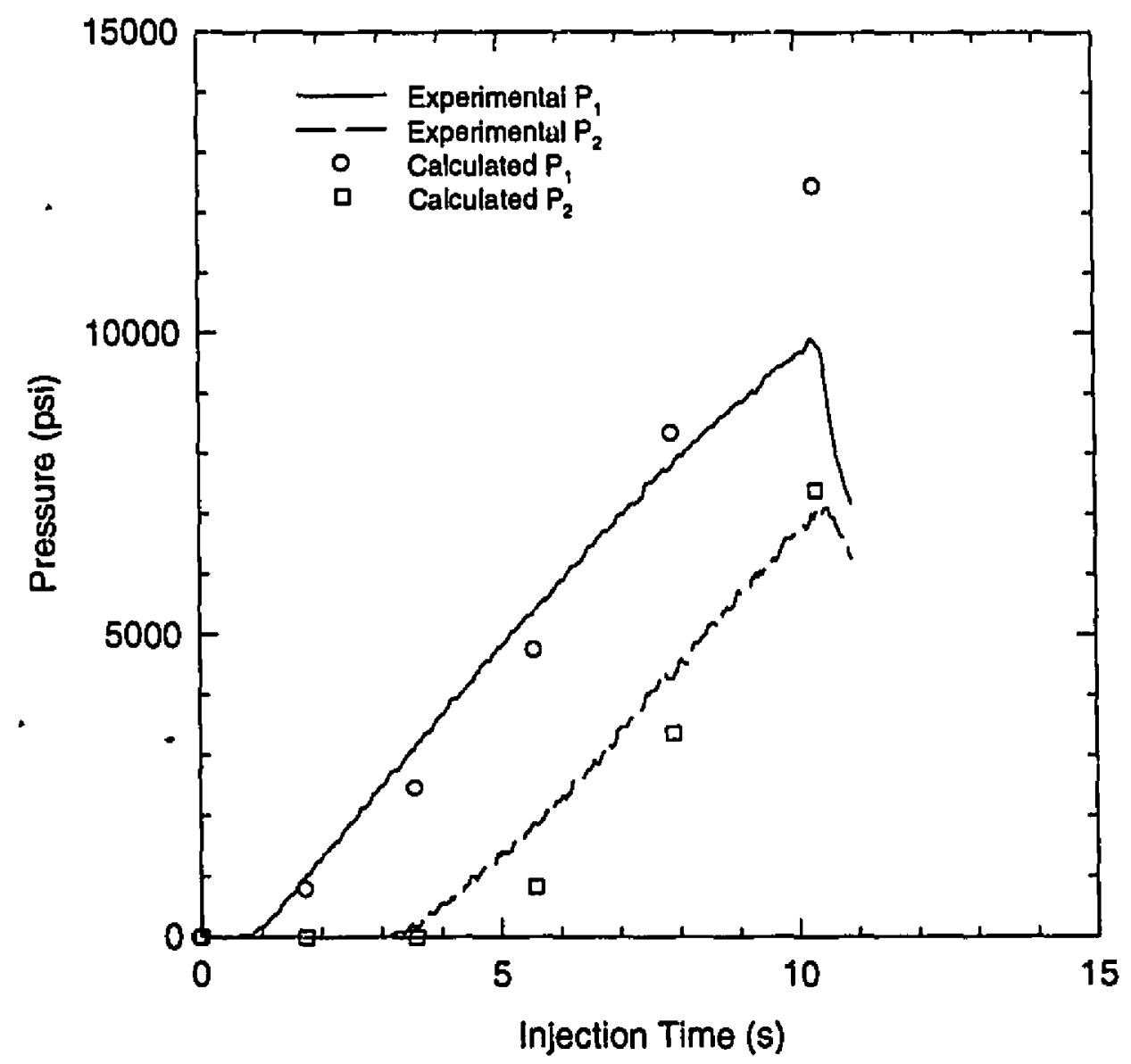

Fig. 10.3 Experimental and calculated pressures for $10 \%$ of maximum injection speed (Dowlex 2049). 
The pressures predicted by the simulation at the nodes near the positions of the pressure transducers are compared with measured values in figure 10.3. The agreement with experiments is very good for the pressure in the runner $\left(P_{1}\right)$ at the beginning of the filling phase, but the calculated value is about $25 \%$ above the measured value toward the end. In the cavity, the prediction is better toward the end of the filling phase but is of by as much as $40 \%$ at the beginning. No values were obtained experimentally or calculated for positions $P_{3}$ and $P_{4}$ because of the short shot ( $48 \%$ filled volume).

\subsubsection{20\% of Maximum Injection Speed}

The calculated how rate is given by equation 10.3:

$$
Q\left(\mathrm{~cm}^{3} / \mathrm{s}\right)=9 \pi(0.4455-0.0251 x)
$$

The simulation was done using the following how rate profile $(\alpha=0.74$, total injection time $=8$ sec.):

Table 10.2 Imposed variable flow rate for $20 \%$ of maximum injection speed (Dowlex 2049)

\begin{tabular}{|c|c|c|}
\hline Time Step & Flow rate $\left(\mathrm{cm}^{3} / \mathrm{s}\right)$ & Duration $(\mathbf{s})$ \\
\hline $\mathbf{1}$ & 9.0 & 0.8 \\
\hline 2 & 8.7 & 0.8 \\
\hline 3 & 8.2 & 0.8 \\
\hline 4 & 7.8 & 0.8 \\
\hline 5 & 7.4 & 0.8 \\
\hline 6 & 7.0 & 0.8 \\
\hline 7 & 6.6 & 0.8 \\
\hline 8 & 6.2 & 0.8 \\
\hline 9 & 5.8 & 0.8 \\
\hline 10 & 5.4 & 0.8 \\
\hline
\end{tabular}

The pressures obtained from the simulation are compared with measured values in figure 10.4. The agreement with experiment is again very good for the pressure in the runner $\left(P_{1}\right)$ at the beginning of the filling phase, but the calculated values differ from experiment values toward the end by abnut $25 \%$. In the cavity, the prediction is better toward the end of the filling phase but is 
off by as much as $40 \%$ at the beginning. $\Lambda$ gain, no data were oblained experimentally or calculated for positions $P_{3}$ and $P_{4}$ because of the short shot (55\% filled volume),

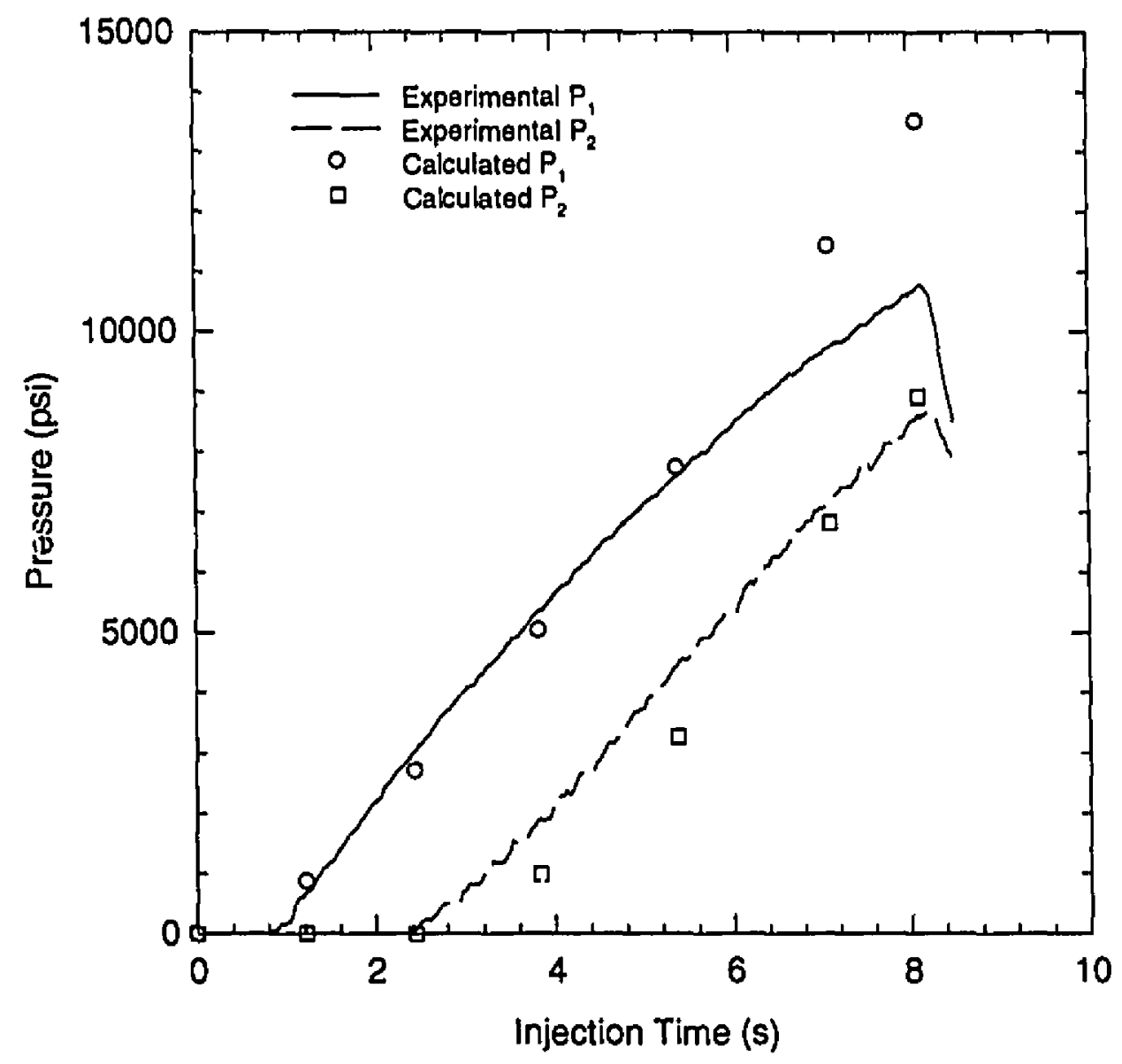

Fig. 10.4 Experimental and calculated pressures for $20 \%$ of maximum injection speed (Dowlex 2049).

\subsubsection{Simulations for Exxon 6706}

\subsubsection{20\% of Maximum Injection Speed}

The flow rate calculated from the screw position vs. time is given by:

$$
Q\left(\mathrm{~cm}^{3} / \mathrm{s}\right)=9 \pi(0.7027-0.0371 x)
$$


The following flow rate profile was used for the simulation $(\alpha=0.76$, total injection time $=9$ sec.):

Table 10.3 Imposed variable flow rate for $20 \%$ of maximum injection speed (Exxon 6706)

\begin{tabular}{|c|c|c|}
\hline Time Step & Flow rate $\left(\mathrm{cm}^{3} / \mathbf{s}\right)$ & Duration (s) \\
\hline $\mathbf{1}$ & 14.7 & 0.9 \\
\hline $\mathbf{2}$ & 14.0 & 0.9 \\
\hline $\mathbf{3}$ & 13.3 & 0.9 \\
\hline $\mathbf{4}$ & 12.6 & 0.9 \\
\hline $\mathbf{5}$ & 11.9 & 0.9 \\
\hline $\mathbf{6}$ & 11.1 & 0.9 \\
\hline $\mathbf{7}$ & 10.4 & 0.9 \\
\hline $\mathbf{8}$ & 9.7 & 0.9 \\
\hline $\mathbf{9}$ & 9.0 & 0.9 \\
\hline $\mathbf{1 0}$ & 8.3 & 0.9 \\
\hline
\end{tabular}

The pressures calculated using Plasfill are compared with experimental data in figure 10.5. There is good agreement in the runner $\left(P_{1}\right)$, but only at the beginning of the filling phase. Near the end, the calculated value of $P_{1}$ is $40 \%$ higher. However, the experimental curve for $P_{1}$ should not cross the one for $\mathrm{P}_{2}$; it is possible that the data in the runner are erroneous and that the real curve is closer to the predictions from Plasfill. Calculated pressures are too low for the first pressure transducer in the cavity $\left(\mathrm{P}_{2}\right)$ at the beginning of the filling phase and too high near the end (between 15 and $30 \%$ error). Data for $\mathrm{P}_{3}$ are also slightly high, except at the end. Finally, the predictions for $\mathrm{P}_{4}$ are near zero, in agreement with the measured pressure. 


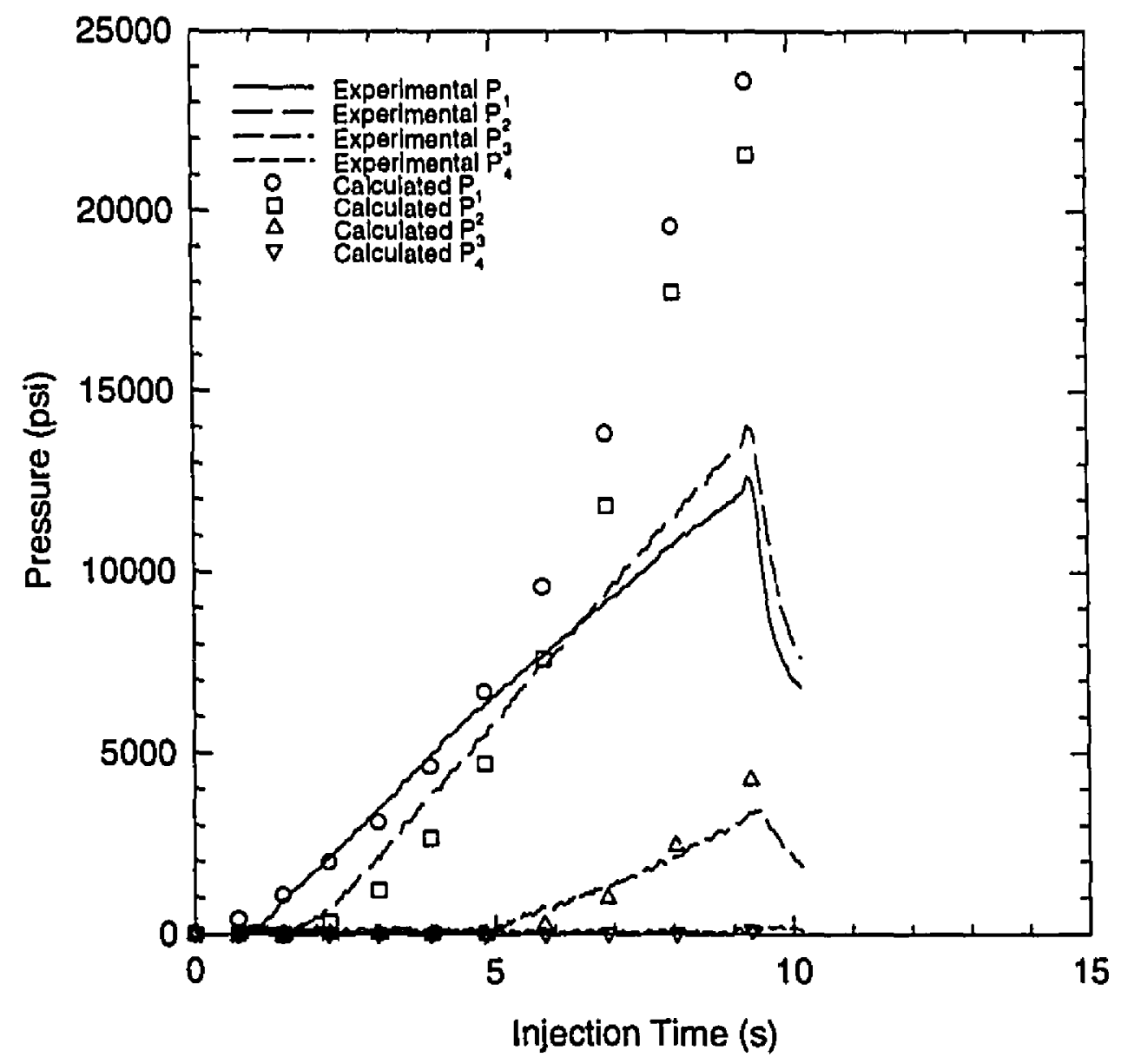

Fig. 10.5 Experimental and calculated pressures for $20 \%$ of maximum injection speed (Exxon 6706).

\subsubsection{30\% of Maximum Injection Speed}

We obtained the following calculated flow rate:

$$
Q\left(\mathrm{~cm}^{3} / \mathrm{s}\right)=9 \pi(3.152-0.878 x)
$$

The simulation was done using the flow rate profile shown in table $10.4(\alpha=0.83$, total injection time $=2 \mathrm{sec}$.): 
Table 10.4 Imposed variable flow rate for 30\% of maximum injection speed (1:xxon 67)6)

\begin{tabular}{|c|c|c|}
\hline Time Step & Flow rate $\left(\mathrm{cm}^{3} / \mathrm{s}\right)$ & Duration (s) \\
\hline $\mathbf{1}$ & 72 & 0.2 \\
\hline 2 & 68 & 0.2 \\
\hline 3 & 64 & 0.2 \\
\hline 4 & 60 & 0.2 \\
\hline 5 & 55 & 0.2 \\
\hline 6 & 51 & 0.2 \\
\hline 7 & 47 & 0.2 \\
\hline 8 & 43 & 0.2 \\
\hline $\mathbf{9}$ & 39 & 0.2 \\
\hline 10 & 35 & 0.2 \\
\hline
\end{tabular}

The pressures obtained by simulation are compared with experimental values in figure 10.6. The best agreement is with the first pressure transducer in the cavity $\left(\mathrm{P}_{2}\right)$, with a maximum error of $10 \%$ near the end of the filling phase. The calculated pressure in the runner $\left(P_{1}\right)$ is too high, with a maximum error of $25 \%$. As in the previous case, the experimental curve for $P_{1}$ should not cross the one for $P_{2}$, and it is possible that the data in the runner are erroneous. Data for $\mathrm{P}_{3}$ are well reproduced at the beginning of the filling phase, but a large error $(35 \%)$ is seen near the end. Finally, the predictions for $\mathrm{P}_{4}$ are mainly on the low side and do not reproduce the onset of the pressure reading. 


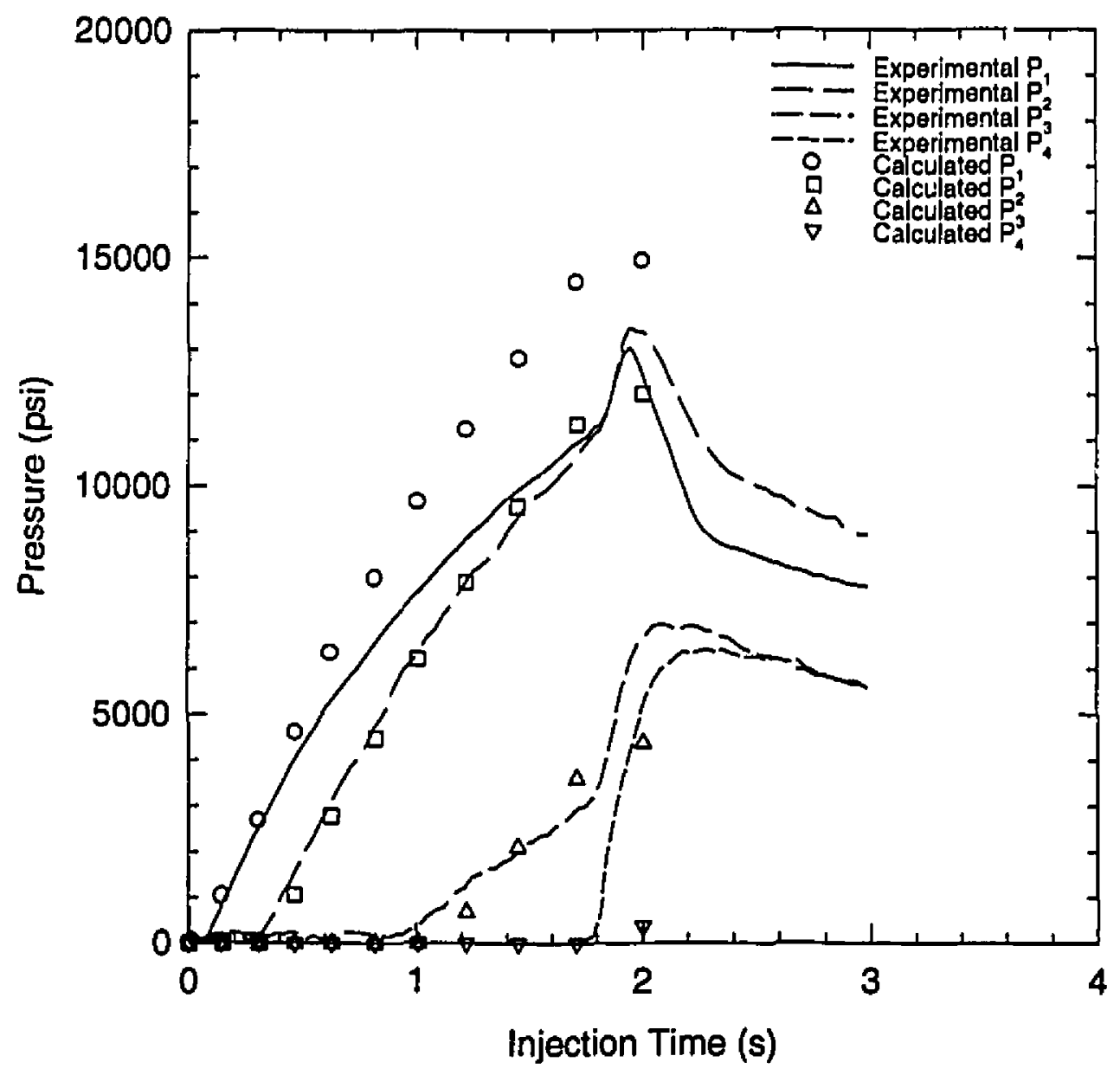

Fig. 10.6 Experimental and calculated pressures for $30 \%$ of maximum injection speed (Exxon 6706). 


\subsection{Critical Conditions for the Occurrence of Flow Marks}

The significant differences between calculated and measured pressures requires some comments. It was found that the Plasfill predictions could be as much as $40 \%$ higher than the culculated pressures, especially for short shots near the end of the filling phasc. First, when a short shot occurs, there is a mechanical limitation on the capacity of the injection molding machine to push the material inside the mold. However, in Plasfill the computation will go on as long as there is a free channel for the flow, even if this channel is just a few microns thick. Another possibility is the assumption that the material is incompressible, which could explain why the calculated pressure rises more than the experimental pressure since in reality the material is compressible. Iinally, Hele-Shaw flow is a simplified model of the filling phase, and its use is based on observations for normal injection molding conditions. In most of this work, we used unusual conditions to generate flow marks, such as low melt tensperature, long injection time or slow injection speeds. Because of the uncertainties in the calculated pressures, the following discussion about the critical shear stress for the onset of flow marks should be considered to be speculative.

In Appendix B, the calculated distributions of shear stress and shear rate at the wall for the following four conditions are shown:

1) Dowlex $2049,10 \%$ of maximum injection speed, $30 \%$ fill

2) Dowlex 2049, 20\% of maximum injection speed, $30 \%$ fill

3) Exxon 6706, 20\% of maximum injection speed, 50\% fill

4) Exxon $6706,30 \%$ of maximum injection speed, $50 \%$ fill

For each resin, at the lower injection speed the plate is free of surface defects while the higher injection speed is where flow marks first appear. In the second case, the percentage of fill represents the fraction of the plate covered with flow marks. Conditions 1 and 2 (Dowlex 2049) clearly show that the wall shear stress, and even more so the wall shear rate, are higher in the casc where flow marks appear. The same conclusion can be drawn for Exxon 6706 (conditions 3 and 4) except that the wall shear stresses differ as much as wall shear rates.

In order to quantify the level of wall shear stress and wall shear rate at the flow front, for every percentage of fill we chose a node on the flow front and examined the calculated values of wall 
shear stress and wall shear rate for each condition. The results are shown in figures 10.7 and 10.8 for Dowlex 2049 and in figures 10.9 and 10.10 for Exxon 6706.

For Dowlex 2049, the wall shear stress and the wall shear rate at the flow front are higher in the case where flow marks are observed. From these results, the critical shear stress for the onset of now marks is thought to be around $0.25 \mathrm{MPa}$. For Exxon 6706, a greater difference is observed between the wall shear stresses for the "no flow mark" and the "flow marks" conditions. The critical shear stress for the onset of flow marks is around $0.28 \mathrm{MPa}$, very close to that for Dowlex 2049. However, the wall shear rate is much higher for the "no flow mark" condition. This result is surprising, considering the fact that the injection is much faster in the second case than in the first onc ( 2 sec. vs. 9 sec. total injection time), and should result in higher wall shear rates. However, one possible explanation is the difference in temperature, which is lower for the first case where the injection time is longer and the resin has more time to cool down. This lower temperature results in a higher viscosity, so even if the shear stress is lower, the effective shear rate can be much higher. 


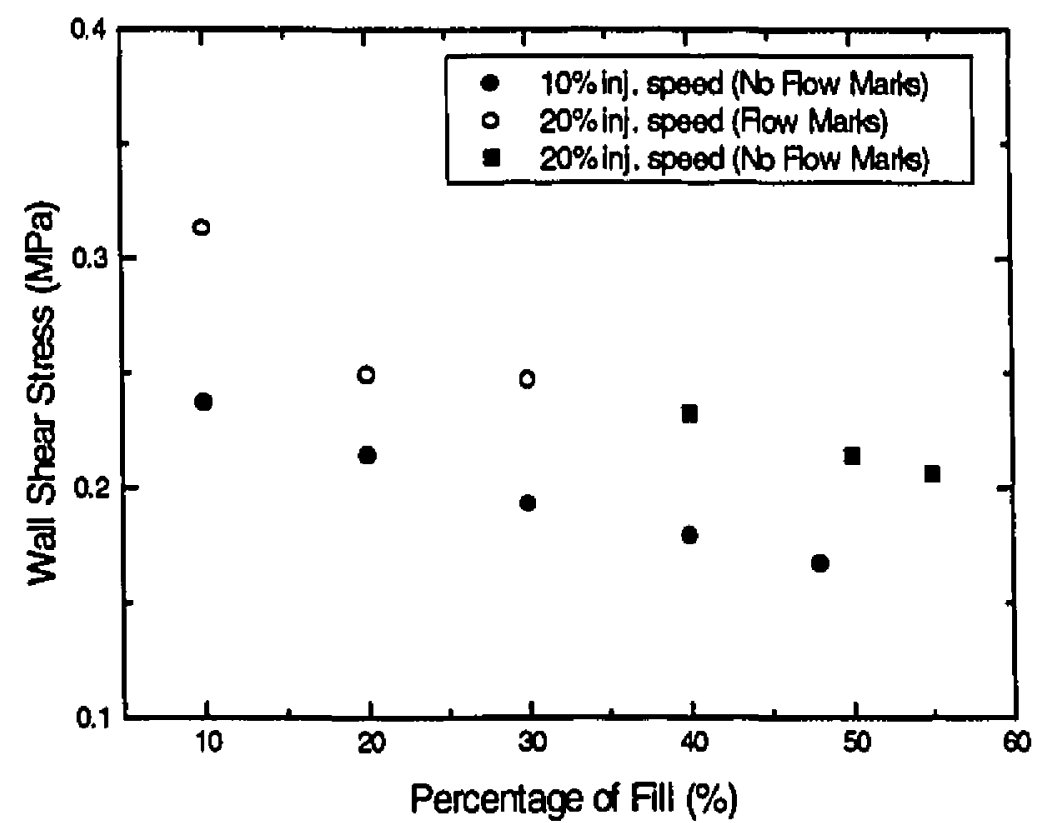

Fig. 10.7 Wall shear stress at the fow front for Dowlex 2049.

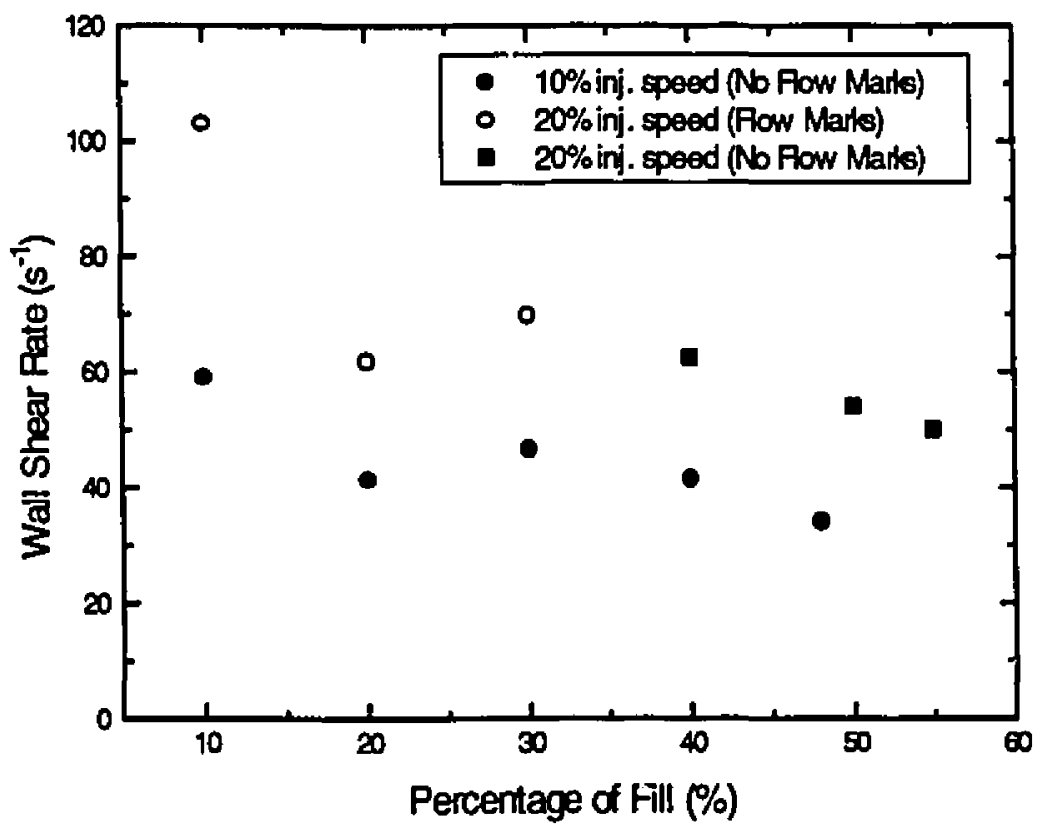

Fig. 10.8 Wall shear rate at the flow front for Dowlex 2049. 


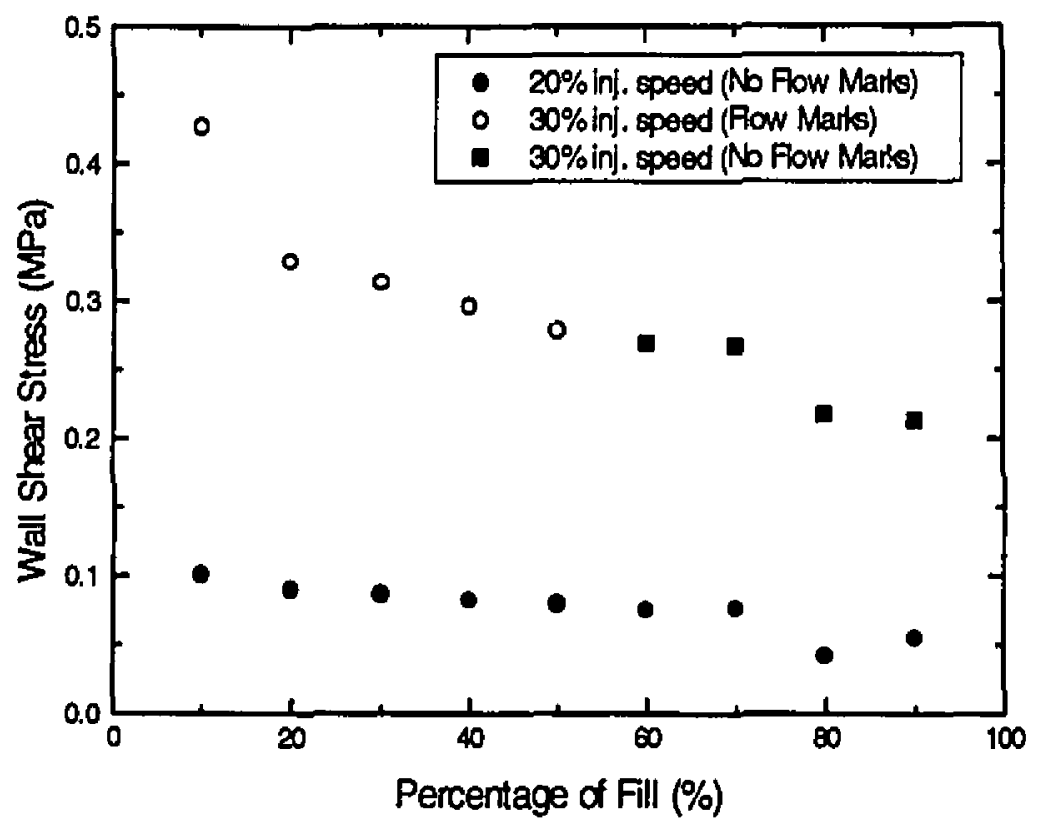

Fig. 10.9 Wall shear stress at the flow front for Exxon 6706.

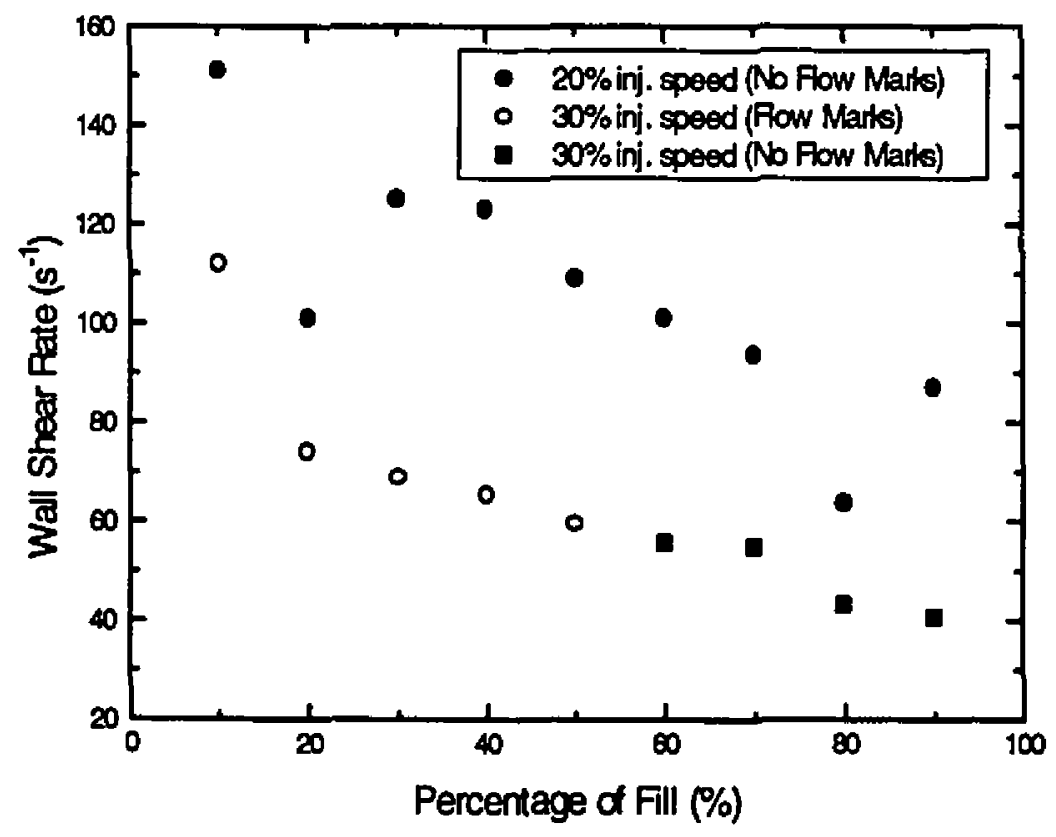

Fig. 10.10 Wall shear rate at the flow front for Exxon 6706. 


\section{Proposed Mechanism for Alternate Flow Mark Formation}

In injection molding, hot melt from the center core reaches the cold walls through a complex shear and elongational flow. At the wall, the melt solidifies, creating a highly oriented skin [53]. The highest stress is known to be at the dynamic, three-phase contact line, whereas the center of the flow front is a stagnation point.

We believe that three main factors are involved in flow mark formation: the surface cohesive strength of the semi-solidified polymer, the adhesion between the solid layer and the mold, and the high shear stress in the melt as it fills the mold. If the shear stress at the dynamic three-phase contact line exceeds the combined effects of the polymer-mold adhesion and the cohesive strength of the material, the solidified layer near the flow front can be dragged across the surface of the mold and thorn apart at the same time. If the stress is sufficiently released by this process, adhesion is reestablished. In this case, the mechanism of flow mark formation is a combination of "stick" and "slip-stretch" of the semi-solidified layer. The reason flow marks are believed to occur in the solid state is that the torn structure would "heal" if the polymer were in the melt state.

Since flow marks on the two sides of a plate are out of phase, i.c. since there is a displacement by one half of the mark spacing, this phenomenon does not occur simultaneously on the upper and lower walls of the plate. Yokoi [22] has observed that when boundary conditions between the upper and lower cavity walls instantaneously change, for example after a small step in the cavity, for a brief instant the melt lower surface has no resistance and flows momentarily more casily in the cavity region. The flow then starts swirling due to the unbalanced upper and lower flow velocities, resulting in an unsymmetrical flow pattern. It is believed that this phenomenon often occurs during molding processes, but it was not visualized prior to Yokoi's work. This phenomenon, coupled to the "stick" and "slip-stretch" of the semi-solidified layer, would explain the defect pattern seen on the molded plates.

This mechanism is very similar to the one described by Hobbs [24] in his paper on the development of flow instabilities during the injection of multicomponent resins: "During molding it 
appears that slip occurs on one face of the mold. Most likely, this happens at or near the point where the flow front first contacts the mold surface, since this is the region of greatest stress. High frequency ripples develop as the melt front chatters across the surface. This slip produces a distortion in the velocity gradient across the flow channel and causes the flow front to oscillate back and forth across the two faces of the mold. [24]". He also mentioned that the structures that are formed during this process are strikingly similar to the "waves of detachment" (Schallamach waves) observed when rubbers are dragged over various substrates $[54,55]$. The irregular pattern that we observed is similar to the Schallamach "waves of detachment", and their origin could be related. Accordingly to Hobbs [24], such waves could be reproduced in BPAPC/ABS melts by sliding a partially molten rod across a cold, polished metal surface as it solidifies. We also obtained such waves by sliding a cold metal plate over a partially molten HDPE part as it solidifies (figures 11.1 and 11.2).

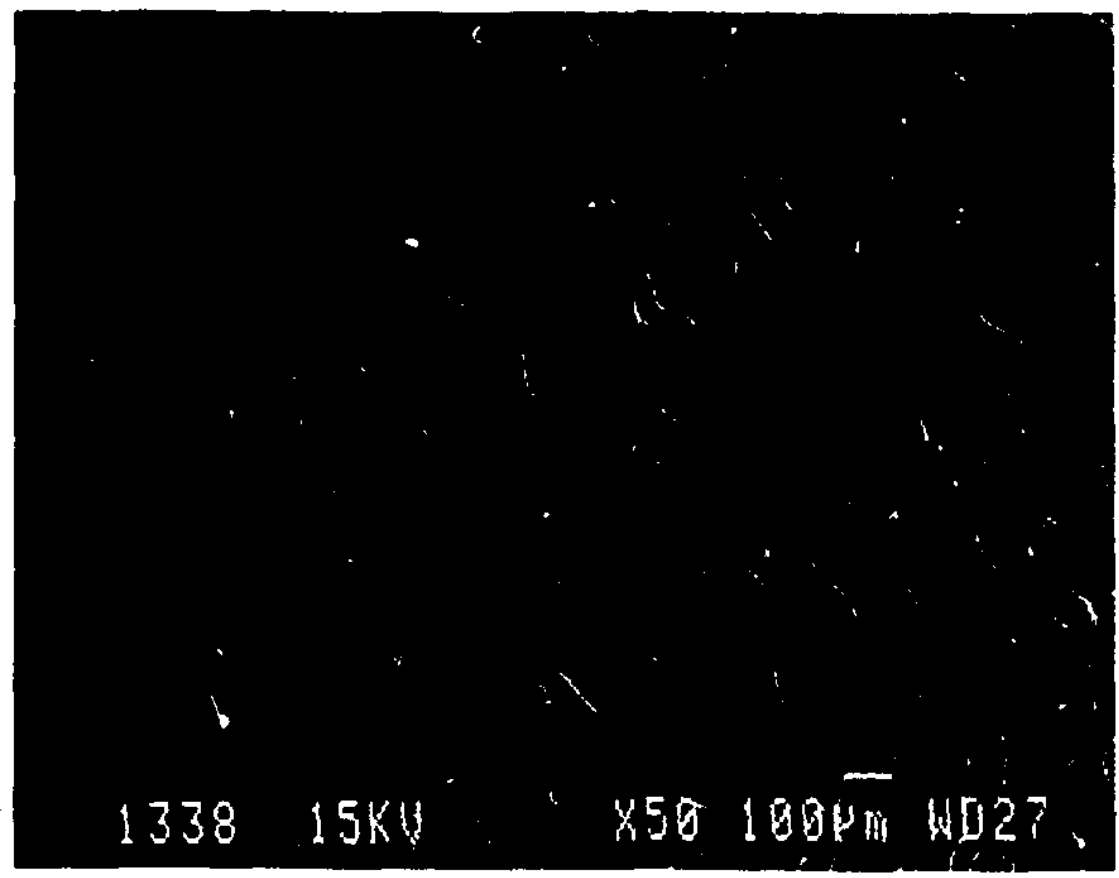

Fig. 11.1 Waves created on a partially molten HDPE plate (50X). 


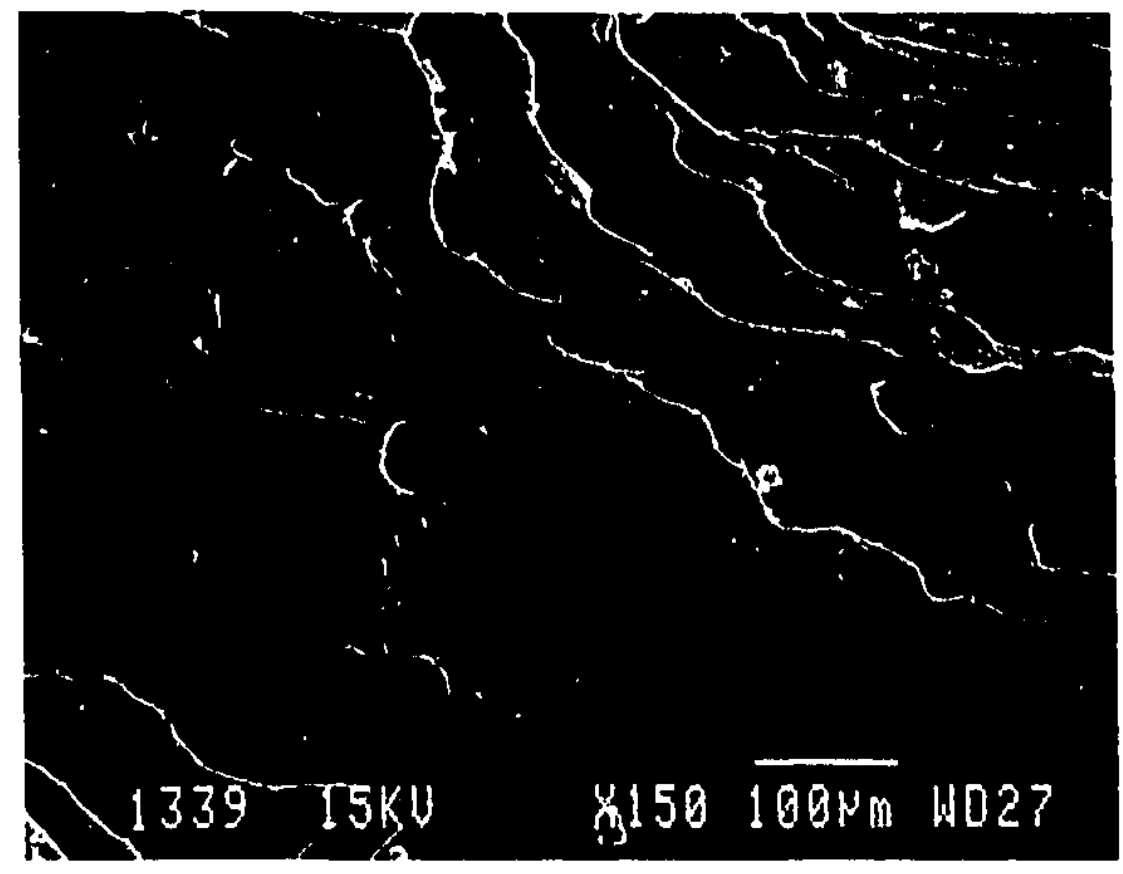

Fig. 11.2 Waves created on a partially molten HDPE plate (detail, 150X). 


\section{Recommendations for Future Work}

In view of the uncertainties still remaining regarding the mechanism of flow mark formation, some experiments should be repeated with improved control of experimental conditions. We first suggest the use of a mold with the same surface roughness on both walls, since flow mark formation is surface-related and probably sensitive to surface conditions. Additional temperature sensors should be installed in the mold. SENSOTRONTM sensors would be particularly appropriate, since temperature and pressure can be obtained simultaneously with a single device. These could be placed on the fixed part of the mold, opposite the ejector pins side. This way, pressure measurements could be obtained at both walls, and any difference between these readings could be recorded and analyzed.

Once temperatures in the mold are measured, validation of the heat transfer coefficient in the simulation can be performed. A combined study of shear stress / shear rate and solid layer evolution would shed some light on the conditions for flow marks occurrence. It would also be interesting to repeat injection molding experiments with interruption of the molding cycle, to observe how early the flow marks are generated during filling. Finally, the use of a mold with a durable Teflon ${ }^{\mathrm{TM}}$ coating would reveal the role of surface adhesion on the surface appearance of the finished part.

Since the fountain region of the flow front is lost in the Hele-Shaw approximation for the filling of thin cavities, a separate stress analysis in the thickness direction should be performed, in order to evaluate the magnitude of the shear stress at the three-phase dynamic contact line. The software FIDAP would be an appropriate tool to perform this analysis. Since it can also incorporate simple slip models, the effect of slip could also be investigated. 


\section{Conclusions}

In this work, it was fol!nd that injection speed is the controlling factor for llow mark generation during the injection molding of linear polyethylene. From the Teflon ${ }^{\mathrm{TM}}$ coating experiments, it was found that there is no obvious relationship between wall slip and the occurrence of flow marks. Microscopic observation of molded surfaces suggested instead that the mechanism of flow mark formation is a combination of "stick" and "slip-stretch" of the semi-solidified layer. Through computer simulation of the filling phase, it was possible to relate the occurrence of llow marks to a critical shear stress, which was similar for an LLDPE extrusion grade resin (0.25 $\left.\mathrm{MP}^{3} \mathrm{a}\right)$ and for an HDPE injection grade resin $(0.28 \mathrm{MPa})$. Further work is needed to verify the validity of the proposed mechanism of alternate flow mark formation. We also demonstrated the feasibility of incorporating a wall slip model into the $2.5 \mathrm{D}$ computer simulation of the injection molding process. 


\section{References}

[1] Kennedy, P., "["low Analysis of Injection Molds", Hanser Publishers, Munich Vienna New York, 1995

12) Agassant J.1 ., Avenas P., Sergent J.Ph., Carreau P.J., "Polymer Processing - Principles and Modeling", Hanser Publisheis, Munich Vienna New York, 1991

[3| Benbow J.J., Charley R.B., Lamb P., "Unstable Flow of Molten Polymers", Nature, 192, p. 223, 1961

[4] Hatzikiriakos S.G., Dealy J.M., "Role of Slip and Fracture in the Oscillating Flow of HDPI: in a Capillary", J. Rheol., 36(5), p. 845-884, 1992

[5] Hatrikiriakos S.G., Dealy J.M., "Wall Slip of Molten High Density Polyethylene. I. Sliding Plate Rheometer Studies", J. Rheol, 35(4), p. 497-523, 1991

[6] Hatzikiriakos S.G., Dealy J.M., "Wall Slip of Molten High Density Polyethylene. II. Capillary Rheometer Studies", J. Rheol, 36(4), p. 703-741, 1992

[7] Hatzikiriakos S.G., Stewart C.W., Dealy J.M., "Effect of Surface Coatings on Wall Slip of LLDPE", Intern. Polymer Processing VIII, Hanser Publishers, Munich, p. 30-35, 1993

[8] Hatrikiriakos S.G., "The Onset of Wall Slip and Sharkskin Melt Fracture In Capillary Flow", Polymer Engineering and Science, 34(19), p. 1441-1449, 1994

[9] Piau J.M., El Kissi N., Tremblay, B., "Influence of Upstream Instabilities and Wall Slip on Melt Fracture and Sharkskin Phenomena during Silicones Extrusion through Orifice Dies", J. Non-Newt. Fluid Mech., 34, p. 145-180, 1990

[10] Tremblay B., "Sharkskin Defects of Polymer Melts: The Role of Cohesion and Adhesion", J. Rheol., 35(6), p. 985-998, 1991

[11] El Kissi N., Piau J.M., "Adhesion of Linear Low Density Polyethylene for Flow Regimes with Sharkskin", J. Rheol., 38(5), p. 1447, 1994

[12] Yokoi H., Nagami S., Kawasaki A., Murata Y., "Visual Analyses of Flow Marks Generation Process Using Glass-Inserted Mold - Part I. Micro-Grooved Flow Marks", ANTEC '94 - Society of Plastic Engineers, p. 368-372, 1994

[13] Yokoi H., "Flow-Marks Visualization", PPS $10^{\text {th }}$ Annual Conference Presentation, p. 171-172, 1994 
[14] Chang M.C.O., "On the Siudy of Surfice Defects in the Injection Molding of Rubber-Modified Thermoplastics". ANTEC '94 - Society of Plastic Engineers, p. 361)367,1994

[15] Kamal M.R., Goyal S.K. L'hu l:., "Simulation of Injertion Mold liilling of Viscoelastic Polymer with Fountain Flow", AIChE Jourral, 34(1), p. 94-1166, 1988

[16] Chu E., "A Comprehensive Integraled Compuler Simuiation of the Injection Molding Process for Thermoplastics", Ph. D. Thesis, McGill Univ., Montreal, 1992

[17] Schowalter W.R., "The Behavior of Complex liluids at Solid Boundaries", J. NomNewt. Fluid Mech., 29, p. 25-36, 1988

[18] Poslinski A., GE Corporate Research \& Development,private communication, 1995

[19] Yokoi H., Hayashi T., Morikita N., Toda K., "Direct Observation of Jelling Phenomena under a High Injection Pressure by Using a Prismatic-Cilass Inserted Mold". ANTEC '88 - Society of Plastic Engineers, p. 329-333, 1988

[20] Yokoi H., Nagami S., Kawasaki A., Murata Y., "Visual Analyses of lilow Marks Generation Process Using Glass-Inserted Mold - Part II. Synchronous Flow Marks with Same Phases on Both Top and Bottom Surfaces of Molded Samples", ANTEC '94 Society of Plastic Engineers, p. 829-832, 1994

[21] Yokoi H., Inagaki Y., "Dynamic Visualization of Cavity lïlling Process along Thickness Direction Using a Laser-Light-Sheet Technique", ANTEC '92 - Society of Plastic Engineers, p. 457-460, 1992

[22] Yokoi H., Kamata S., Kanematsu T., "Visual Observation of Three-1)imensional Melt Flow Inside a Mold Cavity by Gate-Magnetization Mcthod", ANTEC '91 - Society of Plastic Engineers, p. 358-362, 1991

[23] Hamada H., Tsunasawa H., "Heterogeneous Structures through Thickness Direction of Polymer Alloy Injection Moldings", ANTEC '95 - Society of Plastic Engineers, p. 722 727,1995

[24] Hobbs S.Y., "The Development of Flow Instabilities During the Injection Molding of Multicomponent Resins", Folym. Eng. Sci., to be published

[25] Tadmor Z., Gogos C., "Principles oí Polymer Processing", John Wiley \& Sons, New York, 1979

[26] Kwon T.H., Park J.B., "Finite Element Analysis Modeling of Powder Injection Molding Filling Process Including Yield Stress and Slip Phenomena", Polym. Eng. Sci., 35(9), p. 741-753, 1995 
[27] Dealy J.M., Wissbrun K.I'., "Melt Rhcology and its Role in Plastics Processing", Van Nostrand Reinhold, New York, 1990

[28) Kalika D.S., Denn M.M., "Wall Slip and Extrudate Distorsion in Linear Low-Density Polycthylene", J. Rheol., 31(8), p. 815-834, 1987

[29] Hatzikiriakos S.G., Dealy J.M., "Effect of Interfacial Conditions on Wall Slip And Sharkskin Melt Fracture of HIDPE", Intern. Polymer Processing VIII, Hanser Publishers, Munich, p. 36-43, 1993

[30] Ramamurthy A.V., "Wall Slip in Viscous Fluids and Influence of Materials of Construction", J. Rheol., 30(2), p. 337, 1986

[31] J im F.J., Schowalter W.R., "Wall Slip of Narrow Molecular Weight Distribution Polybutadienes", J. Rheol., 33(8), p. 1359, 1989

[32] Stewart C.W., Dealy J.M., "Technical Note: New Information on the Mechanism of $\Lambda$ ction of the Adhesion Promoter Reported in "Wall Slip of Molten High Density Polyethylene [J. Rheol. 35, 497 (1991)]", J. Rheol., 36(5), p. 967-969, 1992

[33] M.L. Sentmanat, "The Effect of Pressure on the Wall Slip of Linear Polyethylene", Ph. D. Thesis, McGill Univ., Montreal, 1995

[34] M.L. Sentmanat, J.M. Dealy, "Some Factors Affecting Capillary Rheometer Performance", ANTEC ‘95 - Society of Plastic Engineers, p.1068- 1072, 1995

[35] H. Lobo, C. Cohen, "Measurement of Thermal Conductivity of Polymer Melts by the Line-Source Method", Polym. Eng. Sci., 30(2), p. 65-70, 1990

[36] Encyclopedia of Materials Science and Engineering, MIT Press, Cambridge Mass., Vol. 5, p.3772, 1986

[37] "New Product Showcase: Tough Direct-Contact Sensors", Injection Molding Magazine, 2(10), p.93 (1994)

[38] "Plasfill User's Manual", National Research Council Canada, Industrial Materials Institute, January 1995

[39] Chu E., Kamal M.R., Goyal S.K., "A Computer Simulation of the Injection Molding Process Including Filling, Packing, and Solidification", ANTEC' 89 - Society of Plastic Engineers, p. 344-347, 1989

[40] Gao D.M., Nguyen K.T., Girard P., Salloum G., "Numerical Simulation of the Sequential Filling in Injection Molding Process", ANTEC '94 - Society of Plastic Engineers, p. 554-558, 1994 
[41] Gao D.M., Nguyen K.T., Girard P., Salloum G., "liffect of Variable Injection Speed in Injection Mould Filling ", ANTEC' 94 - Society of Plastic Engineers, p. 712-715, 1994

[42] Nguyen K.T., Gao D.M., "Non-Isothermal Analysis of the lïlling Stage in the Injection Molding Process", Advances in Computer-Aided Engineering (CAE) of Polymer Processing, ASME, MD-Vol. 49/HTD-Vol. 283, p. 89-102, 1994

[43] Hirt C.W., Nichols B.D., "Volume of Fluid (VOl') Method for the Dynamics of lirec Boundaries", Journal of Computational Physics, 39, p. 201-225, 1981

[44] Tucker Charles L., "Fundamentals of Computer Modeling for Polymer Processing", Hanser Publishers, Munich, New York, 1989

[45] Hatzikiriakos S.G., "A Slip Model for Linear Polymers Based on Adhesive liailure", Intern. Polymer Processing VIII, Hansers Publishers, Munich, p. 135-142, 1993

[46] Keunings R., "An Algorithm for the Simulation of Transient Viscoelastic I'lows with Free Surfaces", Journal of Computational Physics, 62, p. 199-220, 1986

[47] Bagley, E.B., "End Corrections in the Capillary Flow of Polyethylene", J. Appl. Phys., 28, p. 624, 1957

[48] Sentmanat M.L., private communication, 1995

[49] Hatzikiriakos S.G., Hong P., Ho W., Stewart C.W., "The Effect of Tellon Coatings in Polyethylene Capillary Extrusion", J. Appl. Polym. Sci., 55, p. 595-603, 1995

[50] Fassett J., "Thin Wall Molding: Differences in Processing over Standard Injection Molding", ANTEC '95 - Society of Plastic Engineers, p. 430-433, 1995

[51] Kamal M.R., Mutel A.T., Salloum G., Garcia-Rejon A., "Heat Transfer Measurements at the Mold Surface During Injection Molding of Thermplastics Melts", ANTEC '91 - Society of Plastic Engineers, p.483-487, 1991

[52] Titomanlio G., Speranza V., Brucato V., "On the Simulation of Thermoplastic Injection Molding Process", Intern. Polymer Processing $X$, Hanser Publishers, Munich, p. $55-61,1995$

[53] Mavridis H., Hrymak A.N., Vlachopoulos J., "Mathematical Modeling of Injection Mold Filling: A Review", Adv. Polym. Techn., 6(4), p. 457-466, 1986

[54] Schallamach A., "How does Rubber Slide?", Wear, 17, p.301-312, 1971

[55] Roberts A.D., "Adhesion and Friction of Elastomers", Rubber Chem. Tech., 54(5), p.944-962, 1981 


\section{Appendix A : Geometry and Meshing of the Plate Mold}

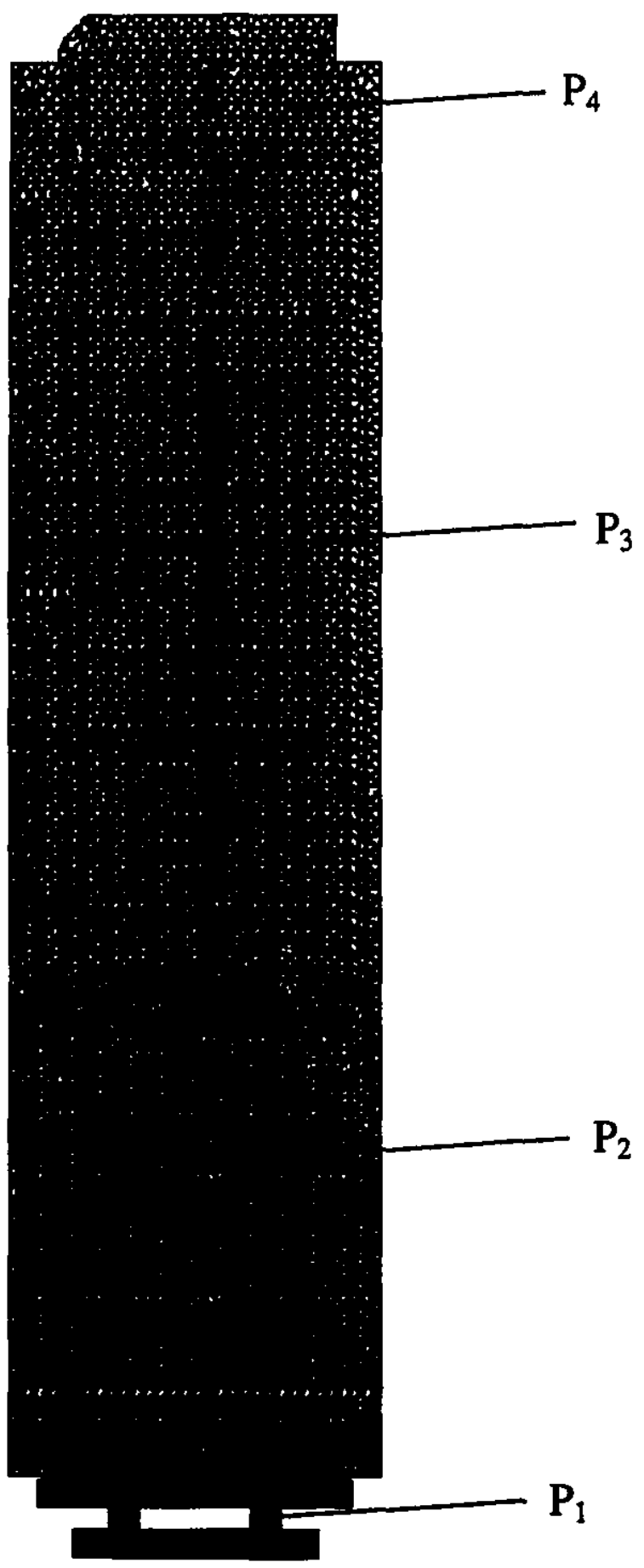

Positions of the four pressure transducers are shown. 


\section{Appendix B : Results from Plasfill Simulations}

Fig. B1 Dowlex 2049, 10\% of Maximum Injection Speed, 30\% Iïll, Wall Shear Stress (I'a)

Fig. B2 Dowlex 2049, 20\% of Maximum Injection Speed, 30\% Fill, Wall Shcar Stress ( $\left.P_{a}\right)$

Fig. B3 Dowlex 2049, 10\% of Maximum Injection Speed, 30\% Fill, Wall Shear Rate $\left(s^{-1}\right)$

Fig. B4 Dowlex 2049, 20\% of Maximum Injection Speed, 30\% Fill, Wall Shear Rate $\left(s^{* 1}\right)$

Fig. B5 Exxon 6706, 20\% of Maximum Injection Speed, 50\% Iïll, Wall Shear Stress (Pa)

Fig. B6 Exxon 6706, 30\% of Maximum Injection Speed, 50\% Fill, Wall Shear Stress (Pa)

Fig. B7 Exxon 6706, 20\% of Maximum Injection Specd, 50\% Fill, Wall Shear Rate $\left(s^{-1}\right)$

Fig. B8 Exxon 6706, 30\% of Maximum Injection Speed, 50\% Fill, Wall Shear Rate $\left(s^{-1}\right)$ 


\section{U_S_S(Pa)}

$\mathrm{Max}=+5.500 \mathrm{E}+05$

$\operatorname{Min}=+1.000 \mathrm{E}-03$

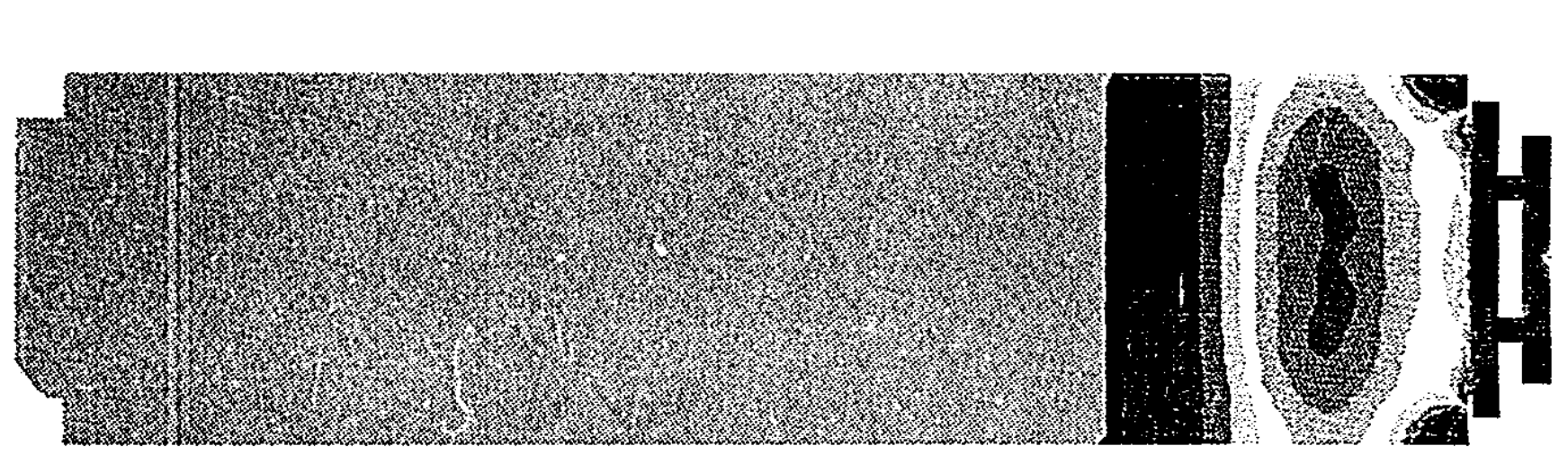

$+5.500 \mathrm{E}+05$

$+5.156 \mathrm{E}+05$

$+4.813 \mathrm{E}+05$

$+4.469 \mathrm{E}+05$

$+4.125 \mathrm{E}+05$

$+3.781 \mathrm{E}+05$

$+3.438 \mathrm{E}+05$

$+3.094 \mathrm{E}+05$

$+2.750 \mathrm{E}+05$

$+2.406 \mathrm{E}+05$

$+2.063 \mathrm{E}+05$

$+1.719 \mathrm{E}+05$

$+1.375 \mathrm{E}+05$

$+1.031 \mathrm{E}+05$

$+6.875 \mathrm{E}+04$

$+3.438 \mathrm{E}+04$

$+1.000 \mathrm{E}-03$

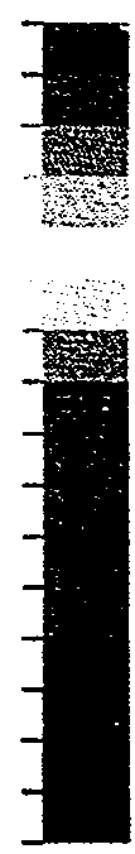

Fig. B1 


\section{U_S_S(Pa)}

Max $=+5.500 \mathrm{E}+05$

$\operatorname{Min}=+1.000 \mathrm{E}-03$
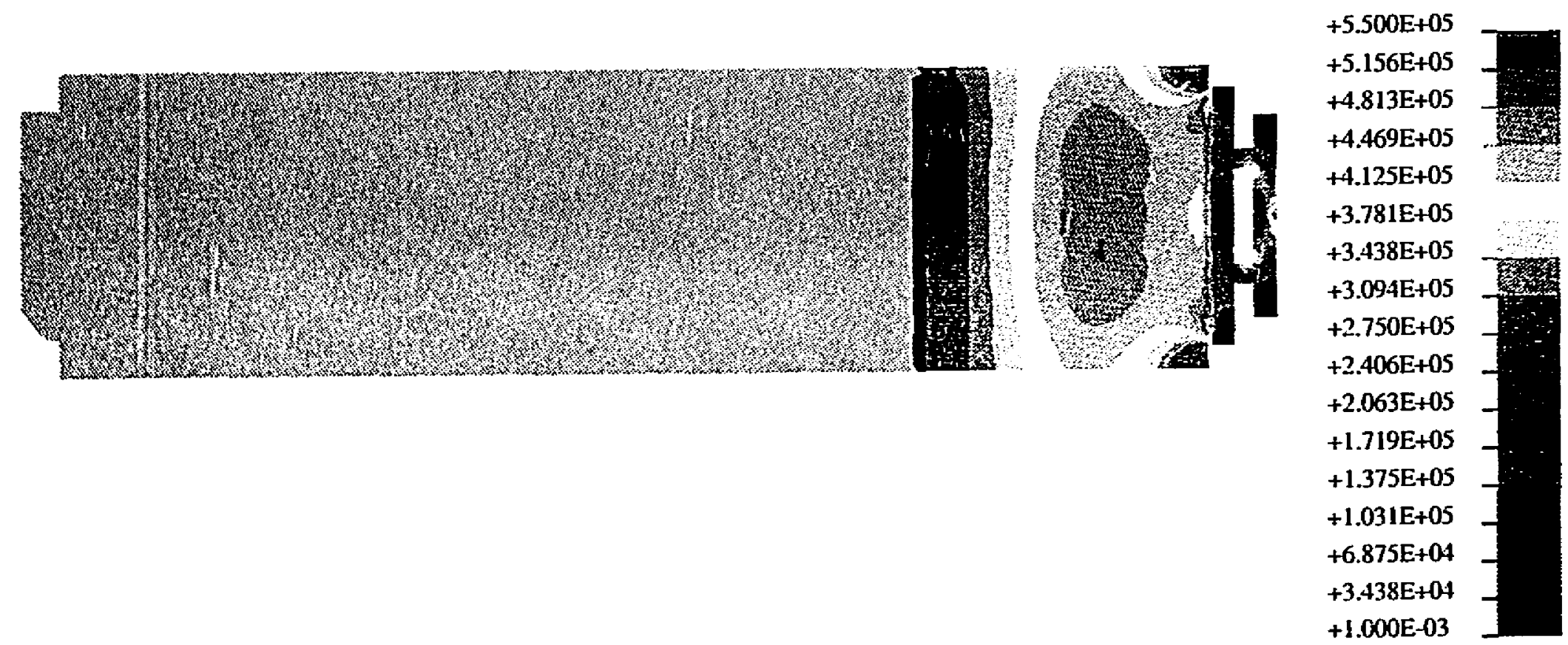

Fig. B2 
U_S_R

$\operatorname{Max}=+9.000 \mathrm{E}+01$

$\mathrm{Min}=+1.000 \mathrm{E}-04$
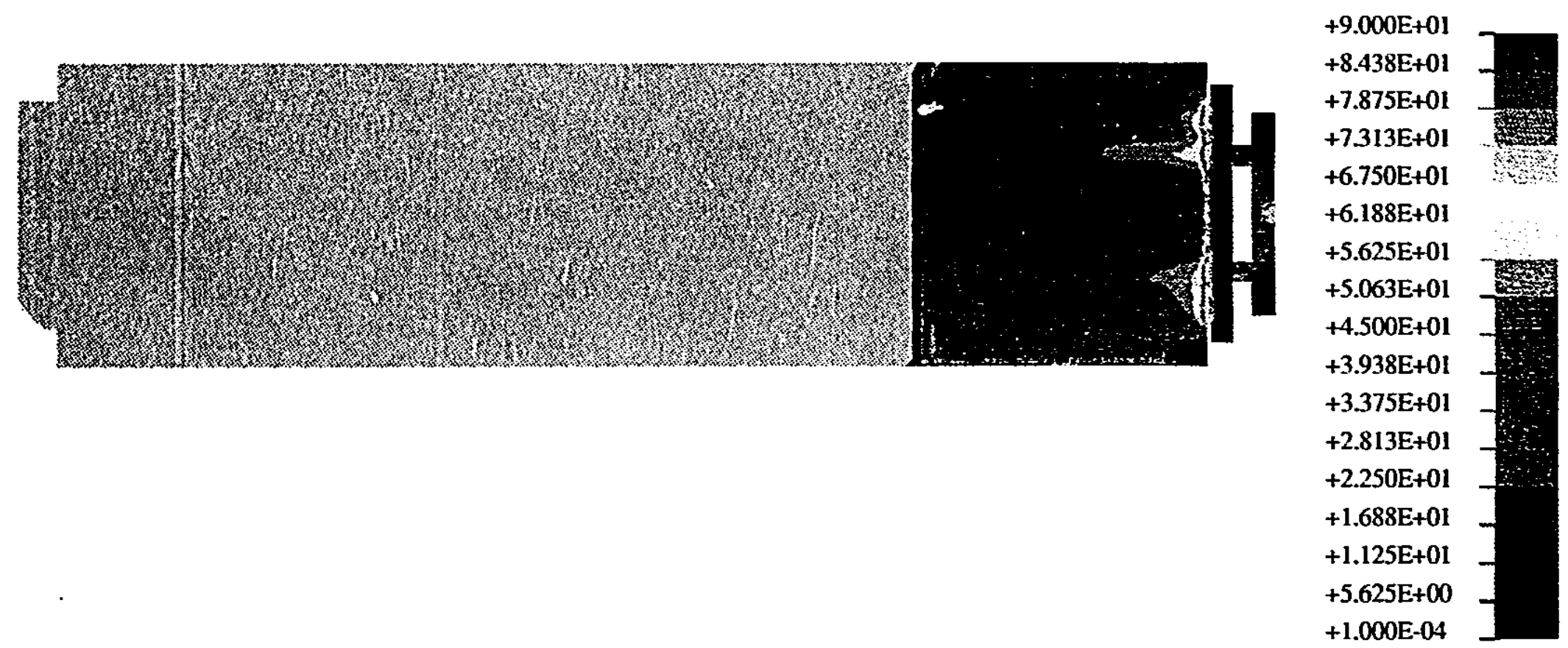

Fig. B3 


\section{U_S_R}

$\operatorname{Max}=+9.000 \mathrm{E}+01$

$\mathrm{Min}=+1.000 \mathrm{E}-04$

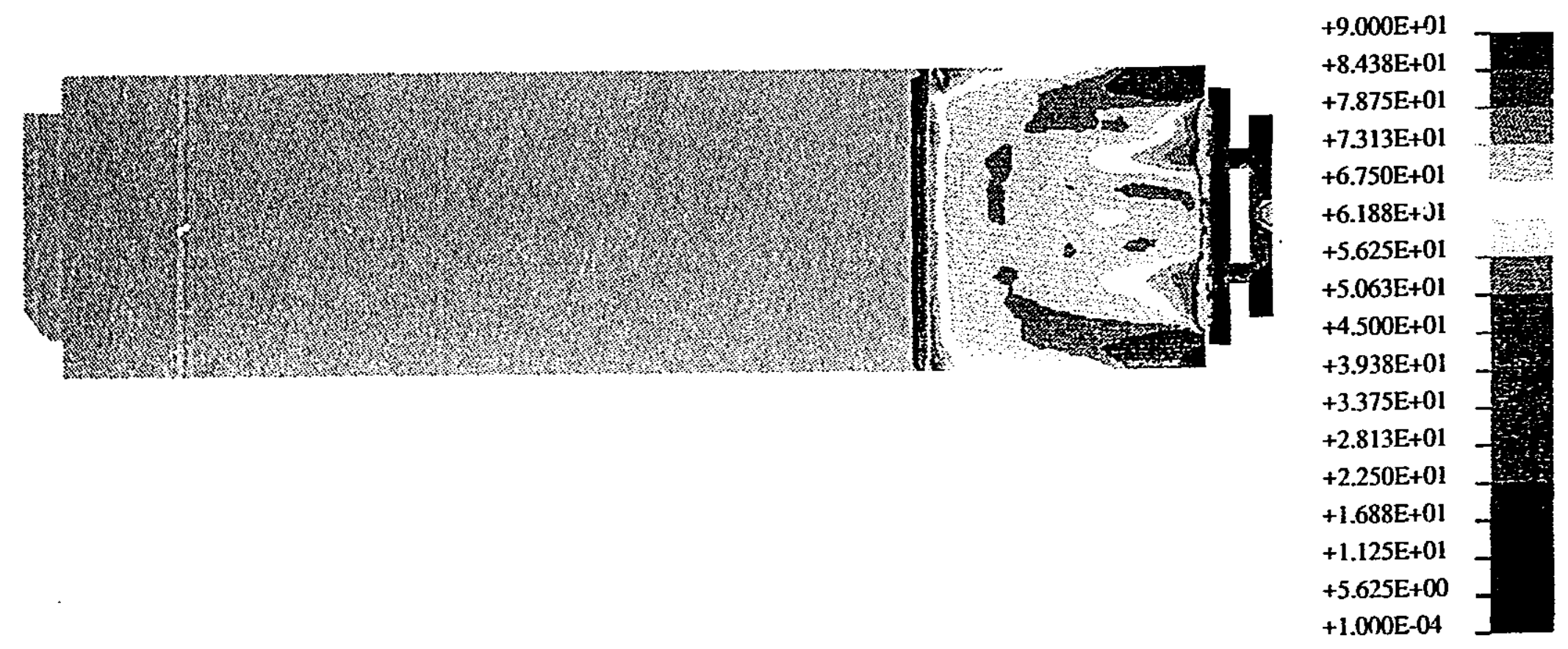

Fig. B4 


\section{U_S_S(Pa)}

$M a x=+4.500 E+05$

$\mathrm{Min}=+1.000 \mathrm{E}-03$

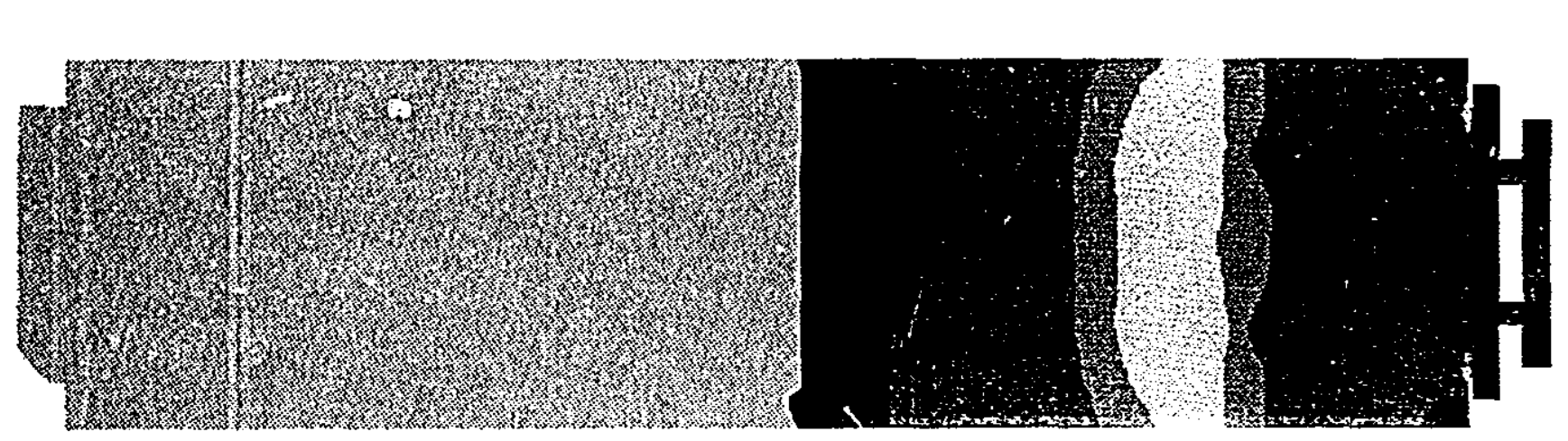

$+4.500 \mathrm{E}+05$ $+4.219 \mathrm{E}+05$

$+3.938 \mathrm{E}+05$

$+3.656 \mathrm{E}+05$

$+3.375 \mathrm{E}+05$

$+3.094 \mathrm{E}+05$

$+2.813 \mathrm{E}+05$

$+2.531 \mathrm{E}+05$

$+2.250 \mathrm{E}+05$

$+1.969 \mathrm{E}+05$

$+1.688 \mathrm{E}+05$

$+1.406 \mathrm{E}+05$

$+1.125 \mathrm{E}+05$

$+8.438 \mathrm{E}+04$ $+5.625 \mathrm{E}+04$

$+2.813 \mathrm{E}+04$

$+1.000 \mathrm{E}-03$

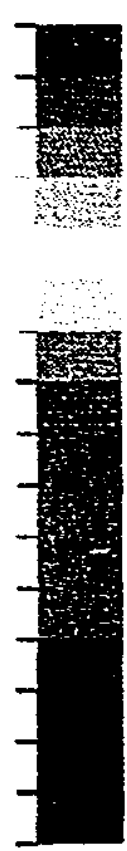

Fig. B5 


\section{U_S_S(Pa)}

$\operatorname{Max}=+4.500 \mathrm{E}+05$

$\mathrm{Min}=+1.000 \mathrm{E}-03$
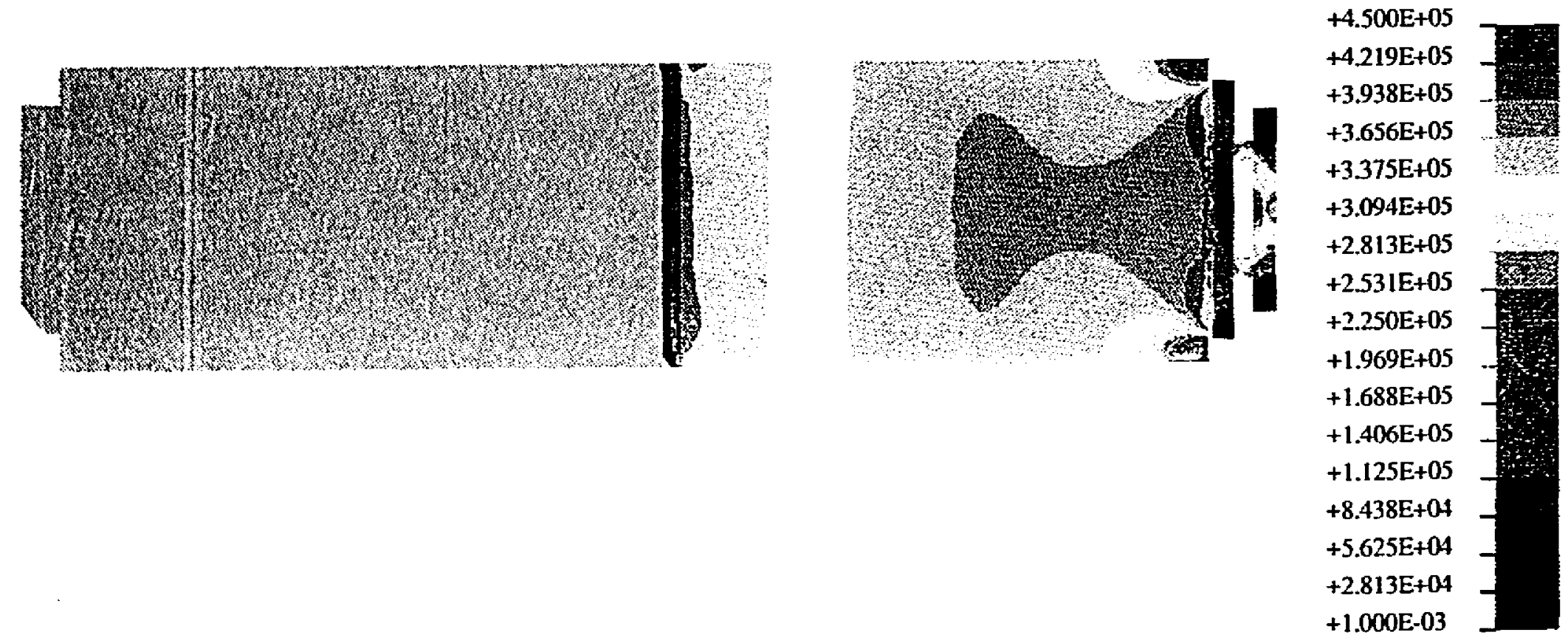

Fig. B6 


\section{U_S_R}

$M a x=+6.500 E+02$

$\operatorname{Min}=+1.000 \mathrm{E}-04$

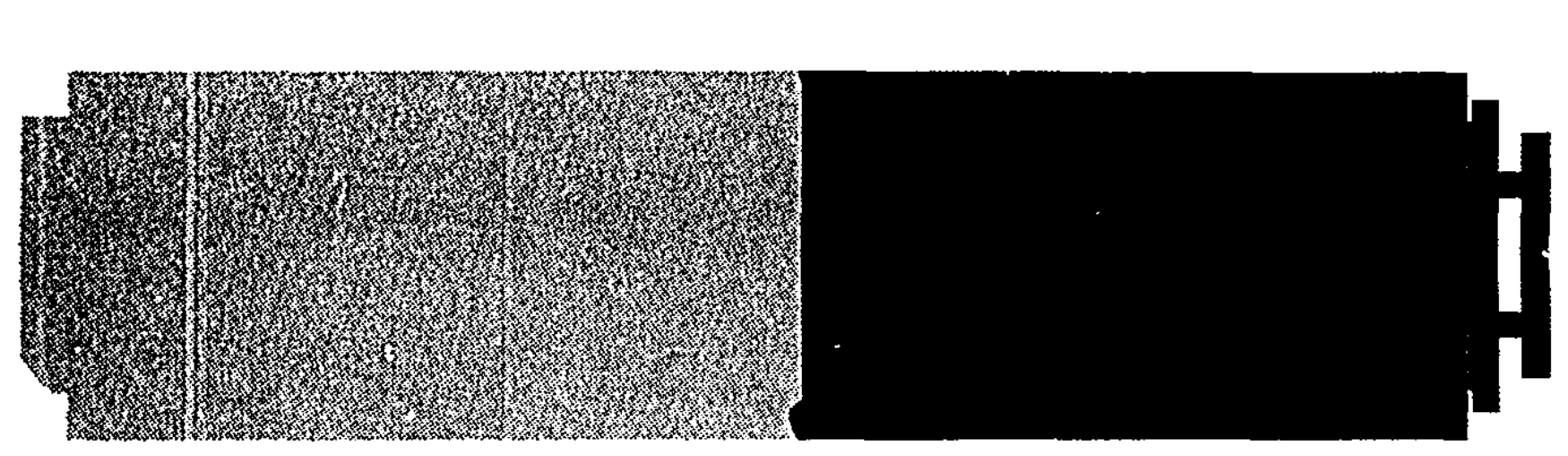

$+6.500 \mathrm{E}+02$ $+6.094 \mathrm{E}+02$

$+5.688 \mathrm{E}+02$

$+5.281 \mathrm{E}+02$

$+4.875 \mathrm{E}+02$

$+4.469 \mathrm{E}+02$

$+4.063 \mathrm{E}+02$

$+3.656 \mathrm{E}+02$

$+3.250 \mathrm{E}+02$

$+2.844 \mathrm{E}+02$

$+2.438 \mathrm{E}+02$

$+2.031 \mathrm{E}+02$

$+1.625 \mathrm{E}+02$

$+1.219 \mathrm{E}+02$

$+8.125 \mathrm{E}+01$

$+4.063 \mathrm{E}+0$

$+1.000 \mathrm{E}-04$

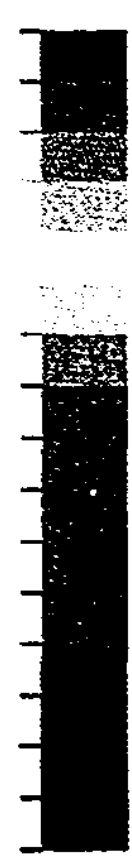

Fig. B7 


\section{U_S_R}

$\operatorname{Max}=+6.500 \mathrm{E}+02$

$\mathrm{Min}=+1.000 \mathrm{E}-04$
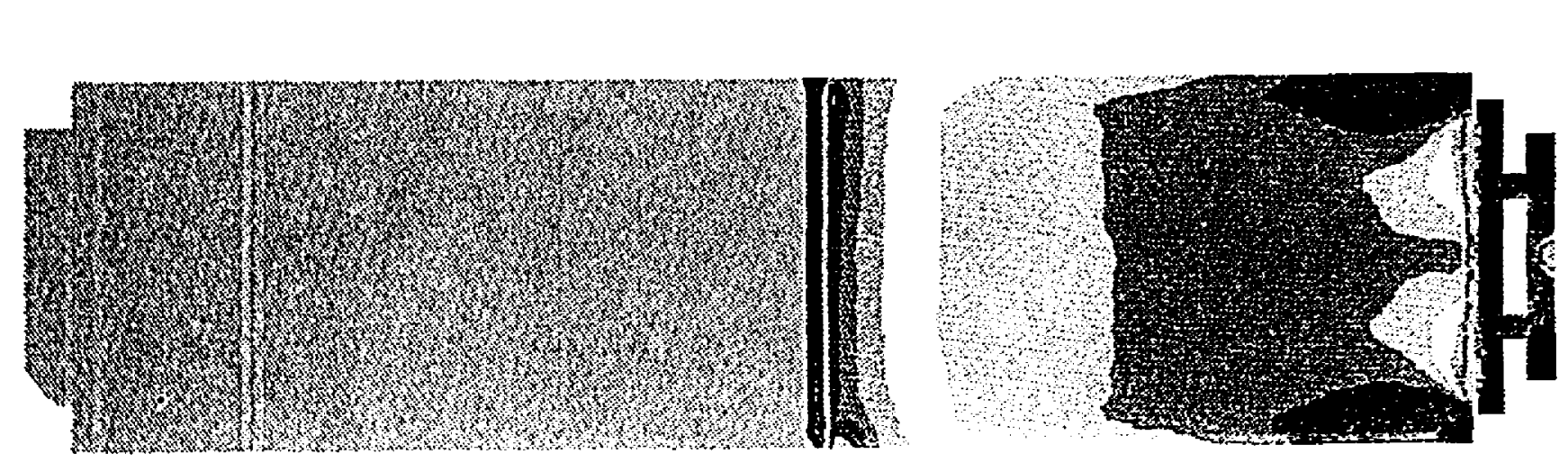

$+6.500 \mathrm{E}+02$ $+6.094 \mathrm{E}+02$ $+5.688 \mathrm{E}+02$ $+5.281 \mathrm{E}+02$ $+4.875 \mathrm{E}+02$

$+4.469 \mathrm{E}+02$ $+4.063 \mathrm{E}+02$

$+3.656 \mathrm{E}+02$

$+3.250 \mathrm{E}+02$

$+2.844 \mathrm{E}+0^{2}$

$+2.438 \mathrm{E}+02$

$+2.031 \mathrm{E}+02$

$+1.625 \mathrm{E}+02$

$+1.219 \mathrm{E}+02$

$+8.125 \mathrm{E}+01$

$+4.063 E+01$

$+1.000 \mathrm{E}-04$

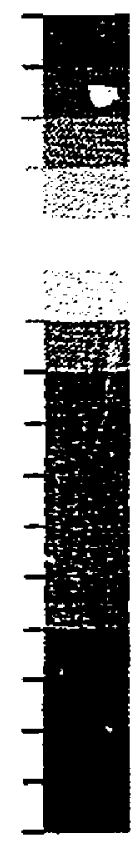

Fig. B8 